\title{
Homosexual men and the HIV epidemic : understanding and changing risk behavior
}

Citation for published version (APA):

Hospers, H. J. (1999). Homosexual men and the HIV epidemic : understanding and changing risk behavior. [Doctoral Thesis, Maastricht University]. Universiteit Maastricht. https://doi.org/10.26481/dis.19991112hh

Document status and date:

Published: 01/01/1999

DOI:

10.26481/dis.19991112hh

Document Version:

Publisher's PDF, also known as Version of record

\section{Please check the document version of this publication:}

- A submitted manuscript is the version of the article upon submission and before peer-review. There can be important differences between the submitted version and the official published version of record.

People interested in the research are advised to contact the author for the final version of the publication, or visit the DOI to the publisher's website.

- The final author version and the galley proof are versions of the publication after peer review.

- The final published version features the final layout of the paper including the volume, issue and page numbers.

Link to publication

\footnotetext{
General rights rights.

- You may freely distribute the URL identifying the publication in the public portal. please follow below link for the End User Agreement:

www.umlib.nl/taverne-license

Take down policy

If you believe that this document breaches copyright please contact us at:

repository@maastrichtuniversity.nl

providing details and we will investigate your claim.
}

Copyright and moral rights for the publications made accessible in the public portal are retained by the authors and/or other copyright owners and it is a condition of accessing publications that users recognise and abide by the legal requirements associated with these

- Users may download and print one copy of any publication from the public portal for the purpose of private study or research.

- You may not further distribute the material or use it for any profit-making activity or commercial gain

If the publication is distributed under the terms of Article $25 \mathrm{fa}$ of the Dutch Copyright Act, indicated by the "Taverne" license above, 
Stellingen bij het proefschrift

\section{HOMOSEXUAL MEN}

AND THE

\section{HIV EPIDEMIC}

Understanding and changing risk behavior

van Harm Hospers 
1 HIV-preventie activiteiten voor homoseksuele jongeren dienen met name het veilig vrijen binnen vaste relaties (of wat daar voor door gaat) aan de orde te stellen (dit proefschrift).

2 Om uitspraken te kunnen doen over seksuele gedragsverandering met losse partners bij homoseksuele jongeren als gevolg van HIV-preventie interventies, is het gezien de lage frequentie van seks met losse partners, aan te raden om een relatief lange nametingperiode te nemen (dit proefschrift).

3 Met een zekere regelmaat wordt beweerd (ook door personen die betrokken zijn bij HIV-preventie) dat homoseksuele mannen verzadigd zijn als het gaat om informatie over HIV en AIDS. Dit geldt in het algemeen niet voor homojongeren in hun coming-out fase en al helemaal niet voor Jantje van vijf die nog niet weet dat hij homoseksueel is.

4 Op 26 juni 1999 stond in de Volkskrant een artikel mer de titel "Bestaat AIDS wel echt?" Gezien de feiten over HIV en AIDS was plaatsing van dit stuk een blunder van de eerste orde.

5 De voorspelling van veilig of onveilig seksueel gedrag van individuen zal beter zijn als men naast de persoonlijke gedragsdeterminanten van deze individuen, ook de determinanten van degenen waarmee zij seks hebben in de voorspelling betrekt.

6 Bij de behandeling van obesitas dient meer aandacht te komen voor het verbeteren van het psychisch welbevinden van patiënten.

7 Dat strenge tutoren lager beoordeeld worden door studenten dan minder strenge tutoren is een wijdverbreid misverstand. 


\section{HOMOSEXUAL MEN}

AND THE

\section{HIV EPIDEMIC}

Understanding and changing risk behavior 


\section{HOMOSEXUAL MEN}

\section{AND THE}

\section{HIV EPIDEMIC}

Understanding and changing risk behavior

\section{PROEFSCHRIFT}

ter verkrijging van de graad van doctor aan de Universiteit Maastricht, op gezag van de Rector Magnificus, Prof. Dr.A.C. Nieuwenhuijzen Kruseman, volgens het besluit van het College van Decanen, in het openbaar te verdedigen op vrijdag 12 november 1999 om 14.00 uur

door

Harm Hospers 
Promotores

Prof. dr. G.J.Kok

Prof. dr. M.W.Ross (University of Texas, Houston, USA)

\section{Beoordelingscommissie}

Prof. dr. L. Boon (voorzitter)

Prof. dr. G.J.P. van Griensven (Centers for Disease Control and Prevention, Division of HIV/AIDS Prevention, International Activities Branch, Atlanta, Georgia, USA)

Prof. dr. J.A.M. Maarse

Prof. dr. G.S. Parcel

dr. R. Stall (Center for ADS Prevention Studies, San Francisco, USA)

\section{Colofon}

Cover design and lay-out: Nora Oosting, Maastricht

Printing: Unigraphic, Maastricht

The study presented in this thesis was performed at the Maastricht Health Research Institute for Prevention and Care (HEALTH), which participates in the Netherlands School of Primary Care Research (CaRe), acknowledge in 1995 by the Royal Dutch Academy of Sciences (KNAW).

The studies presented in this thesis were conducted with financial support from the Dutch Ministry of Welfare, Health and Cultural Affairs (WVC), the Praeventiefonds and the AmS Fonds, as part of the ADS Research Promotion Program (1988-1998).

Glaxo Wellcome, Roche and Abbott financially supported the printing and distribution of this thesis. 


\section{CONTENTS}

Chapter 1 General overview

Chapter 2 Determinants of safe and risk-taking sexual behavior among gay men: A review

Chapter 3 Focus group interviews with risk-taking gay men:

Appraisal of ADS prevention activities, explanations

for sexual risk-taking, and needs for support

Chapter 4 Sexual behavior among young gay men: The pursuit of a primary partner and the development of primary relationships

Chapter 5 Self-efficacy beliefs and intentions to use condoms among young gay men

Chapter 6 An overview of $\mathrm{HIV}$ prevention activities for gay men in the Netherlands between 1983-1993

Chapter 7 Evaluation of an HIV prevention intervention for men who have sex with men at cruising areas in the Netherlands

Chapter 8 Reducing HIV infection risks for young gay men:

The effects of small-group interventions

References

Summary

Samenvatiing

Acknowledgements

Curriculum Vitae 
3.

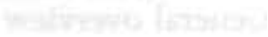

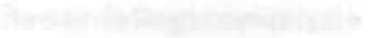

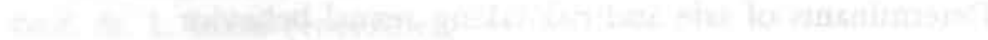

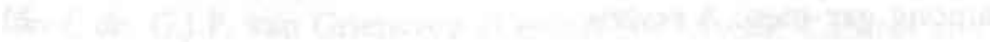

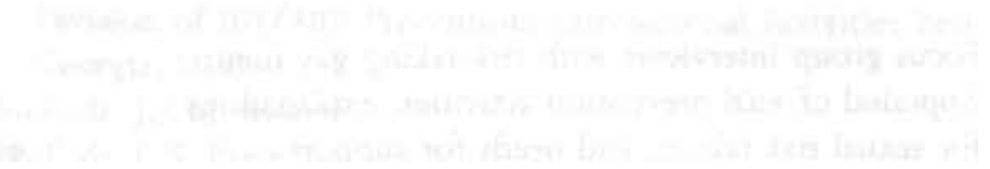


CHAPTER I

General overview 


\section{INTRODUCTION}

The AIDS epidemic has been with us for over 15 years. Since its outbreak, millions of people worldwide have been infected with HIV - the virus that causes AIDS. Many of them have died because the virus broke down their immune system, making them defenseless against opportunistic infections and rare forms of cancer. Billions of dollars have been spent and are being spent to develop vaccines against HIV infection as well as effective treatment for those already infected. Despite considerable progress, especially in the treatment of HIV infection, neither a vaccine nor a cure for HIV infection is available at present.

In the absence of treatment options, prevention of infection through health education action has been one of the cornerstones in the fight against AIDS. This thesis focuses on HIV prevention: it describes efforts to understand and decrease sexual risk-taking behavior - a major HIV transmission mode among men who have sex with men.

Before turning to an overview of the efforts to understand and change sexual risk-taking behavior of homosexual men, a brief summary of the epidemiological history and developments is provided.

\section{HIV AND AIDS}

In the early 1980s, some years after the first people died of ADS, the virus that causes AIDS was discovered. The transmission route is through body fluids, primarily through blood-blood and blood-semen contact. The primary risks for HIV infection are unprotected sexual intercourse, direct contact with infected blood through blood transfusion or contaminated needles, and mother-to-child transmission. More specifically, the majority of HIV infections are a result of unprotected vaginal or anal intercourse, or the exchange of contaminated needles among intravenous drug users. In addition, it is believed that oral sex with ejaculation can also result in HDV infection. In many countries donated blood is now checked for HIV, so that infection through blood transfusions has been virtually eliminated in those countries. Major risk groups are people who are sexually active and have unprotected sex, and intravenous drug users who do not always use clean needles. This thesis focuses on men who engage in homosexual behavior. In many countries in the Western world homosexual men are a substantial subgroup among the total group of people who have been diagnosed with HIV or ADS. For men who have sex with men, unprotected insertive and receptive anal intercourse as well as receptive oral sex with ejaculation are 
the primary risk behaviors that may carry the risk of HIV infection. HIV prevention efforts focus on reducing these risk behaviors.

\section{EPIDEMIOLOGICAL DEVELOPMENTS}

Since the first people died of ADS in the early 80 s, it is estimated that 14 million people have died of AIDS since the beginning of the epidemic and that over 30 million people are currently living with HV or ADS (WHO, 1998). In developing countries in Africa, Asia and South America, HN infection is mainly the result of heterosexual transmission. In these countries vertical transmission (mother-to-child) occurs frequently as well. In the Western world, HIV and ADS have spread fast as well, be it that both intensive prevention efforts as well as treatment opportunities have resulted in lower infection rates and slower progression of $\mathrm{HIV}$ infection to ADS, compared to developing countries. In many countries in the Western world men who have sex with men are an important risk group for HIV infection. In the Netherlands, almost 5000 people were diagnosed with ADS between the beginning of the epidemic and December of 1998 (Inspectie voor de Gezondheidszorg, 1998). Over 3000 of the cumulative number of people diagnosed with AmS are men who were infected through homosexual risk behavior. The number of new diagnoses is decreasing in the Netherlands since 1996. This tendency has also been observed in other countries in the Western world (e.g. Gebhardt, Rickenbach, Egger \& the Swiss HIV Cohort Study, 1998). It is assumed to be primarily attributable to the effects of early treatment of people who are HrV-infected but who have not yet been diagnosed with AIDS. Usually early treatment results in a considerable slowdown of the progression of HIV infection towards AIDS. As a result the monitoring of the epidemic has become more difficult since HIV infection diagnoses are not structurally monitored in the Netherlands.

\section{UNDERSTANDING RISK-TAKING BEHAVIOR}

\section{Theories and models}

A number of theoretical models have served as the basis for research studies on determinants of sexual risk-taking. Especially cognitive theories, which assume that cognitions guide behavioral decisions, have been widely used. 
Most prominent examples of such theories are the Health Belief Model (Janz \& Becker, 1984; Montgomery et al., 1989), the Theory of Reasoned Action (Fishbein \& Ajzen, 1975; Fisher, Fisher \& Rye, 1995), Social Cognitive Theory (Bandura, 1998), and the Theory of Planned Behavior (Ajzen, 1988; 1991). The Health Belief Model (HBM) proposes that a person's decision to engage in protective health behavior is dependent upon four cognitive factors: 1 . the perceived severity of a health threat, 2 . the perceived susceptibility of a health threat, 3 . the perceived benefits of action, and 4 . the perceived barriers of action. Finally, the model distinguishes external factors that may trigger a person to change, the so-called 'cues to action'.

The Theory of Reasoned Action (TRA) proposes that a person's behavior is strongly related to that person's behavioral intention. Behavioral intention, in turn, is determined by 1. the person's attitude, which reflects a person's beliefs (in terms of perceived consequences of behavior) regarding a specific behavior, and 2 . by subjective norms, which reflect the interaction of the perceived norms of significant others regarding a specific behavior and the motivation to comply with these significant others.

Bandura's Social Cognitive Theory (SCT) postulates that beliefs of personal efficacy (self-efficacy) are quintessential to action and to attaining behavioral goals. Thus, a sense of mastery regarding one's motivation, thought processes, emotions, or behavior is a necessary condition for action. Furthermore, the theory distinguishes outcome expectancies which reflects the extent to which a person beliefs that personal action will result in attaining desired outcomes. Determinant studies of risk-taking sexual behavior have usually narrowed SCT down to the determination of self-efficacy beliefs regarding relevant skills, such as condom use skills, and sexual negotiation skills. Ajzen's Theory of Planned Behavior (IPB) is an extension of the TRA. Ajzen added the concept of perceived behavioral control, which also reflects a sense of mastery. It thereby resembles Bandura's self-efficacy concept and in several studies perceived self-efficacy and perceived behavioral control are used interchangeably (see Godin \& Kok (1996) for a review). Thus, in TPB behavioral intentions are determined by attitudes, social influence, and perceived control.

Besides these generic cognitive models of (health) behavior, others have proposed models that specifically explain sexual risk-taking behavior in the light of the AIDS threat. Catania, Kegeles and Coates (1990) proposed the AIDS risk reduction model (ARRM). The model describes three stages that people pass through if they want to change to safer behavior to avoid getting HIV-infected. The first stage is recognizing and labeling one's sexual behavior as risky for contracting HIV. The second stage is making a commitment to reduce high-risk behavior, and the third stage is to seek and enact strategies that may help to change high-risk behavior. A similar model has been developed by Fisher and Fisher (1993). Their information-motivationbehavioral skills model of ADS risk-behavior change (IMB) supposes that 
adequate information regarding HIV and AIDS is a prerequisite for change. that motivation is the second determinant of ADS-preventive behavior, and that a level of behavioral skills is essential to be able to act upon adequate knowledge and high motivation. Wulfert, Wan and Backus (1996) have integrated the TRA, the HBM and SCT to specifically predict safer sex behavior of gay men. They propose that a high intention to use condoms is determined by high perceived self-efficacy which in turn is determined by a positive attitude towards condoms, positive social influences, and the absence of interpersonal barriers to condom use.

Although these theories and models differ in specificity, explicitness and emphasis, they also have much in common. Summarizing, from these theories and models it can be derived that safe sexual behavior is dependent upon 1. awareness and adequate knowledge, 2. motivation, which may be further divided into positive attitudes, positive social influence, and positive perceived self-efficacy towards safe sex, and 3. sufficient behavioral skills relevant to successful safe sex behavior.

The theories and models outlined above have been important instruments in understanding sexual risk-taking behavior.

\section{Determinants of risk-taking behavior among homosexual men}

The earlier studies on determinants of safe and risk-taking sexual behavior among homosexual men are reviewed in detail in Chapter 2. The most important HIV-preventive behaviors in those studies were refraining from receptive and insertive anal intercourse, and condom use with anal inter course. Determinant studies have identified a number of factors that seem to pertain to these behaviors, and have also confirmed that a number of factors seem less relevant. The following discussion gives a concise summary of the findings regarding determinants. It is based upon studies reported on in this thesis and upon results from the work of colleagues in the field of HTV prevention research.

\section{Demographic factors}

The predictive power of demographic or structural factors, such as income, educational level, and geographical location on safe and risk-taking behavior of homosexual men seems to be limited (Chapter 2). Even if relationships between demographic factors and behavior seem to exist, these relationships are usually equally or better understood by psychosocial factors with which they correlate. For example, some studies have found that risk-taking behavior is more prevalent in rural areas. Low perceived risk of HTV infection or the absence of positive social norms regarding condom use may in those cases well explain that relationship. It should be noted however, that researchers in this research area are probably also more likely to focus on psy- 
chological factors, because of their opportunity for change. Notwithstanding the limited role of structural factors in explaining behavior, they may play a role in decisions on target group selection or segmentation.

It has also consistently been found that knowledge regarding HIV/ADS is usually unrelated to safe or risk-taking behavior. One reason for this is that knowledge levels are invariably high in most samples of homosexual men that have been under study. Therefore, knowledge is usually unable to explain the variation in behavioral intentions and actual behavior that is observed. Several authors have noted that while knowledge and awareness are a prerequisite for safe sexual behavior, more is usually needed to enable people to initiate and maintain safe sexual behavior.

\section{Partner scatus}

One of the most important factors that is consistently related to level of sexual risk-taking behavior is parmer status. Scores of studies have shown that unprotected sex is most common with primary partmers (see Chapters 2, 4 and 8). While the earlier studies did not take partmer status into account it is now common practice to assess risk levels for primary partmers and casual parmers separately. Although the dynamics of safe and risktaking sex within primary relationships are not completely understood, some remarks can be made. First, several studies have shown that engaging in unprotected sex with one's primary partner may be part of a deliberate risk-reduction strategy. For example, a focus group study showed that some men had decided to be monogamous to protect against infection (Offir, Fisher, Williams \& Fisher, 1993). Another focus group study found that several men in primary relationships felt safe when not using condoms with their primary parmer, since they had made agreements not to have unprotected sex with casual partners (De Wit, Teunis, Van Griensven \& Sandfort, 1994). Thus, disposing of condoms within primary relationships may be the result of deliberate risk considerations and explicit agreements with primary partners.

Second, research has shown that feelings of love, intimacy, and sexual arousal may inhibit the motivation and intention to practice safe sex (De Wit et al., 1995; Janssen, De Wit, Hospers, Stroebe \& Van Griensven, 1999; Kelly, Kalichman et al., 1991; Offir et al., 1993). In our research among young gay men we also found high levels of unprotected sex with primary partners (Chapter 4). In addition, we also found that perceived self-efficacy regarding affective mood states (like being in love, or sexually attracted) distinguished men with a lower intention to practice safe sex from men with a high intention (Chapter 5). In focus group interviews that we conducted, older gay men also stated that feelings of love and attraction were impeding their safe sex intentions (Chapter 3).

A number of authors have tried to understand unsafe sexual behavior by studying the sexual communication process between partners. For example, 
Davies and Weatherburn (1991) have suggested that safe and unsafe sex are preceded by some form of verbal or non-verbal communication and negotiation. Further evidence that (lack of) communication may determine safes and risk behavior comes from our study among young gay men in which it was found that lower perceived self-efficacy to resist pressure from a parmer was related to a lower intention to use condoms with anal sex (Chapter 5). Finally, a number of authors have argued that in studying primary relationships, too much focus has been on the identification of individual rational choices and too little attention has gone to the dyadic, symbolic and emotional aspects of romantic relationships (Davies \& Weatherburn, 1991; Flowers, Sheeran, Beail \& Smith, 1997).

\section{Age}

The question whether age and sexual risk-taking are related will be addressed next. In the recent past, several authors have urged the prevention field to focus on young homosexual men, after they observed high levels of HTV infection and risk-taking behavior among young homosexual men (e.g. De Wit, 1996). For example, young gay men's cohort studies in the United States and the Netherlands have reported annual incidence rates around 2\% (Dean \& Meyer, 1995; Osmond et al., 1996; Van Griensven, Van den Bergh, Jansen, De Wit \& Keet, 1997). A study that we conducted among young homosexual men in the Netherlands confirmed the high levels of risk-taking behavior that others reported (see Chapter 4). It was found that while unprotected sex with casual partners was scarce, over $40 \%$ of respondents reported engaging in unprotected oral or anal sex with primary partners in the three months preceding assessment. Results from an intervention study (see Chapter 8) that was conducted among young homosexual men in coming-out groups, showed a similar behavioral pattern: few respondents reported unprotected sex with casual partners, but over $30 \%$ reported unprotected anal sex with their primary partner.

Some authors have suggested that young gay men engage in more risk-taking behavior than older gay men (De Wit \& Van Griensven, 1994; Ekstrand \& Coates, 1990; Hays, Kegeles \& Coates, 1990), while others have not found such a relationship in their data (Davies et al., 1992; Van de Ven, Kippax et al., 1997). Whatever the outcome of future research into this issue, an interesting question that remains is whether the determinant structure of risktaking behavior of young gay men is different from that of older gay men. That is, have differences been identified in the underlying factors that lead up to risk behavior? Although we have not been able to directly compare younger and older gay men in our studies, some suggestions may be made regarding this issue. First, our studies among young gay men found high turnover rates in primary relationships (see Chapters 4 and 8 ). In the first study it was observed that one in five primary relationships broke up in a three-month period, while the second study observed that half of the pri- 
mary relationships broke up in a measurement period of six months. At the same time, these studies found that unprotected anal sex (without HIV tests) was very common in primary relationships, and that many young gay men engaged in unprotected sex shortly after their primary relationship had started. For example, the study that is described in Chapter 4 found that among young gay men in relationships that lasted shorter than 8 months, $55 \%$ engaged in anal sex and of these over $40 \%$ did not use condoms consistently. Hence, our data suggest that young gay men initiate unprotected anal sex with primary partners while it is uncertain at that moment whether the relationship will last.

A second point is the finding that most young gay men in our studies express a desire for a monogamous relationship. This may explain why we found that young gay men in short-lasting relationships either have not discussed issues related to sex with others, or have explicitly agreed to be monogamous. In addition, a focus group study among young gay men where primary relationships were discussed in relationship to risk-taking behavior (Janssen et al., 1999), found that a considerable number of young gay men believed that protected sex was unnecessary if there was a romantic commitment. An implicit or explicit desire for monogamy may lead to an underestimation of the risks of unprotected sex and to the initiation of unprotected sex without conducting HIV tests.

Future research should provide more clarity about the issues raised here. More in particular, studies are needed that compare relationship development and beliefs about primary relationships among younger gay men with thuse among older gay men.

\section{Attitudes, social influence and self-efficacy}

Large numbers of studies have found that sexual risk-taking behavior is correlated with negative beliefs about safe sex in general and condom use in particular, while safe sexual behavior is related to positive beliefs (see Chapter 2). Examples of negative beliefs about safe sex and condoms are that "safe sex spoils the joy of sex", that "safe sex shows distrust towards a partner", or that "condoms decrease physical sensation". Positive beliefs include statements that "safe sex protects for HIV and other STDs", or that "condom use is sanitary".

A relationship between social influence and safe and risk-taking behavior has been described in a number of studies. For example, some studies have found that links with the gay community may facilitate protective behavior. In one of our studies it was found that bisexual men who visit cruising areas reported hardly any ties with the gay community and limited exposure to HIV prevention for gay men (Chapter 7). This might be an explanation for the higher level of unsafe sex that was found for bisexual men in that study. Gold (1995) has warned against over-optimism about the potential of links with the gay community to stimulate safe sex behavior, after he 
found in two studies that links with the gay community were related to unsafe sexual behavior of gay men. He suggests that while it is true that the gay community provides opportunities for reinforcement of safe sex messages for those who seek reinforcement, it also provides opportunities to engage in unsafe sex while discounting or rejecting safe sex information from the gay community.

Social influence may also come from significant people in one's environment, such as partners, family or friends. Several studies, described in Chapter 2, have found that norms towards safe sex are related to safe sex behavior (e.g. consistent condom use or avoidance of anal sex). In our studies among young gay men we have found weak positive relationships between measures of social influence on the one hand and behavioral intentions or behavior on the other hand. Recent focus group interviews with young gay men which touched on this issue (Janssen et al., 1999) found that the large majority of these men did not discuss safer sex issues with others, nor were they aware of safer sex opinions or behavior of significant others. Most expressed to feel uncomfortable to talk open and direct about safer sex. Since many young gay men may be reached through coming-out groups, where young gay men seek social support from peers on issues related to their homosexual feelings, it seems important that future research attempts to understand the potential role that peers may play in promoting and sustaining safe sex behavior.

A large number of studies have demonstrated a relationship between perceived self-efficacy on the one hand and safe and risk-taking behavior on the other hand (Chapters 2 and 5). Self-efficacy has been studied regarding a variety of interpersonal and intrapersonal factors. The interpersonal factors have been measured more often, and include communicating safe sex desires to parmers, and resisting pressure from sex parmers to have unsafe sex. Intrapersonal factors include a variety of mood states, such as being in love, being attracted to someone, being sexually aroused, or being under the influence of alcohol or drugs. It is usually found that low perceived self-efficacy regarding sexual communication skills is related to lower condom use intentions and to higher risk-taking behavior. In addition, our study among young gay men (Chapter 5), showed that young men with lower condom use intentions typically displayed low perceived self-efficacy to engage in safe sexual behavior in a number of mood states (e.g. when in love or when under the influence of alcohol). This finding is in line with focus group research which investigated self-justifications for unsafe sex, and which found that feelings of love and affection, being under the influence of alcohol or drugs, and sexual arousal are prominent justifications that men give for their unsafe sexual behavior (Chapter 5; Boulton, McLean, Fitzpatrick \& Hart, 1995; Offir et al., 1993).

In summary, research on self-efficacy has highlighted the importance of a sense of mastery or control in sexual situations in order to practice safer 
sex, and that this sense of control pertains not only to communication between sexual partners, but also to coping with mood states with a higher likeliboud of being precursors of risk-taking behavior.

The determinants of safe and risk-taking behavior that were described in the previous paragraphs, have been important building blocks of interventions that aimed to influence sexual behavior of men who have sex with men. These efforts to change sexual risk-taking behavior through interventions will be discussed hereafter.

\section{CHANGING RISK BEHAVIOR}

Concurrent with efforts to understand risk-taking behavior of men who have sex with men, numerous interventions have been developed in the past 15 years for this target group. These interventions include information brochures, outreach programs, and small-group information and counseling programs, to name some obvious ones. Chapter 6 gives an extensive overview of programs in the Netherlands, and describes brochures and other written materials and their content, small-group interventions (such as the Safe Sex Videoshows), and outreach activities (such as the prevention projects at cruising areas). These activities can be seen as representative for interventions that were set up in other parts of the Western world for men who have sex with men. The aims of the interventions were to increase knowledge and awareness regarding HIV and ADS, to positively influence attitudes towards safe sex practices, to positively influence social norms regarding safe sex within the gay community, or to increase self-efficacy regarding safe sex through behavioral-skills enhancement interventions. As has been addressed in detail in Chapter 6, it is extremely difficult to pass judgment on the effectiveness of the interventions that have been implemented in the Netherlands, since hardly any study has investigated the effectiveness of these interventions. This problem is not unique for the Netherlands, but has also been observed in other parts of the world, such as Australia (Gold, 1995), and the United States (Kegeles \& Hart, 1998). One reason for the absence of effectiveness indicators lies in the infrastructure of HIV prevention in the Netherlands, where research and practice have often operated separately to a large extent. Most HIV prevention practitioners are expected to respond to prevention issues and developments and to needs of the gay community, and are usually not expected to include effect evaluations when developing interventions. In addition, they often lack the time and financial resources to conduct effect evaluations (see Chapter 6). Researchers, on the other hand, have focussed primarily on determinants of 
sexual risk-taking behavior. Determinant studies are indispensable in intervention development (Fisher \& Fisher, 1992; Kelly \& Murphy, 1992), but it is has also been noted that HIV prevention practice needs interventions that work, and that HIV prevention research can contribute to the development, implementation, and evaluation of such interventions (Kegeles \& Hart, 1998: Kelly \& Murphy, 1992; Peterson, Ostrow \& McKirnan, 1991).

There are a limited number of published studies that have investigated effectiveness of HIV prevention in terms of behavior change or change of behavioral determinants, two of which are reported in this thesis (Chapters 7 and 8). In their review of HIV prevention interventions for gay men (Kegeles \& Hart, 1998), three types of interventions are distinguished: individual, small-group and community-level interventions. The seting in which individual interventions mostly take place is pretest and postlest counseling surrounding HIV-testing. Kegeles and Hart (1998) were unable to find studies that reported the effects of counseling on subsequent sexual behavior or on related behavioral determinants. Similarly, we are not aware of studies in the Netherlands in this area. Yet, the HIV test counseling situation does offer an excellent opportunity for prevention, and future studies could investigate its current effectiveness and develop and evaluate strategies that may increase effectiveness of HIV test counseling.

With respect to small-group interventions the pioneering work of Jeffrey Kelly and his colleagues stands out. Their studies have shown that smallgroup skills-training interventions result in an increase in behavioral skills to withstand coercive pressures to engage in risk-taking behavior, and sig. nificantly reduce actual risk-taking behavior in the long term (Kelly \& St.Lawrence, 1990; Kelly, St.Lawrence, Betts, Brasfield \& Hood, 1990; Kelly, St.Lawrence, Hood \& Brasfield, 1989). Similar results have been achieved with small-group work among African-American men who have sex with men (Peterson et al., 1996). A study in the United Kingdom showed that small-group work with gay men resulted in higher self-efficacy ratings to cope with sexual bigh-risk situations. However, no changes were found at the behavioral level (Wanigaratne, Billington \& Williams, 1997). Our small-group work with young gay men in coming-out groups (see Chapter 8) was built upon the insights from determinant studies and the results from small-group work that was discussed above. We tested the effectiveness of three different single-session interventions compared to a waiting-list control condition, and randomly assigned coming-out groups to conditions. The first intervention focussed on accurate risk know]edge and safer sex attitudes, the second focussed on skills training, while the third attempted to increase safer sex intentions and behavior by inducing of anticipated regret (see Chapter 8 for details). The results were disappointing with respect to sex with primary partners. None of the iuterventions was effective in changing behavioral intentions or actual sexual behavior with primary partners, despite a considerable level of unsafe sex with 
primary partners. Regarding sex with casual partners the interventions were able to achieve significant changes in safe sex intentions. Unfortunately, it was not possible to assess effects at the behavioral level, due to very low levels of unsafe sex with casual partners at pretest and at posttest. The most important lesson that was learned from this study is that young gay men's perceptions, attitudes and intentions towards primary partners are more resistant to change than was anticipated and that therefore different approaches need to be developed in the future to achieve change in this important domain. Also, it was satisfactory to observe relatively low levels of unsafe sex with casual partners at pretest. The interventions may have strengthened the safe sex intentions regarding casual partners and hopefully caused prolonged safe behavior with casual sex parmers. Finally, the process evaluations as well as informal feedback from participants have highlighted the excellent opportunities that the setting of coming-out groups offer for HIV prevention. Concurrent to the development of a more effective intervention, efforts should be devoted to structurally implement HIV prevention interventions in coming-out groups in the Netherlands.

With respect to community-level interventions, Kegeles and Hart (1998) have reported that despite a wealth of this type of intervention, hardly any of these has been rigorously evaluated. Again, Kelly and colleagues are among the few who have conducted a randomized controlled trial of a community-level program which was effective in reducing risk-taking behavior (Kelly et al., 1997). Another innovative community-level study worth mentioning was carried out and evaluated in the United States by Kegeles, Hays and Coates (1996). Their experimental program included peer outreach, small group meetings and a publicity campaign, all focussing on young gay men. Their results show impressive changes in sexual risktaking behavior with primary partners as well as with casual partmers. No changes were observed in the community they used as the control condition.

Randomized controlled community-level trials have never been reported in the Netherlands (see Chapter 6). A considerable number of men who have sex with men have been exposed to outreach programs, but these programs were usually not tested for their efficacy. This thesis reports on one study that has assessed the potential effects of outreach at cruising areas in the Netherlands (Chapter 7). Although the circumstances prevented us to set the study up as a randomized control trial, we were able to show that men who had been reached by a volunteer reported less risk-taking behavior than men who had not been exposed to the outreach activity. Furthermore, the study identified behaviorally bisexual men as a target group for prevention, given their higher risk-taking behavior and their limited access to current HN prevention aimed at gay men.

Given the results from our studies as well as the studies from other researchers that we have discussed in the previous paragraph, it can be con- 
cluded that there still is a need for carefully planned, theory-based interventions and that special attention should be given to study design and evaluation. The studies reported thus far should be seen as initial steps in the development of interventions that result in sustainable change in sexual risktaking behaviors of the different subpopulations of men who have sex with men.

\section{FUTURE DIRECTIONS}

A number of developments in the HIV/AIDS field will pose important challenges for HIV prevention in the years to come. First, the availability of antiretroviral combination therapy has resulted in significant improvements in the health status of people affected with HIV and ADSS. In the Netherlands this development has recently lead the Dutch Health Council to advise changing the Dutch HIV testing policy (Gezondheidsraad, 1999). While HIV testing was not encouraged in the past (which has resulted in a high level of unawareness of HIV status among gay men in the Netherlands (see Kok (1999) and Chapters 4 and 8) men who have sex with men are now advised to undergo an HIV test. This more active approach will most likely lead to an increase of men who know their HIV status, and more in particular more men will know that they are HIV-positive. Kok (1999) has convincingly argued that HIV-positives should be chosen as a special target group for additional preventive interventions, and the first steps are now being set to develop such interventions.

Second, the availability of antiretroviral combination therapy has also lead to concerns that safe sex intentions and safe sex behaviors will decrease. In a recent study (Kelly, Hoffmann, Rompa \& Gray, 1998) it was found that in a sample of homosexual and bisexual men, $4 \%$ of respondents agreed with the statement "if someone is HIV-positive but taking new medications that reduce viral load, safer sex isn't important", while $8 \%$ agreed with the statement "I practice safer sex less ofien since new medical treatments for HN/AIDS came along". Among HJV-positive men on combination therapy, $18 \%$ agreed with the latter statement. These findings, which are similar to anecdotal evidence from HIV prevention workers in the Netherlands, underscore the importance of developing interventions that maintain high perceptions of the need to practice safer sex.

Third, post-exposure prophylaxis (PEP) has recently been made available in case of unprotected sexual intercourse where there is a realistic chance that HIV transmission has occurred (Lust for Life, 1999). In a sample of 327 HIV-negative homosexual and bisexual men in the United Stated, Kalichman 
(1998) found that men with an intention to use PEP were younger, less educated and reported more unprotected receptive anal sex. Kalichman calls for behavioral interventions concurrent to the introduction and advancement of PEP. Careful communication about PEP is needed, which stresses the invasiveness of PEP and motivates people to continue to have safe sex and to see PEP as a last resort.

Fourth, as we have argued above, carefully planned theory-based interventions that take into account new developments and new insights are still needed. Important areas of interest that have been discussed in this chapter include counseling issues regarding HIV testing, primary relationship development, especially among young gay men, and prevention targeted at HIVpositive men.

Finally, as DeGuzman and Ross (1999) have argued, more attention should be directed to the use of Internet as a channel for HIV/ADS education and counseling. We are currently planning an intervention where volunteers will discuss safer sex issues with men who visit 'chatboxes' for men who have sex with men. We believe that this may be a way to reach men who are not usually reached by current HIV prevention efforts.

This thesis describes the efforts that have been made to understand sexual risk-taking behavior as well as precautionary behavior of men who have sex with men in the ADS era. It further describes research on interventions that aimed at changing rish-caking behavior and related beh̀avioral determinants. Continued efforts to understand and effectively change risk-taking behavior in turbulent times will be the challenge for the future. 


\section{CHAPTER 2}

\section{Determinants of safe and risk-taking sexual behavior among gay men: A review}

\section{Published as:}

Hospers, H.J., \& Kok, G.J. (1995). Determinants of safe and risktaking sexual behavior among gay men: $A$ review. AlDS Education and Prevention, 7, 74-96. 


\section{INTRODUCTION}

Since the outbreak of the ADS epidemic in the beginning of the 1980 's, an estimated number of 12.9 million people around the world have been infected with the Human Immunodeficiency Virus (HIV) by early 1992 22 (Mann, Tarantola \& Netter, 1992). In several parts of the world gay men form the group that has been hit hardest by the disease. Estimated proportions of gay men of the total number of HIV-infected people per region are $47 \%$ for Western Europe, 54\% for Latin America, 56\% for North America, $80 \%$ for Eastern Europe, and $87 \%$ for Oceania (Mann et al., 1992).

At this moment primary prevention is the only possible way to limit the spread of HIV. In their effort to influence the course of the disease, social scientific researchers have devoted considerable attention to the identification of determinants that distinguish between safe and risk-taking sexual behavior of gay men because insight into these determinants is vital for the development of effective ADS prevention interventions. In this review we present the knowledge that is currently available. Before giving an overview of determinants we briefly recapitulate the behavioral changes among gay men that have occurred as a result of the epidemic.

\section{BEHAVIORAL CHANGES AS A RESULT OF AIDS}

Once the routes of viral transmission were known, two major recommendations for gay men to prevent infection were given: 1. reduce the number of partners, and 2. refrain from insertive and receptive anal intercourse, or use condoms when having insertive or receptive anal intercourse (McKusick, Conant \& Coates, 1985; Solomon \& Dejong, 1986).

Many studies have documented drastic reductions in the number of partners (Centers for Disease Control, 1985; Joseph et al., 1987a; Martin, 1987;

McKusick, Conant \& Coates, 1985; Schechter et al., 1988; Van Griensven et al., 1987; Winkelstein et al., 1987). This reduction has resulted in a considerable decrease of the probability of infection at an aggregate level. However, compared to consistent condom use, reducing the number of sexual partmers is far less effective (Reiss \& Leik, 1989). Especially in high prevalence areas, reducing the number of partners only leads to a marginal reduction of risk (Handsfield, 1985). Thus, the 'reduce your number of partmers' approach may have the serious drawback that individuals might use their compliance with this recommendation to justify the high risk behavior in which they still engage. The majority of studies report impressive changes with respect to unprotected anal intercourse (see Becker \& Joseph (1988) and Stall, Coates \& Hoff 
(1988) for reviews). Siegel, Bauman, Christ and Krown (1988) showed that $22 \%$ of their sample shifted to safer sex behavior over a period of six months. Winkelstein et al. (1987) reported a decrease of $60 \%$ in the prevalence of risk-taking sex over a two-year period and Martin (1987) found a reduction of $70 \%$ in risk-taking sexual episodes since respondents heard about AIDS. These changes in risk-taking behavior were accomplished by either refraining from anal intercourse or using condoms with anal intercourse. Although condom use with anal intercourse is now generally accepted as an adequate means of reducing risk, failure rates of condoms (breakage, improper use) vary around 10\% (Ross, 1987; Valdiserri et al., 1988; Van Griensven \& De Vroome, 1987) and thus do not totally eliminate risk of HIV infection.

\section{Behavioral changes across time}

A less promising picture emerges when the available data are inspected on an individual level rather than on an aggregate level. A considerable number of people continue to engage in risk-taking sexual behavior. It also seems that people may shift from one risk category to another over time. Table 2.1 provides an overview of longitudinal studies that examined these kind of changes. All studies compared individual sexual behavior at two points in time, with varying intervals. Respondents were categorized as either low or high risk at both time 1 and time 2. Cross-tabulation of time 1 with time 2 behavior results in four categories: low risk at both time 1 and time 2 (stable low risk), high risk at time 1 and low risk at time 2 (change to low risk), low risk at time 1 and high risk at time 2 (change to high risk), and high risk at both time 1 and time 2 (stable high risk). Despite the differences in study characteristics, some general conclusions may be drawn from these studies. First, it is clear that a great number of gay men have either maintained safe sex behavior or have changed to safer sexual behavior. In fact, many of them have successfully maintained this behavior for long periods of time. Second, a substantial number of men reported one or more instances of risk-taking sexual behavior at both time 1 and time 2. If we assume that men in this category were aware of the risks, then we can conclude that a number of men are unwilling or unable to modify their sexual behavior. It should be noted, however, that in most of the studies in Table 2.1, one instance of unprotected anal intercourse during the measurement period puts men in the stable high risk category. Third, a relatively small, but nevertheless important, proportion of men were identified who changed from safe to risk-taking sexual behavior. It is important to note that classification in this category is not tantamount to total relapse. Men in this group showed one or more occurrences of risktaking sexual behavior during the period of study. Hence, within this category a further distinction can be made between men who relapsed to 
Table 2.I Indivldual behavloral patterns at two points in time. Each entry lists the percentage of respondents with stable low or stable high risk at both Time I and Time 2, and the percentage of respondents who changed from high to low risk or vice versa from Time I to Time 2.

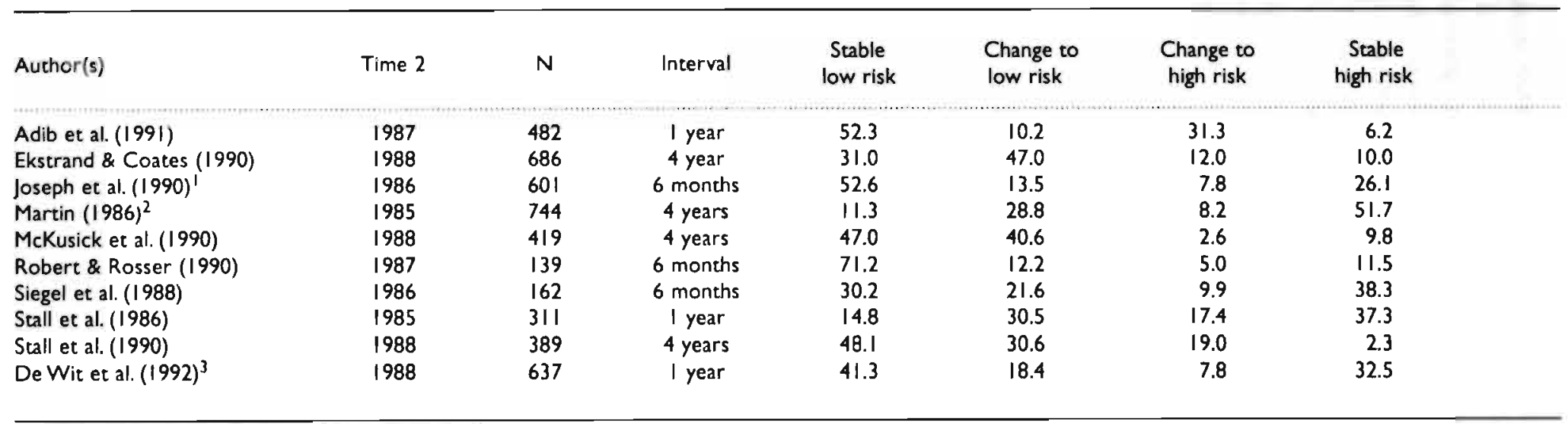

I Ambiguous categories evenly divided between stable and change categories

2 Pre-AIDS behavior compared with post-AIDS behavior

${ }^{3}$ Study reports four I-year periods (1984-1988) 
risk-taking behavior, men who alternated between safe and risk-taking behavior, and men who showed a temporary slip to risk-taking sexual behavior and who thereafter returned to safe sexual behavior. The reported studies do not supply data on the proportion of men in each of these subgroup.

In short, there have been major changes in the sexual conduct of gay men as a consequence of the ADS epidemic. We should, however, bear in mind that protective behaviors against HIV infection (practicing safe sex with all partners for an unknown but probably long period of time) are extremely difficult to maintain. Consequently, it is not surprising to find that a substantial number of gay men sill expose themselves to situations in which they are at risk of becoming infected with HIV. Therefore, intervention programs are needed that focus on change towards consistent safe sexual behavior. Understanding the determinants of safe and risk-taking sexual behavior is crucial in the development of such interventions.

\section{DETERMINANTS OF SAFE AND RISK-TAKING SEXUAL BEHAVIORI}

\section{Characteristics of reported studies}

Table 2.2 presents the main findings of the determinant studies included in this review. In order to be included in Table 2.2, a study had to report on determinants of safe and risk-taking behavior. A study also had to include a comparison of a low-risk group to a high-risk group using a cross-sectional design, or a comparison of changes in safe or risk-taking behavior using a longitudinal design. Furthermore, we included only those studies that examined behaviors related to anal intercourse, because it is the most prominent risk factor related to HV infection among homosexual men (Chmiel et al., 1987; Detels et al., 1983; Glasner \& Kaslow, 1990; Kingsley et al., 1987). A great variety of possible determinants has been studied. For this review we have selected demographical variables (age, income, race, and educational level), relationship status, drug and/or alcohol use, knowledge, risk perception, attitudes, social influence and norms, and self-efficacy.

I In this review, we use the terms determinant, predictor, factor, variable, and correlate interchangeably to denote concepts that are scudied in rebationship to AIDS-related sexual behavior. Although the terms predictor and determinant may suggest causation, the research design of most presented studies permits correlational rather than causal inferences. 
Table 2.2 Studies on determinants of safe and risk taking sexual behavlor among gay men. For each study Is Ilsted which behavioral comparison was made, whether thls comparison was cross-sectional or longitudinal (C/L), the number of subjects for the comparison (N), and the relationship with determinants. For each determinant that was studied, is listed whether there is a positive relationship (+), no relationship (0), or a negative relationship (-) (see coding legend below for detailed information).

\begin{tabular}{|c|c|c|c|c|c|c|c|c|c|c|c|c|c|c|c|c|}
\hline & \multirow[b]{2}{*}{$\mathrm{C} / \mathrm{L}$} & \multirow[b]{2}{*}{$N$} & \multicolumn{4}{|c|}{ Demographic } & \multirow{2}{*}{$\begin{array}{l}\text { Relation- } \\
\text { ship }\end{array}$} & \multicolumn{4}{|c|}{ Alcohol/drug use } & \multirow[b]{2}{*}{ Knowledge } & \multirow{2}{*}{$\begin{array}{c}\text { Risk } \\
\text { Perception }\end{array}$} & \multirow[b]{2}{*}{ Attitude } & \multirow[b]{2}{*}{ Norms } & \multirow[b]{2}{*}{ Self-Efficacy } \\
\hline & & & Age & Income & Race & Education & & Alcohol & Drug & Both & Nitrites & & & & & \\
\hline \multicolumn{17}{|l|}{ Adib et al. (1991) } \\
\hline $\begin{array}{l}\text { maintenance of SB) } \\
\text { (change to URAI versus }\end{array}$ & L & 402 & 0 & 0 & 0 & 0 & - & & & 0 & & & & 0 & + & + \\
\hline maintenance of SB) & $\mathrm{L}$ & 402 & 0 & 0 & 0 & 0 & 0 & & & 0 & & & & 0 & + & + \\
\hline $\begin{array}{l}\text { Bauman \& Siegel (1987) } \\
\text { (from S8 to RTB, three levels) }\end{array}$ & $c$ & 153 & & & & & & & & & & & 0 & & & \\
\hline $\begin{array}{l}\text { Bochow }(1990) \\
\text { (UAI versus Al with }\end{array}$ & C & 333 & & & & & - & & & & & & & & & \\
\hline $\begin{array}{l}\text { Connell et al. (1990) } \\
\text { (UAI versus no UAI) }\end{array}$ & C & 394 & 0 & 0 & & 0 & & & & 0 & & & & t & + & \\
\hline Dallas (1990) & & דינד & 8 & & & & & & & 0 & & & & + & + & \\
\hline $\begin{array}{l}\text { (Al versus no Al) } \\
\text { Ekstrand \& Coates (1990) }\end{array}$ & C & 70 & & & & & & & & & & & & + & & + \\
\hline $\begin{array}{l}\text { (UAI versus no UAI) } \\
\text { (maintenance of URAl or } \\
\text { UIAI versus maintenance of } \\
\text { SB or change to SB) }\end{array}$ & C & 686 & + & & & & & - & & & & & & & & \\
\hline Fitzpatrick et al. (1989) & & & & & & & & & & & & & & & & \\
\hline (Al versus no Al) & C & 225 & & & & & - & & & & & & & & & \\
\hline Fitzpatrick et al. (1990) & & & & & & & & & & & & & & & & \\
\hline $\begin{array}{l}\text { (RA| versus no RAI) } \\
\text { Gold et al. (|99|) }\end{array}$ & C & 356 & + & 0 & & & - & & & & & & 0 & 0 & & \\
\hline (UAI versus no UAI) & C & 181 & & & & & - & 0 & 0 & & 0 & & & + & & \\
\hline
\end{tabular}




\begin{tabular}{|c|c|c|c|c|c|c|c|c|c|c|c|c|c|c|c|c|}
\hline & \multirow[b]{2}{*}{$\mathrm{ClL}$} & \multirow[b]{2}{*}{$N$} & \multicolumn{4}{|c|}{ Demographic } & \multirow{2}{*}{$\begin{array}{l}\text { Relation- } \\
\text { ship }\end{array}$} & \multicolumn{4}{|c|}{ Alcohol/drug use } & \multirow[b]{2}{*}{ Knowledge } & \multirow[b]{2}{*}{$\begin{array}{c}\text { Risk } \\
\text { Perception }\end{array}$} & \multirow[b]{2}{*}{ Attitude } & \multirow[b]{2}{*}{ Norms } & \multirow[b]{2}{*}{ Self-Efficacy } \\
\hline & & & Age & Income & Race & Education & & Alcohol & Drug & Both & Nitrites & & & & & \\
\hline \multicolumn{17}{|l|}{ Hays, Kegeles \& Coates (1990) } \\
\hline (UAI versus no UAI) & $c$ & 99 & & & 0 & 0 & & 0 & & & & & + & + & 0 & $+10^{1}$ \\
\hline \multicolumn{17}{|l|}{$\begin{array}{l}\text { Kelly, StLawrence \& Brasfleld } \\
\text { (I99I) } \\
\text { (change to UAI versus }\end{array}$} \\
\hline maintenance of SB) & $\mathrm{L}$ & 68 & + & & & 0 & & & & - & 0 & 0 & & + & & \\
\hline \multicolumn{17}{|l|}{$\begin{array}{l}\text { Kelly, StLawrence, Brasfield, } \\
\text { Lemke et al. (1990) }\end{array}$} \\
\hline (risk-index score) & C & 481 & + & & & 0 & & & & & & + & + & & + & \\
\hline (CU index) & C & 292 & 0 & & & 0 & & & & & & + & + & & + & \\
\hline \multicolumn{17}{|l|}{$\begin{array}{l}\text { Kelly, St.Lawrence, Brasfield, } \\
\text { Stevenson et al. (1990) }\end{array}$} \\
\hline (UIAI versus no UIAI) & C & 352 & & & & & & & & & & & & & + & \\
\hline (URAI versus no URAI) & C & 352 & & & & & & & & & & & & & + & \\
\hline \multicolumn{17}{|l|}{ Kelly, Kalichman et al. (1991) } \\
\hline (UAI versus no UAI) & C & 325 & + & & & + & & & & & & & & & & \\
\hline \multicolumn{17}{|l|}{ Linn et al. (1989) } \\
\hline (from SB to RTB, four levels) & $\mathrm{C}$ & 812 & + & 0 & + & 0 & & & & - & & & & & & \\
\hline \multicolumn{17}{|c|}{$\begin{array}{l}\text { McCusker, Stoddard et al. (1989) } \\
\text { (maintenance of URAI }\end{array}$} \\
\hline $\begin{array}{l}\text { versus change to } \mathrm{SB} \text { ) } \\
\text { (maintenance of } \mathrm{UAI}\end{array}$ & $\mathrm{L}$ & 78 & & & & & & + & & & 0 & & + & & 0 & \\
\hline versus change to $\mathrm{SB}$ ) & $\mathbf{L}$ & 99 & & & & & & 0 & & & 0 & & 0 & & 0 & \\
\hline \multicolumn{17}{|l|}{ McCusker, Zapka et al. (1989) } \\
\hline (no CU versus $\mathrm{CU}$ ) & C & 129 & 0 & & & 0 & & & & & & & & & & \\
\hline
\end{tabular}


Table 2.2 Continued.

\begin{tabular}{|c|c|c|c|c|c|c|c|c|c|c|c|c|c|c|c|c|}
\hline & \multirow[b]{2}{*}{$\mathrm{C} / \mathrm{L}$} & \multirow[b]{2}{*}{$N$} & \multicolumn{4}{|c|}{ Demographic } & \multirow{2}{*}{$\begin{array}{l}\text { Relation- } \\
\text { ship }\end{array}$} & \multicolumn{4}{|c|}{ Alcohol/drug use } & \multirow{2}{*}{ Knowledge } & \multirow{2}{*}{$\begin{array}{l}\text { Risk } \\
\text { Perception }\end{array}$} & \multirow[b]{2}{*}{ Attitude } & \multirow[b]{2}{*}{ Norms } & \multirow[b]{2}{*}{ Self-Efficacy } \\
\hline & & & Age & Income & Race & Education & & Alcohol & Drug & Both & Nitrites & & & & & \\
\hline \multicolumn{17}{|l|}{ McKusick et al. (1990) } \\
\hline $\begin{array}{l}\text { (UAI versus no UAI) } \\
\text { (maintenance of UAl }\end{array}$ & $\mathrm{C}$ & 308 & + & & & & - & & & & & 0 & 0 & + & & + \\
\hline $\begin{array}{l}\text { (maintenance of UAl } \\
\text { versus change to SB) } \\
\text { (maintenance of SB }\end{array}$ & $\mathrm{L}$ & 146 & 0 & & & & & & & & & 0 & 0 & + & & 0 \\
\hline versus change to UAI) & $\mathrm{L}$ & $?$ & 0 & & & & & & & & & 0 & 0 & + & & 0 \\
\hline $\begin{array}{l}\text { Ostrow et al. (1990) } \\
\text { (change to SB versus }\end{array}$ & $L$ & 2130 & + & & & & & & - & & - & & & & & \\
\hline \multicolumn{17}{|l|}{$\begin{array}{l}\text { maintenance of R1B) } \\
\text { Ross \& McLaws (1992) }\end{array}$} \\
\hline ( $C \cup$ index) & C & 173 & & & & & & & & & & & & 0 & + & \\
\hline \multicolumn{17}{|l|}{ Seage et al. (1992) } \\
\hline (URAI versus no URAI) & C & 481 & & & & & & & 0 & & - & & & & & \\
\hline consistent RTB) & L & 100 & & & & & & 0 & - & & & & 0 & & $+10^{2}$ & + \\
\hline \multicolumn{17}{|l|}{$\begin{array}{l}\text { Stall et al. (1986) } \\
\quad \text { (low versus medium versus }\end{array}$} \\
\hline high RTB score) & C & 463 & & & & & & - & - & & - & & & & & \\
\hline $\begin{array}{l}\text { Valdiserri et al. (1988) } \\
\text { (consistent CU versus }\end{array}$ & & & & & & & & & & & & & & & & \\
\hline never $\mathrm{CU}$ ) & C & 955 & 0 & & 0 & 0 & - & & & - & & 0 & 0 & + & 0 & \\
\hline De Wit, Sandfort et al. (|99|) & & & & & & & & & & & & & & & & \\
\hline $\begin{array}{l}\text { (Al versus no } \mathrm{Al} \text { ) } \\
\text { (consistent } \mathrm{CU} \text { versus }\end{array}$ & C & 611 & + & & & & & & & & & & & + & + & + \\
\hline inconsistent $\mathrm{CU}$ ) & C & 611 & + & & & & & & & & & & & 0 & + & + \\
\hline
\end{tabular}




\section{Table 2.2 Continued.}

\section{Abbreviations:}

$S B=$ safe behavior, $R T B=r i s k$-taking behavior, $C U=c o n d o m$ use, $A I=a n a l$ intercourse, $U A I=$ unprotected anal intercourse,

URAI=unprotected receptive anal intercourse, UIAI=unprotected insertive anal intercourse.

Notes:

I communication skllls + , self-efficacy scale 0

2 emotional support + , network affiliation 0

\section{Coding legend}

Demographic variables:

age: + means older age related to SB

income: + means higher income related to $\mathrm{SB}$

race: + means white more $S 8$ than other ethnical groups

education: + means higher educational level related to $S B$

Relationship status:

\section{+ means sex with regular partner safer}

Alcohol/drug use:

alcohol: + means (more) alcohol use related to SB

drugs: + means (more) drug use related to SB

both: + means (more) alcohol and/or drug use related to SB

nitrites: + means (more) nitrite use related to SB

Knowledge:

+ means higher knowledge related to SB

Risk Perception:

+ means men who behave safe perceive less risk of getting infected with HIV or perceive more risk of unsafe sexual practices

Attitude:

+ means either positive attitude towards SB related to SB or positive attitude towards RTB related to RTB

Social norms:

+ means either positive social norms towards SB related to SB or positive social norms towards RTB related to RTB

Self-efficacy:

+ means higher self-efficacy related to SB 
There are several serious sampling problems in any study that investigates male homosexual behavior. First, defining the population from which samples are drawn is complicated. Although homosexual behavior is not limited to the segment of the population that labels itself as homosexual (Kinsey, Pomeroy \& Martin, 1948), it is usually this segment that is studied. As Doll et al. (1992) have demonstrated, there are important differences between homosexually and non-homosexually identified men who have sex with men. In their study, homosexually identified men were more likely to belong to gay organizations. Furthermore, significantly more heterosexually identified men reported engaging in unprotected anal intercourse. Second, the majority of studies included in this review reported on samples that consisted of self-selected individuals. As Davies, Hickson, Weatherburn and Hunt (1993) have argued, those samples may overrepresent self-confident and openly homosexuals, as homosexual behavior coninues to be stigmatized. In addition, studies that looked at differences between volunteers and non-volunteers found substantial differences in attitudes towards sex and sexual behavior (see Catania, Gibson, Chitwood \& Coates (1990) for an overview). Furthermore, within studies included in this review, samples are predominanly white and overrepresent individuals with higher education and incone. For example, according to the 1990 US census, whites make up $80 \%$ of the United States population (Bureau of the Census, 1992). By contrast, in all US studies shown in Table 2.2 (except Hays et al. (1990), and Linn et al., (1989)), the proportion of whites exceeds $90 \%$ (range 91 $96 \%)$. Finally, the majority of studies were conducted in geographical areas with bigh ADDS prevalence rates among gay men.

These biases may constitute drawbacks for the generalizability of results. The sampling strategy employed in some studies to reduce the effects of selection bias, is to target as many segments of the gay community as possible, such as members of gay organizations, patrons of gay bars, saunas and discos, and health and STD clinics with a high proportion of gay clientele.

\section{Validity and reliability of self-reported behavior}

Without exception, the studies that were selected for this review had to rely in self-reports from respondents concerning their sexual behavior. As Catania, Gibson, Chitwood et al. (1990) have noted, a solid validity index for individual sexual behavior does not exist. One could use other data to corroborate self-reported sexual behavior, such as incidence of sexually uransmitted diseases (STDS) or number of condoms sold. However, the authors conclude that these indices are also biased, since STDs do not have a one-to-one relationslip with frequency of sexual behavior and condom 
sales do not have a one-to-one relationship with use.

Several methods have been used to get an impression of the validity of data on self-reported sexual behavior. Firstly, studies used sexual behavior data from partners of respondents. One study found moderate to high respondent-partner agreement with respect to frequency of receptive and insertive anal and oral sex (Spearman's r: 0.56-0.81, Seage, Mayer, Horsburgh, Cai \& Lamb, 1992). A similar study investigated the agreement on frequencies of sexual activities between men with either AIDS or ADS-related condition and their sexual contacts (Coates et al., 1988). Agreement on the frequencies of 17 sexual activities was moderate to high (Spearman's r: 0.49-0.91).

However, agreement significantly decreased as the lapsed time between the interview and the date of the last sexual encounter increased. The authors of both studies conclude that the results indicated that self-reported sexual behavior data were reasonably valid for use in epidemiological analyses. A few studies have examined the reliability of self-reported sexual behavior by either using a test-retest procedure or comparing retrospective reports of sexual activity for different time frames. The test-retest procedure for both frequency as well as number of partners for several practices were moderate (kappa's: 0.47-0.62, Saltzman, Stoddard, McCusker, Moon \& Mayer, 1987). Kauth, St.Lawrence and Kelly (1991) obtained self-reports of the frequency of several sexual practices for three overlapping time frames in the past: two weeks, three months, and twelve months. They found that the frequency of infrequent sexual practices showed the greatest consistency across time frames. They further found that the average correlation over all practices decreased significantly as the period of recall increased: the average correlation between two weeks and three months was 0.73 while the correlation between two weeks and twelve months was 0.31 . They conclude that selfreport measures of sexual behavior should use relatively short retrospective periods. Based on a review of studies of response bias in sex research, Catania, Gibson, Martin, Coates and Greenblatt (1990) advise the use of 1 - or 2-month recall periods. Another study compared agreement between 1 - and 12-month recall periods with several cognitive strategies used to recall sexual practices and partners. They found that the degree of consistency was lowest for non-person-oriented strategies (such as thinking of places or locations where partners were met), and highest for person-oriented strategies (such as names or faces of partmers, Blake, Sharp, Temoshok \& Rundell, 1992).

To summarize, the few studies which were conducted on validity and reliability of self-reported sexual behavior highlight the limitations of these measures. More methodological research is needed to optimize our measures of ADS-related behaviors. Meanwhile, researchers in this field should try to increase recall accuracy by using relatively short recall periods. One way to do this is to use person-oriented strategies to estimate the frequencies of sexual practices and the number of partners. To reduce self-presenta- 
tion bias, Catania, Gibson, Chitwood et al. (1990) suggest the construction of a nonjudgmental context, the use of open-response formats, the use of a sexual terminology that the group under study is comfortable with, and maximizing respondent privacy.

\section{Designs}

Research on determinants of safe and risk-taking sexual behavior among gay men usually used cross-sectional designs, longitudinal designs, or a combination of both. Cross-sectional studies generally report comparisons between respondents who practice safe sex and respondents who engage in high risk sexual acts (with varying definitions of these behaviors). Longitudinal studies usually use data from cohorts that were established in the AIDS epicenters (e.g. San Francisco, New York, Amsterdam). These studies generally report correlates that are associated with changes in these sexual behaviors over time.

\section{Behavioral measures}

While all the studies in Table 2.2 examined self-reported safe and risktaking sexual behavior, there is considerable variation in the operational definitions of these behaviors. The majority of cross-sectional studies compared men who had engaged in unprotected anal intercourse with men who had not engaged in anal intercourse or who had consistently used condoms. Some of these studies differentiated between receptive and insertive anal intercourse. Another group of studies examined the differences between men who consistently used condoms and men who did not consistently use condoms. Finally, one study used a risk-index (frequency of unprotected anal intercourse $x$ number of intercourse partners (Kelly, St.Lawrence, Brasfield, Lemke et al., 1990)), and two studies used a condom use index (proportion of anal intercourse occasions when condoms were used (Kelly, St.Lawrence, Brasfield, Lemke et al., 1990); sum of frequency of condom use during receptive and insertive oral and anal intercourse (Ross \& McLaws, 1992)).

Most longitudinal studies compared men who maintained high-risk behavior over a period of time with men who maintained low-risk behavior or changed to low-risk behavior. It is apparent that this variety in operational definitions provides us with detailed information on the sexual behavior of gay men and the changes in this behavior as a result of ADS. However, it also limits the comparability of results across studies. 
The value of sociodemographic variables for behavior change interventions is limited, because these factors themselves are, in general, not easily influenced. Demographical characteristics of target groups are primarily used to guide the development and implementation of interventions.

Relatively few sociodemographic factors have been investigated and even fewer seem to pertain to risk behavior. For example, studies in general find no relationship between risk-taking or preventive behaviors and income (Adib, Joseph, Ostrow \& James, 1991; Connell et al., 1990; Fitzpatrick, McLean, Boulton, Hart \& Dawson, 1990), or educational level (Adib et al., 1991; Connell et al., 1990; Hays et al., 1990; Kelly, St.Lawrence \&

Brasfield, 1991; Kelly, St.Lawrence, Brasfield, Lemke et al., 1990; McCusker, Zapka, Stoddard \& Mayer, 1989; Valdiserri et al., 1988).

With respect to the relationship between risk-taking behavior and ethnic origin of respondents, it must be concluded that little is known. With respect to the studies in Table 2.2, all studies conducted outside the United States and a minority of studies conducted in the United States do not report the racial or ethnic origin of their respondents. Of those studies that do provide such information (12 studies), four included it as a variable in their analyses. These analyses showed no relationship between ethnic origiu and risk-taking behavior in two of the four studies (Adib et al., 1991; Valdiserri et al., 1988). In the study by Hays et al. (1990) a higher percentage of non-whites engaged in high-risk behavior compared to whites (30\% versus $14 \%$ respectively). This difference approaches significance $(\mathrm{OR}=1.61$, $95 \% \mathrm{CI}=0.98-2.64, \mathrm{p}<.06$ ). Finally, the study by Linn et al. (1989) showed a highly significant relationship between race and level of risk-taking behavior. Their unsafe category contained $59 \%$ of whites, $69 \%$ of African-

Americans, and $81 \%$ of Latin-Americans. It is possible that these dissimilar findings are a result of the varying proportions of non-whites in these samples. The percentage of non-whites was $8 \%$ in the study from Adib et al. (1991), 4\% in Valdiserri et al. (1988), 21\% in Hays et al. (1990), while non-whites made up one third of the sample of Linn et al. (1989). Low proportions of non-whites result in relatively wide confidence intervals around association estimates which may account for the non-significant results.

Two demographic factors, age and geographical location, seem related to AIDS risk behavior. They will be discussed below.

\section{Age}

Several studies have found younger age to be related to risk-taking sexual practices. Ekstrand and Coates (1990) found in a longitudinal study that younger respondents showed higher levels of unprotected anal intercourse than older respondents in both 1985 and 1988. De Wit, Sandfort, De 
Vroome, Van Griensven and Tielman (1991) found that the younger men in their sample had more anal sex and used condoms less consistently than older men. Similar results were reported by Fitzpatrick et al. (1990), Kelly, St.Lawrence, Brasfield, Lemke et al. (1990), Kelly, St.Lawrence et al. (1991), Kelly, Kalichman et al. (1991), McKusick, Coates, Morin, Pollack and Hoff (1990), and Ostrow et al. (1990).

Few authors bave tried to explain this tendency among younger men. As a possible answer, Ekstrand and Coates (1990) suggest that younger men might have less social support for practicing safe sex, they might perceive themselves to be invulnerable, or they might have poorer skills for buying condoms or negotiating safe sex.

The abovementioned studies reported an association between age and risktaking behavior. It is importanl to note that men who engaged in risktaking sex were younger, but not necessarily young. There are two studies that specifically looked at sexual behavior of young gay males. RotheramBorus and Koopman (1991) studied sexual behavior of 59 black and Hispanic gay adolescents (ages ranging from 14 to 18 years old). Fourteen adolescents $(24 \%)$ had engaged in unprotected anal intercourse in the previous three months. Hays et al. (1990) compared low versus high risktaking among gay men aged 18-25. They also found high levels of risk-taking behavior: $43 \%$ of their sample had engaged in unprotected anal intercourse in the previous six months. A comparison of low risk takers with high risk takers showed that the latter group reported more enjoyment of anal intercourse without condoms, perceived less risk with regard to unprotected anal intercourse, and reported poorer communication skills with sexual partners.

Hays et al. (1990) conclude that special efforts should be made to reach younger gay males. They also add that if interventions succeed in reaching young gay males, the likelihood of low-risk behavioral maintenance might be higher than usual since young gay men with relatively little sexual experience have had less opportunity to develop anal sex as a habitual behavior.

\section{Geographical location²}

Several authors have suggested that gay men in low AIDS prevalence areas engage in more risk-taking behavior (Jones et al., 1987; Kelly, St.Lawrence, Brasfield, Stevenson et al., 1990). While these studies only looked at lowprevalence areas, there are two studies which compared data from lowprevalence areas with data from high-prevalence areas: one in the United Kingdom (Weatherburn, Hunt, Davies, Coxon \& McManus, 1991), the other in the United States (St.Lawrence, Hood, Brasfield \& Kelly, 1989). The 
results of the British study showed that men in London were significantly more likely to use condoms compared to men who live outside London ( $49 \%$ compared to $37 \%$ ). The results from the American study showed significantly more occurrences of unprotected anal intercourse, and significantly fewer occurrences of low-risk sexual practices in low-prevalence cities.

The authors of the abovementioned studies relate these findings to the fact that many health education initiatives are targeted at homosexual men who live in ADS epicenters, while men who live outside these areas have less: access to organizations for information and support. Furthermore, both St.Lawrence et al. (1989) and Jones et al. (1987) presume that the relatively low number of persons with AIDS in these areas results in an underestimation of risk of infection which in turn leads to persistence of high-risk behavior.

Situational and behavioral variables

Relationship status

With respect to safe and risk-taking sexual behavior three forms of relationships are usually distinguished: 1 . one regular partner, exclusive, 2 . one regular partner, non-exclusive, and 3. casual parmers only ${ }^{3}$. Studies that include measurements of relationship status generally find that men who are in a primary relationship show significantly lower levels of risk-taking behavior with casual partners than with their regular partner (Bochow, 1990; Fitzpatrick, Boulton, Hart, Dawson \& McLean, 1989; Fitzpatrick et al., 1990; McKusick et al., 1990; Valdiserri et al., 1988). More specifically, Doornbos (1992) reports that $47 \%$ of the men who had one regular exclusive partner. $28 \%$ of the men who had both a regular partner and casual partners, and $9 \%$ of the men who only had casual partmers, had engaged in unprotected anal intercourse in the previous six months. De Wit, de Vroome et al. (1991) have shown that while $37 \%$ of their respondents quit having anal intercourse with casual partners, $91 \%$ continued this practice with their regular partner. Thus, sexual behavior partly depends on the type of partner involved.

One other point to keep in mind is that in some instances, the labeling of sexual behavior as unsafe is unjustified. If men entered a monogamous relationship in the pre-AIDS era or if both men in a monogamous relationship

3 It is important to note that there are, of course. more ways of classifying the variety of gay male relationships. The level of refinement depends, in part, on the kind of research questions under study. For example, with respect to non-regular partners it might be useful to distinguish between anomymous and nonanonymous sex partners. 
have been tested seronegative, it is clear that unprotected intercourse within their relationship carries no risk of HIV infection.

Summarizing, it appears to be the case that a considerable proportion of gay men have not only limited their number of sexual partners but have also reserved unprotected anal intercourse exclusively for their primary relationship. Although this might seem to be a sensible way to cope with the threat of HIV infection, it also should be noted that as long as the serostatus of the partner is unknown, this coping strategy does not guarantee that one will not get infected.

\section{Drug and alcohol use}

A large number of studies have examined the relationship between substance use (alcohol, drugs, alcohol and/or drugs, and nitrite inhalants) and risk-taking sexual behavior. As can be seen in Table 2.2, almost all studies (there is one exception) either report a negative relationship with protective behavior or fail to find a relationship.

With respect to drug use, both Siegel, Mesagno, Chen and Christ (1989), and Stall, McKusick, Wiley, Coates and Ostrow (1986) reported a relationship between marijuana use during sex and subsequent risk behavior. Men who used marijuana were more likely to fall in the high risk category. Osırow et al. (1990) found that men who used three or more drugs were nure likely to continue risk-taking sexual behavior than men who used none. In other studies the relationship between drug use and high risk sexual behavior was absent (Gold, Skinner, Grant \& Plummer, 1991; Seage et al., 1992).

A number of studies found that alcohol and/or drug use was associated with more risk-taking sexual behavior (Kelly, Kalichman et al., 1991) and less condom use (Valdiserri et al., 1988), while two other studies did not find an association (Adib et al., 1991; Connell et al., 1990).

With respect to the relationship between alcohol use and sexual behavior. the results are not obvious either. Some studies have found that alcohol use prior to or during sex was related to risk-taking sexual behavior (e.g. Stall et al., 1986), while other studies could not discover this relationship in their data (e.g. Hays et al., 1990). In a detailed analysis of sexual diaries of 430 gay men. Weatherburn (1992) found that in 250 sexual encounters that in-volved alcohol use during sex, 58 included anal intercourse. Of these encounters, 46 were with the regular partner ( 35 exclusive), and in 10 of the 12 remaining encounters condoms were used. The authors reject the hypothesis that alcohol use and risk-taking behavior are related. One study found, contrary to expectations, that higher alcohol consumption at the first measurement was related to the adoption of safer sex practices at follow-up (McCusker, Stoddard, Zapka, Zorn \& Mayer, 1989). Another study asked subjects to recall their most recent safe encounter and their most recent risk-taking encounter. Analyses showed that being under the influence of 
alcohol at the start of sex, and the amounts of alcohol used during sex, did not distinguish between type of encounter (Gold et al., 1991).

Investigations into the relationship between the use of inhaled nitrites and protective sexual behavior have found either a negative relationship (Ostrow et al., 1990; Seage et al., 1992; Stall et al., 1986) or no relationship (Gold et al., 1991; Kelly, Kalichman et al., 1991; McCusker, Stoddard et al., 1989).

It is clear that we do not yet fully understand the relationship between substance use and risk-taking sexual behavior. Some authors who found a relationship suggest that this relationship might be causal (e.g. Stall et al., 1986). The same point of view can be found in several publications on HIV prevention policy (e.g. Adib \& Ostrow, 1991; Peterman, Cates \& Wasserheit, 1992; Peterson et al., 1991; Shernoff \& Bloom, 1991). However, other authors have expressed doubts about a direct causal relationship between substance use and engaging in risk-taking sex (Gold et al., 1991; Siegel et al., 1989). They suggest that substance use and risk-taking sex might be manifestations of some unknown variable, such as desire for excitement or a predisposition to risk-taking behavior. Finally, a number of authors explicitly doubt whether there is any association at all (Weatherburn et al., 1993).

Summarizing, research on substance use shows equivocal results with regard to its influence on risk-taking sexual behavior. Although a disinhibition explanation seems appealing (it is in fact the reason that many men give for having engaged in risk-taking sex), there is still uncertainty whether there is a direct causal relationship between substance use and subsequent risktaking sexual behavior.

\section{Psychosocial variables}

In most instances psychosocial variables are explicitly derived from prevailing (health) behavior theories like the Theory of Reasoned Action (Fishbein \& Ajzen, 1975), the Health Belief Model (Janz \& Becker, 1984), Social Learning Theory (Bandura, 1986), and the Theory of Planned Behavior (Ajzen, 1988). In the following section we will summarize research that included one or more of the following psychosocial variables: knowledge, risk perception, attitudes, social norms, and self-efficacy.

\section{Knowledge}

ADS knowledge has been assessed with respect to a variety of domains. Most frequently, studies have looked at knowledge of modes of HIV transmission related to sexual practices, public health guidelines, and risk reduction measures. Some studies included measures of knowledge regarding the interpretation of HIV test results, misconceptions about HIV and AIDs, and prevalence of HIV and AIDS among gay men. 
AIDS education efforts have undoubtedly had a positive influence on gay men's knowledge about the disease. Without exception, studies show very high levels of knowledge (Dallas, 1990; Emmons et al. 1986; Joseph et al., 1987 b; Kelly, St.Lawrence, Brasfield, Lemke et al., 1990; McKusick et al., 1990; Siegel et al., 1989; St.Lawrence et al., 1989; Valdiserri et al., 1988). However, the available data on the relationship between knowledge level and risk behavior do not show one clear tendency. Although some studies have shown that knowledge is related to initial behavior change, especially when ADS was first discovered, it seems that at present it has little predictive value for behavior change or maintenance. Due to ceiling effects, knowledge levels can hardly change. This is probably why an increasing number of researchers have stopped including knowledge as a variable in their studies.

In sum, gay men are well informed about the modes of HIV transmission, public health guidelines, and risk reduction measures. However, the most important conclusion is that, given the complexity of the behavior change that is required, it is not surprising to find that knowledge alone, though a prerequisite for change, is not sufficient to enable behavior modification and maintenance. As has been demonstrated with other health related behaviors as well, within any target group the first distinction one has to make is between adopters and non-adopters (E.M.Rogers, 1983). Among adopters a further distinction can be made with respect to behavior change. A number of people will indeed change their behavior on the basis of health information that gets to them. However, the majority of this group requires more than information to change their behavior. Supportive social norms and the acquisition of necessary skills are examples of what is needed for them to change (E.M.Rogers, 1983).

\section{Risk perception}

Some behavioral theories, especially the Health Belief Model, explicitly hypothesize that a sense of personal susceptibility to a disease (i.e. a perception of risk), among other factors, influences decisions to undertake actions. Several studies have investigated this presumed influence (see Table 2.2). There are two types of risk estimates that are generally asked for in this type of research: 1. absolute risk estimates (e.g. "What are your chances of getting infected with HIV?"), 2. relative risk estimates in comparison to others (e.g. "What are your chances of getting infected with HIV, compared to an average gay man your age?"). In both instances it is found that people systematically underestimate their risk. This finding is usually referred to as 'optimistic bias' and is found with regard to many (health-related) behaviors (Weinstein, 1987). For example, Bauman and Siegel (1987) found that the risk estimates of respondents who practiced risk-taking sex were only slightly higher in comparison with safe and low risk groups in their sample. Furthermore, they found that $51 \%$ of their sample rated their risk as below 
average. The group mean of the estimated risk of getting ADS relative to other gay men was -.35 (range -1 to +1 ), showing the optimistic bias described above.

Although the finding that risks are underestimated is worrisome in itself, the implications for prevention are not very clear. Mixed results have been found when looking at the relationship between risk perception on the one hand and behavior or behavior change on the other hand. Several studies found that risk perceptions differed between low and high risk-taking groups. Hays et al. (1990) found that high risk takers, compared to low risk takers, perceived unprotected anal intercourse to be less risky, while they estimated that their current behavior placed them more at risk for HIV infection. Kelly, St.Lawrence, Brasfield, Lemke et al. (1990) report similar results, i.e. men who practiced unprotected anal intercourse with multiple partners regarded their sexual behavior as more risky than men who practiced safe sex. They also found that the risk estimate decreased as the proportion of protected anal intercourse (i.e. condoms were used) increased. McCusker, Stoddard et al. (1989) found that greater perceived susceptibility at pretest was the strongest predictor of the adoption of consistent safe behavior at post-test.

A number of studies found that risk perceptions did not distinguish between safe and risk-taking behavior (Mckusick et al., 1990; Siegel et al., 1989) or changes in risk-taking behavior (Fitzpatrick et al., 1990; McKusick et al., 1990). In these studies men who showed risk-taking behavior underestimated their risk to such extent that their actual estimates did not differ significantly from men who practiced safe sex.

A review of risk perception research does not clarify whether a relationship with behavior or behavior change exists. There are several possible explanations for the variation in results. First, the operational definitions of risk perceptions vary across studies. While in some studies respondents were asked to rate the riskiness of their current sexual behavior (e.g. Kelly, St.Lawrence, Brasfield, Lemke et al., 1990), other studies asked respondents to rate their absolute chance of developing AIDS (Fitzpatrick et al., 1990), or their chance of developing ADS compared to other gay men (Siegel et al., 1989). Although the number of studies is limited, it seems that respondents have a more realistic appraisal of their risks when they are asked to judge their current or recent sexual behavior than when they are asked to judge possible long-term consequences of their behavior (i.e. developing AIDS). Also, motivation to protect oneself should be framed in terms of susceptibility to the risk behavior (Janz \& Becker, 1984; R.W.Rogers, 1983; Rulus, 1992). Thus, when studying AIDS-protective behavior, a question could be: "What is your risk of contracting HIV if you engage in unprotected anal intercourse". If questions are framed in this way, one would hypothesize. that those respondents who engage in unprotected anal intercourse bave lower risk estimates than those respondents who do not engage in anal 
intercourse or who consistently use condoms (which, in turn, explains current behavior).

Second, the majority of studies have used cross-sectional designs. As

Weinstein (1989) has argued, even if a positive relation between risk perception and behavior is found, the direction of causation is unclear. It could well be that behavior change influences risk perception rather than vice versa.

\section{Attitudes}

Research on attitudes related to risk behavior shows the importance of anal intercourse for many gay men. Comparisons between men who engage in risk-taking sexual behavior and those who do not, show that the former regard anal intercourse as more important and enjoyable (Connell et al., 1990; Hays et al., 1990; Kelly, Kalichman et al., 1991), consider anal sex more as "ultimate intimacy" (Dallas, 1990), experience oral sex as less satisfying (Dallas, 1990; Hays et al., 1990), and are less inclined to avoid anal intercourse (De Wit, Sandfort et al., 1991). Men who reported that unprotected anal intercourse is their favorite technique, were more likely to engage in unprotected anal intercourse (McKusick et al., 1990). Gold et al. (1991) showed that the desire to have intercourse withour a condom, to have exciting sex, and to have excitement in any way possible, were significantly greater in subjects' most recent unsafe encounter compared to subjects' most recent safe encounter. Finally, Connell and Kippax (1990) report that $54 \%$ of their sample rated intercourse without a condom as the most physically satisfying form of sex. Thirty-six percent of their sample rated it as the most emotionally satisfying practice.

In sum, men who have positive attitudes towards anal sex are more likely to practice unprotected anal sex. The qualitative studies of Prieur $(1990 ; 1991)$ show that anal sex is more than just an alternative from the whole gamut of sexual activities. Whenever it is incorporated in the sexual repertoire it becomes valuable to and part of what might be called a gay identity. Connell et al. (1990) argue that for many men anal intercourse is a central part of being gay.

Similar results have been found with regard to attitudes toward condoms. That is, men who have negative attitudes toward condom use are more likely to engage in unprotected anal intercourse (Valdiserri et al., 1988). Using factor analysis, Ross (1988) interprets the most prominent factor (accounting for over a quarter of the total variance) as a negative attitude toward condoms. Items with high loadings on this factor reflect the view that condoms are unerotic, unreliable and uncomfortable. Clearly, neither a positive attitude towards anal intercourse, nor a negative attitude towards condom use promotes safer sex.

There are two possible avenues one may take if one wants to promote safer sex through attitudinal change. First, one might try to change these positive 
attitudes towards anal sex. The aim of such interventions would be to have gay men refrain from anal sex. Second, one might try to change attitudes towards condom use in a positive direction and preserve positive attitudes towards anal sex. The obvious advantage of the former is that refraining from anal sex would eliminate the risk for HIV infection (assuming that no other risk behavior is prevalent). However, given the significance of anal intercourse, many have questioned the feasibility of this approach and have relied on the latter strategy, i.e. promoting condom use. The advantage of this approach is that the positive attitude towards anal intercourse can be left unaffected. This is in line with E.M.Rogers' (1983) argument that innovations have to be compatible with existing values, past experiences, and needs of potential adopters to facilitate adoption. The disadvantage of this approach is that men might judge their behavior as completely safe, while it is known that condom failure rates are substantial.

\section{Social influence and norms}

Norms and values that are supported by peers can have a substantial influence on one's behavior (see Fishbein \& Ajzen, 1975). One of the best examples of the influence of social networks is the swiftness with which safe sex recommendations became known and adhered to by large numbers of gay men. It has also been demonstrated that norms that prevail in peer groups influence the degree of ADS-preventive behavior. A group norm prescribing safe sex has been found to relate to a decrease in number of sex partners (Emmons et al., 1986), avoidance of anonymous parmers (Joseph et al., 1987a), safer sexual behavior (Kelly, St.Lawrence, Brasfield, Lemke et al., 1990; Kelly, St.Lawrence, Brasfield, Stevenson et al., 1990), an intention to behave more safely in the future (Fisher, 1988), avoidance of anal intercourse (De Wit, Sandfort et al., 1991), an intention to use condoms (Ross \& McLaws, 1992), and consistent condom use (De Wit, Sandfort et al., 1991). Adib et al. (1991) report that the absence of peer support was a significant predictor of relapse to unprotected anal intercourse.

Prieur (1990) found that the most noticeable difference between men who do not engage in high risk sex and those who do, is that many of the men that belong to the latter group have a loose social network. Similar results are reported by Connell et al. (1990). They report that involvement with gay community organizations is low for men who engage in unprotected anal intercourse with casual partners. Fishbein et al. (1992) investigated the influence of attitudes and social norms on the intention to engage in 11 sexual behaviors, varying in AIDS risk. The study was conducted in three cities in the US (Seattle, Denver and Albany). They found that the influence of social norms was greatest in Seattle and smallest in Albany. They attribute this difference to the fact that the gay community in Seattle is larger and better organized, which results in well-linked interpersonal networks and more interpersonal interactions. 
Hence, stimulating the development of social networks as well as integration in a social network that enhances safe sex norms may be a very powerful safeguard against HIV infection.

Influencing social norms is easier said than done. Continuous efforts on a community level, advocating adherence to safe sex recommendations are necessary but not sufficient. Concurrent to this, small-scale activities have to be carried out to support men seeking help in changing their high-risk behavior. This can be done through small group interventions or face-toface counseling. An example of this is the "Stop AIDS" community discussion groups that have been conducted in many AIDS epicenters (Miller, Booraem, Flowers \& Iversen, 1990). Another promising approach that Kelly et al. (1992) have applied is the use of peer leaders who are trained to communicate about safe sex with their peers. The results show impressive reductions in unprotected anal intercourse.

Self-efficacy

Self-efficacy is a person's evaluation of the extent to which he is capable of exerting a certain control over his behavior (Bandura, 1986). The value of self-efficacy estimates is more than a reflection on one's past behavior; it also has a predictive value for future behavior (ibid.). With respect to AIDSrelated behavior, self-efficacy is a person's evaluation if, and to what extent, he has the skills to exercise control over sexual situations (Bandura, 1989). The relationship between self-efficacy and AIDS risk behavior has repeatedly been demonstrated. De Wit, Sandfort et al. (1991) found that self-efficacy in using condoms was the strongest predictor of consistent condom use. Other studies have shown that a non-assertive attitude predicted relapse to unprotected anal intercourse (Adib et al., 1991), and that men who engaged in unprotected anal intercourse rated their sexual communication skills lower than men who only practiced safe sex (Hays et al., 1990). A comparison of gay men who consistently practiced safe sex with gay men who consistently engage in risk-taking behavior, showed that the latter group expressed more difficulty in changing their sexual behavior (Siegel et al., 1989). Dallas (1990) asked respondents to rate their self-efficacy with respect to behaving safely for the subsequent ten years. Of the respondents who did not engage in anal intercourse, $27 \%$ stated they thought it would be difficult while $47 \%$ of the respondents who actually engaged in anal intercourse stated likewise.

One important point that has been made is that ADS risk behavior is special in the sense that it always involves an interaction with one (or more) other individual (Davies \& Weatherburn, 1991). In connection to self-efficacy Bandura has nored:

Trunslating health knowledge into effective self-protection action against AIDS infection requires social skills and a sense of personal power to exercise control 
over sexual situations. [...] Problems arise in following safer sex pructices because self-protection often conflicts with interpersonal pressures and sentiments. [...] The weaker the perceived self-efficacy, the more such social and affective factors can increase the likelihood of risky sexud behavior. (1989, p. 129)

Thus, interventions designed to enhance self-efficacy should be well aware of the interpersonal nature of AIDS risk behavior. One potent strategy is the development of social skills to cope with these interpersonal situations. The desired effects of learning social skills are the ability to cope effectively with high-risk situations and to build up self-assurance. After assessment of existing coping skills for situations where self-efficacy is low (i.e. high-risk situations) adequate coping skills are identified and acquired skills are practiced, preferably by means of role plays. Finally, ample feedback should be given on achievements.

Again, small group interventions or face-to-face counseling are the most suitable settings to apply these techniques (Kelly, St.Lawrence, Betts et al., 1990).

\section{CONCLUSIONS}

To a certain extent the threat of HIV infection has prompted changes towards safer sexual behavior among gay men: many have reduced their number of partners and have increased their use of condoms. Despite these changes, however, a significant number of gay men still put themselves at risk. This is similar to other health related behaviors. That is, some people adopt protective behaviors faster than others, and some people experience more difficulty in maintaining changes they have made in their behavior. Continuous efforts to improve and innovate interventions are warranted. In order to be able to develop effective interventions, a good understanding of the determinants of safe and risk-taking sexual behavior is needed.

We will conclude with general recommendations for future research on determinants of ADS-related sexual behavior and related methodological issues.

Recommendations for research on determinants

1 To benefit the development of prevention activities, studies need to be conducted that increase our knowledge with respect to the observed relationship between age and risk-taking behavior. Whether young gay men 
constitute a high-risk group that needs special attention is a question that needs to be addressed.

2 More research is needed among ethnic minorities and gay men with lower SES status.

3 Future research should try to answer questions on the possible (causal) role that substance use may play in ADS-related behavior. If substance use is related, either causal or non-causal, it becomes important to understand the underlying processes of the relationship.

4 Future research should answer unresolved questions with respect to the influence of ADS-risk perceptions on AIDS-related behavior.

5 The nature of the disease demands behavioral changes that have to be maintained for long periods of time. It may well be that determinants that are related to initial behavior change differ from determinants that are related to long-term maintenance or relapse. For this reason, more research should be conducted that provides insight in factors that enable gay men to maintain behavior change or cause gay men to return to risktaking sexual behavior. This implies long-term monitoring of sexual behavior and possible determinants.

\section{Recommendations with respect to methodological issues}

1 In our opinion it is vital for the generalizability and comparability of results of studies that greater consensus is reached on the operational definitions of behavioral measures. In addition, as mentioned before, efforts should be made to increase the validity and reliability of selfreported sexual behavior.

2 The use of theories that explain behavior or behavior change is recommended. The results of determinant studies are extremely valuable for the development of effective interventions. As Fisher and Fisher (1992) have demonstrated in their review of ADS risk-reduction interventions, interventions that are conceptually based appear to have the greatest impact. Therefore, intervention development based on theories will most likely benefit from determinant studies that are also conceptually based (see also Kelly \& Murphy, 1992). In addition, we recommend that researchers use and test complete theories instead of isolated concepts, as most behavior is determined by a combination of different determinants. Only complete theories contain a sufficient number of determinants to explain complex behavior such as ADS-related sexual behavior.

3 Researchers are encouraged to provide ample information on the measures they used in their research.

In this contribution we have reviewed the literature on determinants of safe and risk-taking behavior among gay men. Our recommendations show that 
efforts have to be made to expand our understanding of AIDS-related sexual behavior and enhance the quality of the research in this area. At the same time we hope that concurrent to this endeavor, efforts will also be made to develop, implement, and evaluate prevention interventions for gay men that are based on the theoretical concepts that seem to pertain to risk behavior change and maintenance. 


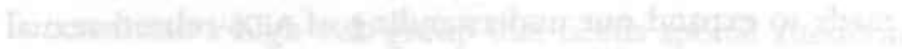

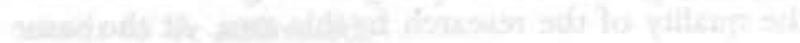

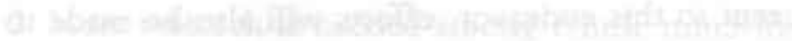

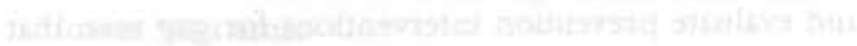

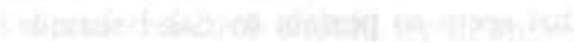




\section{CHAPTER 3}

Focus group interviews with risk-taking gay men: Appraisal of AIDS prevention activities, explanations for sexual risktaking, and needs for support.

Published as:

Hospers, H.J., Molenaar, S., \& Kok, G.J. (1994). Focus group interviews with risk-taking gay men:Appraisal of AIDS prevention activities, explanations for sexual risk-taking, and needs for support. Patient Education and Counseling, 24, 299-306. 
The behavioral changes that gay men have made as a result of the ADS epidemic are well documented (Becker \& Joseph, 1985). In sum, significant decreases in the number of partners and the frequency of anal intercourse were demonstrated, as well as an increase in the use of condoms. Despite these impressive changes on an aggregate level, studies that looked at data on an individual level report that a considerable number of gay men alternate between safe and risk-taking behavior (i.e. one or more instances of unprotected anal intercourse (UAI) during the measurement period). For example, behavioral patterns from 310 participants in the Amsterdam Cohort Study show that $35.5 \%$ practiced safe sex or changed to safe sex from 1984 to 1991 (one measurement per year), and $8.7 \%$ reported at least one instance of UAI in every year. The remaining 55.8\% show both safe sex behavior as well as instances of UAI between 1984 and 1991 (De Wit, Van den Hoek, Sandfort \& Van Griensven, 1993). These patterns imply inconsistent sexual behavior, which is especially harmful in the case that risks are taken with casual partners.

Besides data that show inconsistent behavior, there are two recent studies that show an increase in risk-taking sex. Firstly, data from the Amsterdam Municipal Health Service on anal gonorrhea among gay men, show that the number of cases gradually decreased from approximately 500 in 1982 to only 35 cases in 1988. However, from that date the incidence of anal gonorrhea significantly increased (44 cases in 1989, 89 cases in 1990, and 138 cases in 1991) while the number of consultations remained constant. Further analyses revealed that the strongest increase occurred among gay men who were younger than 30 years (Van den Hoek, Haastrecht, Henquet \& Coutinho, 1993). Secondly, data from the Amsterdam Cohort Study (De Wit et al., 1993) show a sudden increase in UAI from 1990 to 1991. This increase is almost completely accounted for by UAI with casual partners: in $1990,13 \%$ of the cohort members reported one or more instances of UAI with casual partners while in 1991 this percentage had almost doubled (24\%). The examples in this paragraph were all taken from research in the Netherlands. However, studies in other countries that examined behavioral maintenance and relapse have yielded comparable results (Adib et al., 1991; Centers for Disease Control, 1989; Ekstrand, 1992; Ekstrand \& Coates, 1990; Stall et al., 1990).

These epidemiological developments led to a critical review of Dutch AIDS prevention activities. It was concluded that efforts had to be made to better understand the circumstances under which AIDS risk behavior occurred and that new prevention activities had to be developed to promote consistent safe sex behavior.

In the first phase of this project, an effort was made to better understand the underlying processes of ADS risk behavior. For this purpose, focus 
group interviews were conducted with gay men who engaged in risk-taking sex with casual partners despite a positive intention towards safe sex. Focus group techniques are used to gain insight in the opinions and ideas of members of a certain target group. Typically, a focus group consists of five to ten participants, who discuss topics that are of interest to researchers or program planners (Basch, 1987; Krueger, 1988; Morgan, 1988). With regard to AIDS, focus group interviews have been conducted with several target groups, such as minority women (Kline, Kline \& Oken, 1992), drug users (Pakanachwong et al., 1991), and college students (Williams et al., 1992).

In our focus groups, participants addressed the following questions:

1 How do you appraise current ADS prevention activities for gay men?

2 What explanations do you have for the fact that you engage in risk-taking behavior?

3 Which kind of support would meet your needs with respect to ADS prevention activities?

\section{METHOD}

\section{Recruitment}

Several channels were used to recruit participants for the focus group interviews. Advertisements appeared in three major Dutch daily newspapers. A short article with a description of the project appeared in De Gay Krant (national Gay newspaper, published biweekly), AIDS Info (published monthly), and xL (magazine of the Dutch Gay and Lesbian Association, published monthly). Finally, posters and flyers were distributed among gay bars and saunas in Amsterdam through the distribution network of the municipal health education department. In all publications mentioned above, gay men were asked to volunteer, if they had engaged in risk-taking sex with casual partmers on one or more occasions in the near past. It was emphasized that their information would be used for the development of prevention activities aimed at consistent safe sex. Finally, we offered to reimburse all expenses, such as travelling costs.

\section{Procedure}

Twenty-six men contacted us by telephone. Nineteen men agreed to participate in one of the three groups that were scheduled. The remainder of men 
either could not participate on the scheduled dates $(2 x)$, only engaged in safe sex $(3 x)$, or had misunderstood the message (2x). The mean age of participants was 38 (range 28-62) and the majority of men lived in Amsterdam (68\%). Each focus group was led by two gay moderators (a psychologist and a health educator). Each session started with a brief

$50 \ldots$ description of the study. Furthermore, after anonymity and confidentiality were guaranteed, permission was asked to audiotape the discussion. At that point, participants were given the opportunity to leave if they did not agree with the study purposes and/or the study procedures. However, all participants agreed to take part. Finally, participants were requested to treat other participants' contribution to the discussion as confidential information. Sessions lasted approximately $2 \frac{1}{2}$ hours. After all focus group interviews were completed, complete transcriptions of the audiotapes were made. For each of the research questions, two researchers independently extracted relevant statements from the transcriptions of the three focus group interviews. Subsequently, these statements were further clustered into themes. A theme was considered for discussion in the following results section if it had been addressed in all groups.

\section{RESULTS}

\section{Appraisal of current AIDS prevention activities}

It was remarkable that almost all men criticized the current AIDS prevention activities. Most men did not appreciate the profusion of written information materials (brochures, leaflets, posters, etc.), which, in their opinion, are being distributed by too many organizations. Also, the fact that it was difficult to distinguish older materials from recent materials, was felt as a drawback. The issue that was most extensively discussed was the information on HIV transmission in relation to oral sex. In 1992 a Dutch study reported that of 102 homosexual men who seroconverted, four reported that they had not engaged in anal intercourse in the 6-9 months preceding seroconversion. Since these four men reported to have engaged in oral sex, the authors concluded that in these cases oral transmission of HIV might have occurred (Keet, Albrecht van Lent, Sandfort, Coutinho \& Sandfort, 1992). These findings found their way in the Dutch mass media, however, without the usual scientific reserve. It resulted in much anxiety among homosexual men and, as the discussion in the focus groups demonstrates, still causes confusion, anger, and defensive reactions. The following statements illustrate this: 
"Whether oral sex is safe or not, is still unclear to me."

"The physician at the STD clinic told me that oral sex wos risky, which scared me. About two months later I stopped believing that, becouse if it were true more men had to be infected."

"I have decided that I don't believe it."

\section{Explanations for engaging in risk-taking behavior}

This issue was the one most extensively discussed by the men in the focus groups. They were very eager to express their feelings about risk-taking sex and to share their experiences with the group. The explanations for risktaking sex are divided into five categories. They will be described in the following paragraphs.

\section{Attitudes towards anal sex and condom use}

Anal intercourse is highly valued by the participants. They describe it as an intimate, special, and exciting technique. Several participants state that they have become increasingly interested in anal sex. They aturibute this to the Dutch prevention message that advises gay men to refrain from anal intercourse or to use condoms if they want to engage in anal intercourse. The following statements illustrate this:

"I became must more interested in anal sex because it was forbidden. Things that are forbidden are attracting to me. It has become a game to me to see where the limits are."

"It's a good feeling to take risks ... to do things that are forbidden."

"It's a kind of challenge. In general I have no problems with safe sex, but for some reason the focus on safe sex also increases the attractiveness of anal sex."

The reasons that men give for not using condoms are as follows. Only a few men state that they find condoms to expensive or hard to get hold of. For the majority of men price nor availability are barriers for use. Also, most men believe that they have sufficient skills to use condoms correctly. Non-use of condoms is predominantly determined by participants' negative attitudes towards condoms and their negative expectations about the consequences (i.e. decrease of sexual pleasure, loss of intimacy).

"It's just less exciting to use condoms. Without is the best for me. I'm even disappointed if a partner insists on using them." 
"Fucking without condoms is ultimate intimacy. It's as close as you can get to another person."

Thus, engaging in unprotected anal intercourse depends on positive attitudes to the sexual technique on the one hand, and negative atritudes towards $52 \ldots . . .$. condoms on the other hand.

\section{Relationship aspects}

A considerable number of men report more difficulties with safe sex if it involves partners with whom they have sex more often. In general, sex with these regular partners occurs at home. On the other hand, these men have no difficulty with avoiding risks in anonymous situations.

"With one night stands, or in anonymous situations, I have no difficulty at all to set limits .. when I get to know a sexual partner better, I find it hard to live up to those limits."

"In a relationship it's hard ... there is more intimacy which makes it difficult to say that you don't want to fuck."

"After a few wecks, when I get to know a person somewhat better, I start thinking irrational. For example, I tell myself, he's young, or he probably hasn't had many partners. That's when things go wrong."

Other participants tell the opposite story. For them, risk-taking sex typically occurs in anonymous situations. They seem to feel less responsible for their sexual partners in those situations. They accept a certain level of risk, and do not want to make decisions for their partner. As two men stated:

"When I have sex at home I know to behave, but when I'm in a darkroom, for example, I have no idea who the other is. We have sex, we leave and continue with our lives. I hate to think that I would have infected someone I know."

"If I have unsofe sex, it happens in the park. At home I have everything [condoms] neur at hand and I think more about it. In the park everything happens so fost."

\section{Situational aspects}

According to the participants, being in love is an important determinant of risk-taking sex. Avoiding risks is difficult in that situation. Similarly, if one is physically attracted to a person, safe sex becomes harder. This is especially the case if such a partner takes the initiative to engage in risk-taking sex. In those instances they are less able to insist on safe sex, mainly because they do not want to disappoint their partner. 
"I've always been safe, until I fell in love with this guy. Since then I'm baving trouble with safe sex."

"If I encounter the man of my life, I'm weuk and let him muke decisions."

"If I'm very attracted to a man and he wants to have unsafe sex, the temptution is too great."

The majority of men mention alcohol use as an important determinant of risk-taking sex, especially in anonymous situations or with casual partners. The men in our focus groups think that using alcohol reduces awareness of AIDS risks, and makes them more indifferent to possible infection with HIV. Some characteristic statements:

"I periodically have unsafe sex. It always happens when I've been drinking. It throws away my usual inhibitions."

"When I have too much to drink I couldn't care less about safe sex. The next moming I feel so stupid, when I remember what I've been doing."

Negative emotions

A number of men name their psychological well-being as an important reason for risk-taking behavior. Feelings of worthlessness or loneliness, or being unhappy are examples of negative emotional states in which protection against HIV infection is relatively unimportant to these men. Furthermore, these men are more likely to give in to desires of sexual partners, also if these partners prefer unprotected sex. Two illustrative statements:

"It pleases me if I someone gives me attention. When that happens I'm willing to do whatever he likes. And that includes having unsafe sex."

"When I feel worthless or lonely, my norms change. If someone wants to have sex with me, I let it happen. My emotional well-being is crucial."

\section{Coping with the AIDS threat}

The final category of reasons for risk-taking behavior concerns perceptions about risks of risk-taking versus benefits of safe sex. A number of men, who were already sexually active when the epidemic started, are clearly disappointed that they still have to practice safe sex. They had expected that there would be a vaccine or treatment available by now. As one man said: "It [vaccine or treatment] takes too long; I hoped that in ten years time they would have been able to treat it." The prospect of having to protect themselves and their sexual partners for an indefinite number of years, made several men reconsider 
risks. In some cases this resulted in trivializing or denying the risks associated with their sexual behavior.

"In traffic you run risks as well ... we all die in the end."

"If you die, you die. It's all in the game."

"When you realize that you have to be atcentive for another twenty years ... you're inclined to take risks again."

Needs for support

In all groups, participants emphasized that they expect unequivocal information on HIV and AIDS from different sources (e.g. health educators, physicians). They specifically expressed the need for more information on the risks of oral sex. Several men acknowledge that it is impossible to give exact risks for each sexual technique. On the other hand, they would welcome more information on how to interpret information about the risk level of several sexual techniques. One man said: "I think it's important that it is told why something is dangerous. For example, how they came to conclude that oral sex involves a risk. If I get that kind of informotion, I can better evaluate risks that are associated with my own sexual behurior."

In addition, a number of men would welcome skill training. They emphasize that knowing the risks is different from knowing how to avoid the risks. The skills they would like to acquire are framed in terms of personal control over critical situations. The following statements illustrate this:

"I know what the risks are, but for some reason I can't control it ... I want to get control over my weaknesses."

"Cun you offer me something that makes me decide to have safe sex in crucial moments ... a trick to keep in control?"

The majority of men would like to share their experiences with other gay men who engage in risk-taking behavior as well. It is noteworthy that many of these men state that they have feelings of guilt or shame over their behavior. They furthermore feel that it is inappropriate to talk about their difficulties with safe sex, because risk-taking behavior has become a taboo. One man said: "I felt very guilty that I had unsafe sex. A friend of mine had the same feelings and we talked about it. For me, it's important to share my experiences with others." 


\section{DISCUSSION}

In this study, information was obtained from a specific target group, namely gay men who engaged in risk-taking sex with casual partners on one or more occasions in the near past. All participating men were very knowledgeable concerning HIV and AIDS and were aware that their sexual behavior put them at risk of HIV transmission. Moreover, they expressed great concern over their risk-taking behavior and, without exception, were motivated to change their behavior.

With respect to the appraisal of current AIDS prevention activities, focus group participants underscore the importance of unequivocal information. These men receive information on HIV and AIDS from several sources. It is unfortunate that different sources in some instances contradict one another. The best example in this regard is the risk information on oral sex. While several sources view oral sex without ejaculation as a low risk or no risk activity, other sources convey the message that it does contain a risk, and therefore advice gay men to refrain from oral sex or to use condoms. The discussion in our groups make it clear that this situation has a number of unwanted effects. The inconsistency in the information about the risks of oral sex led to confusion, disbelief, anger, and defensive reactions. In our groups, the majority of men do not (want to) believe that oral sex without ejaculation is risky, and continued having oral sex. Furthermore, several men in our groups say that they have become suspicious of HIV risk information in general. It has been demonstrated in other domains that contradictory information may lead to a decreased credibility of the message as well as of the source(s) of the message (McGuire, 1985).

The following section discusses the explanations that focus group members give for their risk-taking behavior. First, it appears that risk-taking behavior is attributed to positive attitudes towards anal sex on the one hand, and negative attitudes towards condom use on the other hand. These findings are in line with the results of other studies (Connell et al., 1990; Hays et al., 1990; Ross, 1988; Valdiserri et al., 1988). It is also remarkable that several men state that they have become more interested in anal sex over time. They explain this by pointing to the prevention message that encourages men to avoid anal sex or to use condoms if they wish to have anal sex. Their statements suggest that they interpret this message in a prohibitive way. Engaging in anal sex is interpreted as a 'forbidden' behavior, and therefore apparently becomes more appealing.

Two explanations with respect to relationship aspects of risk-taking behavior were consistently found in all groups. Some men find it more difficult to avoid risks as they have sex more often with the same partner, while they have no difficulty to avoid risks with casual partners. About the same number of men report that they usually engage in risk-taking behavior with casual partners, and feel less responsible to avoid risks with casual partners 
as opposed to regular partners. It is noteworthy that in participants' accounts of these risk-taking encounters with casual partners, they are always the insertive partner. It might be that these men perceive insertive anal sex as carrying no or little risk for them (De Wit et al., 1994; Offir et al., 1993). On the other hand, one man was careful not to infect acquaintances (he assumed he was HIV-positive). It is troublesome to find that he was less careful for anonymous partners.

The third category of explanations for risk-taking behavior concerns situational factors. Risks occur when one is in love, if the partner is very attractive, or if one is sexually aroused. Alcohol use was another situational factor that was mentioned by almost all participants. What happened in these situations was typically described as a loss of control. Again, these findings are similar to that in other studies that investigated reasons for risk-taking behavior (Hays et al., 1990; Kelaher, Ross, Rohrsheim, Drury \& Clarkson, 1994; Kelly, Kalichman et al., 1991; Offir et al., 1993).

Several men named negative emotional states (e.g. depression, loneliness) as their prime reason for risk-taking. These men attempt to alleviate these negative feelings, usually by seeking sexual contact. Protecting themselves from infection becomes secondary, and they typically let their sexual partner decide whether to avoid risks or not. This relationship between negative emotional states and sexual risk-taking behavior is, to our knowledge, infrequently reported in the literature (De Wit et al., 1994). However, research on relapse with regard to other behaviors (Marlatt \& Gordon, 1985) has identified negative mood states as an important antecedent. Finally, several men in our groups expressed a concern for their future behavior. These men were already sexually active at the start of the AIDS epidemic, and have for a long time hoped that a vaccine or cure would become obtainable. This has motivated them for a relatively long period of time to change their sexual behavior. However, they have come to realize that it is unlikely that a vaccine or treatment will be available in the near future. As a result their motivation to protect themselves against infection has decreased. Typically, these men say that they have started to weigh the pros and cons of protective behavior against each other, which in several cases has resulted in more risk-taking behavior. Little is known about the dynamic aspects of the AIDS epidemic. Although several determinants of high-risk. behavior have been identified, primarily using cross sectional designs (Hospers \& Kok, 1995), there is little insight in how individual behavioral determinants change over time. These results show that the perspective of individuals may change as they realize that behavioral changes have to be maintained for an unknown period of time. It may well be that determinants that are related to initial behavior change differ from determinants that are related to long-term maintenance.

Men in our groups would like to be informed about the factual basis of HIV/AIDS information and learn how to assess the risk level of several sexual 
techniques. Other needs are skill training to cope with high-risk situations, and interaction with men who also find it difficult to comply with the safe sex directives.

The focus group technique proved to be a satisfactory tool to provide answers to our research questions. However, the generalizability of the results may be limited since the number of participants was small. Also, men were all highly motivated to participate in the focus groups. Furthermore, all men engaged in high-risk behaviors and were well aware of the risks associated with these behaviors. Hopefully, the information gathered with this research will be tested in quantitative research with larger samples.

\section{Implications for HIV prevention}

Individuals receive information on HIV and ADS from a great variety of sources ranging from mass media to individual counselors (e.g. general practitioners, health educators). The results of this study underscore the importance of unequivocal information on HIV and ADS. More efforts should be made to attune the information from different sources to each other in order to preserve the credibility of the sources. In addition, it might be effective to teach individuals how to assess the level of risk associated with their sexual behavior. To promote accurate risk assessments, individuals could be given more information on the mechanisms of HIV transmission, and on the rationality behind safe sex directives.

Participants describe several circumstances in which they perceive a loss of control over the situation. These include being intoxicated, sexually aroused, or in love. Relapse prevention theory (Marlatt \& Gordon, 1985) suggests that it might be worthwhile to teach behavioral skills to cope with these situations. Offir et al. (1993) have suggested that these kind of explanations might in fact be ex post facto justifications that serve to reduce cognitive dissonance. They propose to make individuals cognizant of how they use dissonance-reducing strategies.

Several results of this study suggest the development of small-group interventions. Individuals who are motivated to change their behavior, like the participants in this study, might benefit from interaction with peers. These groups could address several issues related to behavioral maintenance. For example, a group could discuss high-risk situations, offer support for men who feel lonely or depressed, or address issues related to dynamic aspects of the AIDS epidemic. These groups may provide a non-judgmental setting for men who feel that their risk-taking behavior has become a taboo.

It is important to note in this respect that the implementation of smallgroup interventions will probably encounter several barriers. It might prove to be difficult to reach men who have raised objections against the current AIDS prevention practice, who in some instances feel stigmatized for their 
risk-taking behavior, and some of who have accepted a certain level of risk or use dissonance-reducing strategies that make them feel safe. Careful planning and pretesting, in co-operation with members of the target group and representatives of the gay community may help to overcome these barriers. The focus group interviews provided new insights about aspects of sexual risk-taking behavior. Especially noteworthy are the complexity of the interactions between risk-taking behavior and relationship aspects, the relationship between negative mood states and risk-taking behavior, and the changing perceptions about risk-taking behavior among gay men who have realized that the threat of HIV infection will be present for a long time to come. 


\section{CHAPTER 4}

Sexual behavior among young gay men:

The pursuit of a primary partner and the development of primary relationships

Submitted for publication as:

Hospers, H.J., De Wit, J.B.F., Ross, M.W., \& Kok, G.J. (1999).

Sexual behavior among young gay men:The pursuit of a primary partner and the development of primary relationships. 


\section{INTRODUCTION}

Recent epidemiological research - conducted mostly in ADS epicenters - has demonstrated that young gay men are at substantial risk of becoming infected with HIV (De Wit, 1996). For example, data from the Amsterdam Young Gay Men Cohort (AYGMC) - established in 1995 - show an initial HIV prevalence of $5 \%$ and an estimated incidence of HIV infection of $1 \%$ per year (Van Griensven et al., 1997). In the United States, the incidence rates in young gay men's cohorts in San Francisco (SFYGMC) and New York (NYYGMC) were reported to be $2.6 \%$ and $2.0 \%$ per annum respectively (Dean \& Meyer, 1995; Osmond et al., 1996). These studies also found high levels of sexual risk-taking behavior (i.e. unprotected anal sex).

Several studies have attempted to identify factors related to high-risk behavior and HIV seroconversion among young gay men. In the SFYGMC it was found that recent number of receptive anal sex partners, injecting drug use, initiation of sex with men before 1985, and non-white ethnic background were related to being HIV-positive (Osmond et al., 1994). In the AYGMC, more lifetime sexual partners as well as a larger number of years of practicing anal sex were associated with being HIV-positive (Van Griensven et al., 1997). Research in New York among 141 gay adolescents between 14 and 19 years of age, tested the predictive power of cognitive-behavioral, risk-taking, and stress \& coping models regarding safer sex practices. A more positive attitude towards safe sex, greater self-efficacy and self-control, and lower anxiety were significantly related to safe sexual practices. HIV/ADS knowledge, risk perceptions, conduct problems, alcohol or drug use, depression, and stressful life events did not distinguish between safe and risk-taking adolescents (Rotheram-Borus, Reid, Rosario \& Kasen, 1995). In a Dutch study among 152 young gay men who lived in the vicinity of Amsterdam, inconsistent condom use with anal sex was related to lower self-efficacy to have safe sex, a lower risk perception of insertive anal sex compared to receptive anal sex, and having a primary partner. Demographic variables (race, age, educational level) and psychosocial variables (attitudes, social norms) did not differentiate between consistent and inconsistent condom use (De Vroome, Sandfort, Van den Bergh, Keet \& Van den Hoek, 1995). A study among 239 gay men between 13 and 21 years of age in Minneapolis compared high and lower sexual risk subjects, and did not find demographic differences, nor differences in sexual abuse history, conduct problems, mental health problems, HN antibody testing, HIV/ADS knowledge, and risk perceptions. However, highrisk subjects were more likely to currently have a primary partner, to ever have had a primary partner, to have anal intercourse with one of their last three sexual partners, and to report drug use during sex (Remafedi, 1994). In summary, demographic factors seldom distinguish young gay men pracLicing safe sex from young gay men taking sexual risks. Furthermore, several cognitive variables, like high self-efficacy and positive safe sex 
beliefs, seem to pertain to safer sex. Finally, without exception studies have found that unprotected sex is related to partmer status: with primary partners anal sex is more prevalent and more often unprotected compared to sex with casual partners. The factors that relate to safe or unsafe sexual risktaking seem to be quite similar to those that have been found in studies among older gay men (see Hospers \& Kok (1995) for a review).

The robust finding that partner status determines level of risk-taking behavior, raises the question how sexual behavior evolves in primary relationships among young gay men. A recent study that was conducted among young gay men in three cities at the west coast of the USA compared short versus longer primary relationships (Hays, Kegeles \& Coates, 1997). It was found that in longer-lasting relationships a higher proportion of young gay men had anal sex, and that anal sex was more often unprotected. Poor sexual communication skills, erroneous beliefs about safer sex and HIV transmission, and greater interpersonal barriers to safe sex were especially predictive for unsafe sex within shorter relationships.

With respect to relationship development among gay men in general, McWhirter and Mattison's research on stages in gay men's relationships (1984) is noteworthy. They describe how relationships among gay men change as time progresses ${ }^{4}$. In the first phase, which roughly lasts one year, they found that men are extremely focused on one another, which in combination with being in love, contributes to a process of blending. This phase is further characterized by high sexual activity. In the next two stages - roughly year 2 through 5 - they found that in most relationships sexual exclusivity (i.e. monogamy) ceased to exist. Among their subjects they found an initial rate of monogamy of $73.1 \%$, while at the end of the fifth year of relationships, more that $95 \%$ were nonexclusive. Although their research was carried out before HIV hit the gay community, there are indications that these findings are still valid at present. For example, a recent study among 293 gay men found that $80 \%$ of the relationships that lasted shorter than one year were monogamous, while among men in longer-lasting relationships this percentage was 58\% (Buchanan, Poppen \& Reisen, 1996). Since unprotected sexual practices have become dangerous as a result of HIV, and since research shows that unprotected practices are characteristic of primary relationships, a further understanding of the development of primary relationships and unsafe behavior can contribute to developing adequate HIV prevention strategies for young gay men. The purpose of the present study was to collect detailed information on sexual behaviors of young gay men in the Netherlands with casual and primary partners, and more specifically on the evolution of risk behaviors within primary relationships.

4 McWhirter and Matrison distinguish six stages, spanning relationship durations from day I to over 20 years. Furthermore, within each stage they describe a number of processes that characterize each stage. We only included the stages and stage processes that we feel are relevant for the issue at hand. 


\section{METHOD}

\section{Procedure and respondents}

A letters was sent to the 40 support groups for young gay men from De Kringen (a nationwide network of discussion and support groups for gay men and women), to the 38 local chapters of the Dutch Gay \& Lesbian Association, and to 3 independent organizations for young gay men in the Netherlands. These groups and chapters were geographically well spread. The letter described the goals of the survey and asked these organizations to assign a contact person with whom arrangements could be made for the distribution of survey questionnaires. A total of 42 groups replied to the letter. Each contact person estimated the maximum number of young gay men that could be reached through their organization, as well as through snowballing. Slightly more than 500 questionnaires were sent to the contact persons together with free postage return envelopes.

Six months later, 154 men had returned the questionnaires. Thirty-nine percent of respondents were member of De Kringen, 15.6\% member of the COC, $5.2 \%$ member of an independent organization, $14.9 \%$ both member of the $\operatorname{COC}$ and of one of the other two organizations; $25.3 \%$ were not affiliared with any of these organizations.

\section{Questionnaire}

Hirst, respondents were asked to complete questions on demographics, such as age, educational level, and occupation. Second, respondents were asked to answer questions on their sexual experience, such as age of first sexual encounter, and the number of life-time partners. Third, a detailed description was asked of their sexual activity in the preceding three months with primary and casual partners, including information on the frequency of engaging in three sexual risk behaviors (receptive oral sex with ejaculation, and insertive and receptive anal sex). For each behavior respondents were also asked to estimate the frequency of condom use. Fourth, using Ajzen's Theory of Planned Behavior (Ajzen, 1991), five beliefs about anal sex (e.g. "being fucked gives me great physical pleasure"), and four beliefs about condom use with anal sex (e.g. "using a condom creates distrust between partners") were formulated. All beliefs were scored on a 5 -point scale $(-2=$ completely

5 Organizational restraints prevented us from monitoring the number of questionnaires that were actually handed out. Therefore, the true response rate can not be provided. It should be noted, however, that the number of questionnaires that were sent out reflects the most optimistic estimates from our contact persons. which makes it likely that not all questionnaires that we sent to contact persons were actually handed our. 
disagree, $+2=$ completely agree). Negative items were reverse coded. Analyses showed satisfactory reliability for both the Beliefs about Anal Sex Scale $(\alpha=.86)$ and the Beliefs about Condom Use $(\alpha=.75)$.

Finally, subjects with a primary partner were asked to rate their intention to have anal sex with their primary partner, and their intention to use condoms for anal sex with their primary partner on a 7-point scale $(1=$ low intention, $7=$ high intention). Respondents without a primary partner were asked the same intentions, but for a future primary partner. Both intentions were asked to all respondents regarding sex with a casual partner.

\section{RESULTS}

\section{Demographics}

Respondents' mean age was 23.0 years (range $15-32$, median 23 ). The majority (51.0\%) had a high educational level (university/college), $35.1 \%$ a medium educational level (higher secondary high school/vocational training), and $13.9 \%$ a low educational level (elementary school/lower secondary school). Slightly more than half of the respondents $(51.0 \%)$ were employed, while $41.1 \%$ were enrolled in high school, college or university. The remaining 7.9\% were unemployed. Most respondents (45\%) were living in student houses or on their own, $38.8 \%$ were living with their parents, and $5.9 \%$ were living with their primary partner.

\section{Sexual behavior: history}

Ten respondents had not yet had sexual intercourse with a man. The analyses on sexual behavior were conducted on the remaining 144 responderits. The number of lifetime sexual partners averaged 14.2 (range 1-98, median 6 ); the mean number of sexual partners in the preceding 12 months was 5.1 (range $0-80$, median 2 ). The majority $(70.8 \%)$ reported experience with anal sex. The first parmer with whom they engaged in anal sex had been older for $58.4 \%$ of the respondents, had been approximately the same age for $25.7 \%$ of respondents, and was younger for $15.8 \%$ of respondents. About one third (30.8\%) had ever had an HIV test, all with a reported seronegative result. Few respondents report exposure to sexually transmitted diseases: $2.1 \%$ reported they had ever contracted syphilis, $4.3 \%$ gonorrhea, $2.8 \%$ herpes, and $1.4 \%$ hepatitis-B. A small percentage (5.6\%) had ever had sex with a man who they knew beforehand to be HIV-positive. 
Table 4.I Occurrence of sexual techniques with casual partners (part A), and with primary partners (part B) in the preceding three months. For those respondents reporting each behavior the percentage consistent condom use as well as the mean and median frequency in $\mathbf{3}$ months are displayed.

64 A. Sex with casual partners $(N=75)$

\%Yes $\quad \begin{gathered}\text { \% Consistent } \\ \text { condom use }\end{gathered} \quad \begin{gathered}\text { Mean } \\ \text { frequency }\end{gathered} \quad \begin{gathered}\text { Median } \\ \text { frequency }\end{gathered}$

$\begin{array}{lrrrr}\text { Receptive oral with ejaculation } & 5.3 \% & 25.0 \% & 20 & \text { । } \\ \text { Receptive anal } & 17.3 \% & 92.3 \% & 3.9 & 2 \\ \text { Insertive anal } & 20.0 \% & 93.3 \% & 6.2 & \text { I }\end{array}$

B. Sex with primary partner $(N=79)$

\%Yes $\begin{gathered}\text { \% Consistent } \\ \text { condom use }\end{gathered} \quad \begin{gathered}\text { Mean } \\ \text { frequency }\end{gathered} \quad \begin{gathered}\text { Median } \\ \text { frequency }\end{gathered}$

$\begin{array}{lrrrr}\text { Receptive oral with ejaculation } & 27.8 \% & 4.5 \% & 11.4 & 4 \\ \text { Receptive anal } & 54.4 \% & 44.2 \% & 9.4 & 4 \\ \text { Insertive anal } & 57.0 \% & 46.7 \% & 10.8 & 6\end{array}$

Sexual behavior: casual partners

Seventy-five respondents reported sex with casual partners in the three months preceding assessment. Twelve percent of them (9/75) also reported having a primary partner for more than three months 6 . The mean number of casual partners in those three months was 4.3 (range 1-40; median 3). The proportion of men engaging in receptive oral sex with ejaculation was relatively low $(5.3 \%)$, while approximately one in five respondents report insertive or receptive anal sex with casual partners. For anal sex consistent condom use was well over $90 \%$ (see Table $4.1 \mathrm{~A}$ ).

Overall, $64.0 \%$ of respondents had oral sex but no anal sex with casual partners, while $26.7 \%$ also engaged in anal sex. The remainder $(9.3 \%)$ had neither oral or anal sex.

Collapsing all behaviors we found that only 5 out of $75(6.7 \%)$ respondents reported engaging in risk-taking sex with casual partners ( 3 unprotected

6 Seven respondents report both casual partners in the three months preceding assessment and a primary partner with whom they broke up. Unfortunately we do not know whether sex with casual partners occurred before or after the end of the primary relationship. 
receptive oral sex with ejaculation, 2 unprotected anal sex). None of the men with primary partners at time of assessment reported engaging in unprotected sex with casual partners. The intention to have anal sex with a future casual partner was relatively low ( $M=3.0$, range $1-7)$, while the intention to use condoms if one would have sex with a casual partner was very high ( $M=6.7$, range $1-7)$.

\section{Sexual behavior: primary partner}

Slightly more than half of respondents (51.3\%) reported that they had a primary partmer in the preceding three months. In that three month period $19.0 \%$ of primary relationships had broken up. The median duration of the primary relationships was 8 months. The majority of respondents who reported a primary partner in the preceding three months had agreed with their partmer to have a monogamous relationship (67.6\%), $4.1 \%$ had agreed that they could also have sex with casual partners with the restriction that they would not have anal sex, $8.1 \%$ could have sex with casual partners where anal sex was not excluded. The remaining $20.3 \%$ had made no arrangements with their primary partmer about sex with casual partners. Table 4.1B provides a summary of the occurrence and frequency of oral and anal sexual practices with the primary partner in the three months preceding assessment. Approximately one quarter of respondents report oral sex with ejaculation, and condom use was scarce. Half of respondents report insertive and receptive anal sex. For both anal sex practice consistent condom use was approximately $50 \%$.

Overall, $29.5 \%$ of respondents had oral sex but no anal sex, while $66.7 \%$ also engaged in anal sex. The remainder (3.8\%) had neither oral or anal sex. Collapsing all behaviors, $55.7 \%$ report consistent safe or protected sex, $10.1 \%$ report one or more instances of unprotected oral sex (receptive with ejaculation), 17.7\% report unprotected anal sex (receptive and/or insertive), and $16.5 \%$ report both unprotected oral and anal sex.

As can be seen in Table 4.2, men with primary partners who did not report anal sex had significantly lower mean scores on the Beliefs about Anal Sex Scale than men who reported protected and unprotected sex, indicating less positive beliefs about anal sex. Also, they had a lower mean intention to have anal sex with their primary partner. Men who did not have anal sex as

7 Six respondents who reported unprotected anal sex with their primary partner stated that they had an HIV test while in that relationship and that their primary partner had an HIV test with a repored negative result. Therefore, it is debacable whether their unprotected behavior should be labeled as risk-taking (Kippax et al., 1997). However, classifying them as 'protected' results in only marginal changes in proportions, while differences that were tested remain statistically significant. 
Table 4.2 Means for Beliefs about Anal Sex (-2=negative, $+2=$ positive), Beliefs about Condom Use (-2=negative, +2=positive), Intention to Have Anal Sex ( 1 =low intention, 7 =high intention), and Intention to Use Condoms ( 1 =low intention, $7=$ high intention) broken down by whether respondents had anal sex with their primary partner, and whether or not anal sex was protected.

No anal sex

Beliefs about anal sex

Beliefs about condom use

Intention to have anal sex

Intention to use condoms $-0.5^{a}$

I. I $^{\mathbf{a}}$

$4.0^{a}$

$6.3^{\mathrm{a}}$
Protected

$0.4^{b}$

$0.3^{b}$

$0.4^{b}$

$5.9^{b}$

$5.6^{b}$

$3.4^{b}$

Means with different superscripts (horizontally) differ at $p<.001$ (post hoc comparisons: Bonferroni correction)

well as men who had protected anal sex had significantly more positive beliefs about condom use, and higher intentions to use condoms when engaging in anal sex with a primary partner.

Primary relationships and relationship duration

To explore in what way primary relationships developed, a number of analyses were conducted with relationship duration as the key variable for those respondents whose relationship was still continuing at assessment $(\mathrm{N}=60)$. The results are summarized in Table 4.3.

Relationship duration was split at the median ${ }^{8}$ (short: 1-8 months, longer: 9 months and up). A high proportion (82.8\%) of men in longer-lasting relationships practiced anal sex, compared to approximately $50 \%$ in shorter relationships. Unprotected sex was also significantly related to relationship duration: for $41.2 \%$ of men who reported anal sex and who were in shorter relationships that sex was unprotected, compared to $87.5 \%$ of men in longer-lasting relationships ${ }^{9}$. It was further found that the arrangement regarding sex with casual partners differed significantly with relationship duration. Within shorter relationships almost $40 \%$ had no arrangement about sex with casual partners, while the remaining $60 \%$ had agreed to be monoganious. In none of the shorrer relationships an arrangement had been made to have sex with casual partners. Within longer-lasting relationships $67.9 \%$ had an arrangement to be monogamous, and $28.6 \%$ had arranged that sex with casual partners was permitted. The mean relationship duration 
Table 4.3 Proportion of men in primary relationships that engage in anal sex (part A), and that have unprotected anal sex (part B) broken down by relationship duration (at median). Part $C$ shows a cross-tabulation of relationship duration and the arrangements about sex with casual partners.

A. Young Gay Men with Primary Parner $(N=60)$

Relationship duration

\% Having anal sex

$1-8$ months

9 months and up

$828 \%$

$\chi^{2}(1)=5.4, p<.05$

B. Young Goy Men with Primary Partner who have anal sex $(N=41)$
Relationship duration
\% Having unprotected sex

I-8 months

$41.2 \%$

9 months and up

$87.5 \%$

$\chi^{2}(1)=9.9, p<.01$

C. Young Gay Men with Primary Portner ( $N=56$ )

Arrangement with partner about sex with casual partners

Relationship duration

No arrangement Monogamous

Open

I-8 months

$39.3 \%$

$60.7 \%$

$0.0 \%$

9 months and up

$3.6 \%$

$67.9 \%$

$28.6 \%$

$\chi^{2}(2)=16.4, p<.001$

8 Concatenating relationship durations using tertiles or quartiles did not change the essence of the analyses results. However, to avoid empty cells in analyses, as well as for presentational purposes, median split analyses were conducted and presented.

9 From the 31 men in shorter relationships, only those with a relationship duration between three and eight months were selected for this analysis $(N=18)$, since men in relationships shorter than three months could have had sex with casual partners before the start of the primary relationship. 
Table 4.4 Means for Beliefs about Anal Sex $(-2=$ negative, $+2=$ positive), Beliefs about Condom Use (-2=negative, +2=positive), Intention to Have Anal Sex ( $1=$ low intention, $7=$ high intention), and Intention to Use Condoms ( $I=$ low intention, $7=$ high intention) broken down by relationship duration (short vs. longer) and whether respondents do or do not engage in anal sex with their primary partner.

\begin{tabular}{lccccc}
\hline & \multicolumn{2}{c}{ Short } & \multicolumn{2}{c}{ Longer } \\
& No anal sex & Anal sex & No anal sex & Anal sex \\
& -0.4 & 0.3 & -0.6 & 0.5 \\
Beliefs about anal sex & 1.4 & 1.1 & 0.5 & 0.4 \\
Beliefs about condom use & 4.6 & 6.1 & 3.6 & 6.1 \\
Intention to have anal sex & 6.4 & 6.2 & 5.0 & 28 \\
\hline
\end{tabular}

for men without an arrangement was 3.5 months, for men with a monogamy arrangement 11.6 months, and for men with a casual sex arrangement 33.1 months $(F(2,54)=19.2, \mathrm{p}<.001)$. Relationship duration not only related to arrangement but also to reported behavior: among men in shorter relationships $5.6 \%(1 / 18)$ reported sex with casual partners, while among men in longer-lasting relationships $27.6 \%(8 / 29)$ reported casual sex $\left(\chi^{2}(1)=3.5, p<.07\right)$.

Table 4.4 shows the means of the Beliefs Scales and the intentions to have anal sex and to use condoms with anal sex, broken down by whether respondents were having anal sex at time of assessment and relationship duration.

A 2 (Anal Sex: Yes vs. No) x 2 (Duration: Short vs. Longer) AnOva showed significant main effects for Anal Sex on the Beliefs about Anal Sex Scale $(F(1,56)=12.8, \mathrm{p}<.001)$, and for the intention to continue to have anal sex $(F(1,55)=17.5, p<.001)$, with higher scores for men who reported anal sex at assessment.

With respect 10 the Beliefs about Condom Use, a significant main effect for Duration $(F(1,55)=8.0, p<.01)$ was found. Inspection of the means shows that men in longer-lasting relationships have more negative beliefs about condoms than men in shorter relationships. Finally, the analysis on intention to use condoms resulted in a main effect for Anal Sex $(F(1,56)=4.5$, $\mathrm{p}<.05)$ and for Duration $(F(1,56)=18.9, \mathrm{p}<.001)$. The means show that men in shorter relationships have high intentions to use condoms, regardless of whether anal sex is practiced or not, while among men in longerlasting relationships this intention is lower, primarily because men who engage in anal sex have low intentions. 


\section{DISCUSSION}

This study examined sexual behavior among young gay men in the Netherlands. Relatively low levels of risk-taking behavior with casual partners were found: only 5 of $75(6.7 \%)$ men who had sex with casual partners in the three months preceding assessment reported inconsistent condom use with oral and/or anal sex. Of men engaging in anal sex with casual partners $10 \%(2 / 20)$ had unprotected anal sex. The resulis concerning sex with casual partners in this sample seem different from the two studies that reported on young gay men living in the vicinity of Amsterdam. In the Amsterdam Young Gay Men Cohort, 29\% of colhort members that reported anal sex with casual partmers engaged in unprotected insertive anal sex in the preceding six months, and $27 \%$ engaged in unprotected receptive anal sex (Van Griensven et al., 1997). In the cross-sectional study of De Vroome et al. (1995), $43 \%$ of men who reported anal sex with casual partners, engaged in unprotected anal sex with their casual partners in the preceding six months. Furthermore, the proportions of men engaging in anal sex with casual parmers differ as well: $13 \%$ in this study, compared to over $35 \%$ in the AYGMC, and over $50 \%$ in the cross-sectional Amsterdam study. Several possible explanations may account for these differences. First, in contrast to the Amsterdam studies, we sampled mostly among organized young gay men, of whom a substantial number were at that time participating in coming-out support groups. It could be that more men in this sample were in the beginning of their sexual careers, and that engaging in (unprotected) anal sex with casual partners occurs at a later stage. Second, it is clear that Amsterdam - being the nation's gay capital - provides more opportunities for gay men to find sexual partners, compared to the smaller cities and villages where the respondents in this study live. Although this would not directly explain why higher proportions engage in anal sex with casual partners, or why the rates of unprotected sex are higher, it could be that Amsterdam attracts young gay men with different sexual desires or repertoires than the men in this sample. Finally, it cannot be ruled out that the socialization process in the gay community in Amsterdam differs from that in other parts of the country and that different social norms and social influences lead to different sexual lifestyles. The role of young gay men's personal variables like developmental stages concerning coming-out, level of acculturation in the gay community and sexual aspirations on the one hand, and the interaction with situational variables such as size of the gay community and opportunities for sex on the other hand, should be subject of further study.

With respect to sex with primary partners it was found that half of the men were involved in a primary relationship in the three months preceding assessment. However, at time of assessment one out of five relationships had ended. There appears to be a high turnover in primary relationships, 
which was also reflected in the relatively low median relationship duration of eight months of existing primary relationships. In this sample over $90 \%$ of the men who were not in a primary relationships stated that they preferred a primary relationship over being single, of which $80 \%$ preferred a monogamous relationship over an open one. Although primary relationship history was not assessed in this study, the available data suggests patterns of serial partnerships.

Two thirds of men in primary relationships reported engaging in anal sex. Anal sex was associated with positive beliefs about anal sex as well as positive intentions to have anal sex. In $52 \%$ of these relationships, partners did not consistently use condoms. This compares to $59 \%$ for insertive anal sex and $60 \%$ for receptive anal sex in the AYGMC (Van Griensven et al., 1997), and to $70 \%$ for anal sex in the cross-sectional Amsterdam study (De Vroome et al., 1995). In the relationships where condoms were not consistently used, over $80 \%$ had no information on both partners' HIV status. Unprotected behavior was associated with negative beliefs about condoms and negative intentions to use condoms with anal sex. Correlations between beliefs about anal sex and condom use and their concurrent intentions on the one hand, and behavior on the other hand have been found in a number of studies among older gay men (see Hospers \& Kok, 1995). In summary, while few respondents had risk-taking sex with casual partners, half of respondents with primary partners had unprotected anal sex. These differential results regarding risk-taking behavior may have important consequences for prevention. HIV prevention for young gay men would probably be more effective if it specifically addressed risk-taking sex in the context of primary relationships. Although there are some examples of such efforts (e.g. Camden and Islington Community Health Services, 1995), many prevention materials are still focussing on sex with casual partners or do not address relationship issues. While this may be adequate for older gay men, the results of this study suggest that for younger gay men it is the primary relationship in which risks develop. The results suggest yet another reason for a focus on primary relationships. The fact that a majority of these young gay men are striving for a primary relationship, as well as the high turnover in primary partners, questions how 'casual' casual partners are. Most research defines casual partners as sexual partners with whom one has no primary or committed relationship. For older gay men it is an established fact that many have casual partners - while being inside or outside a primary relationship, and that it is, the casualness or anonymity of sexual encounters that is deliberately sought. Further research is needed whether the same goes for young gay men. It may well be that for young gay men a casual partner is a sexual partner with whom the interaction did not result in a primary relationship, despite an initial desire to examine that possibility. This would thus be a situation with a different motivational background which would demand a different prevention approach. 
Furthermore, the results of this study show that among men in shorter primary relationships $22.6 \%$ had unprotected anal sex, compared to $72.5 \%$ in longer-lasting relationships. These findings are similar to those of Hays et al. (1997), and provide further evidence that as relationships progress the likelihood of partners engaging in anal intercourse increases, and that the likelihood that condoms will be used for anal sex decreases. Another factor that was related to relationship duration was the change in arrangements about sex with casual partners. While men in shorter relationships had either no arrangement or an arrangement to be monogamous, men in longer-lasting relationships had either a an arrangement to be monogamous or had arranged that sex with casual partners was permitted. This difference was also reflected in reported behavior with casual partners: a significantly higher proportion of men in longer-lasting relationships reported casual partners compared to men in shorter relationships.

The fact that one in four short relationships is risky is a challenge for prevention in itself. But evenly important seems to be that prevention specifically addresses the dynamics of relationship development. One of such strategies that has been suggested over the last years and that is becoming increasingly popular is 'negotiated safety' (Kippax et al., 1997). This strategy takes the natural course within the majority of primary relationships initiation of anal sex followed by refraining from condom use - as a starting point and then adds several safeguards (HIV tests, mutual agreements, and the building of trust) to increase safety within primary relationships. Although the strategy may be effective for older gay men, two considerations suggest that the strategy may be less suitable for younger gay men. First, the essence of negotiated safety is to make casual sex safe - through clear and unambiguous agreements - in order to facilitate unprotected sex within the primary relationship. The results of this study show that it is not the risk level of casual sex that is at stake, but rather the rapid progression towards risky sex within primary relationships (which may not last very long). Second, introduction of 'negotiated safety' in early stages of relationships could well be too early. Our data suggest that preferences, arrangements and sexual behavior in the early stages of relationships focus mostly on monogamy. It remains to be seen and should be subject to further research whether promotion of 'negotiated safety' is feasible for young gay men in 'young' relationships. If the 'negotiated safety' strategy is not intended to apply to young gay men in shorter relationships, future research should seek to assess whether this is recognized and acknowledged, since it is not unlikely that these men will be exposed to 'negotiated safety' prevention messages.

As stated above, prevention for young gay men should address primary relationship issues, specifically issues that arise as relationships progress and their interaction with risk. Risk, it appears, is part of a relationship developmental stage rather than an isolated behavior. In order to prevent HIV trans- 
mission within primary relationships, young gay men might be persuaded to continue using condoms within their primary relationship longer than is now apparently the case.

A number of limitations of this study should be noted. The educational level of the sample was very high, and therefore generalization of the 72 results to young gay men with lower educational levels may not be appropriate. Furthermore, although the findings on differences regarding relationship duration seem to be corroborated by most other research in this area, this study was cross-sectional which does warrant some caution. Longitudinal studies are more appropriate to study relationship developments and should be initiated to confirm the findings in the present study. Notwithstanding these limitations, the results of this study provide more insight in the lives of young gay men in the context of their pursuit of finding a primary partner as well as their sexual behavior within these primary relationships. Any prevention effort that takes these particular circumstances and dynamics into account will most likely contribute to limiting the spread of HIV among young gay men. 


\section{CHAPTER 5}

Self-efficacy beliefs and intentions to use condoms among young gay men

Submitted for publication as:

Hospers, H.J., De Wit, J.B.F., Ross, M.W., \& Kok, G.J. (1999).

Self-efficacy beliefs and intentions to use condoms among young gay men. 


\section{INTRODUCTION}

Several studies have amplified that young gay men are at risk for getting infected with HIV (see De Wit (1996) for an overview). For example, data from young gay men's cohorts in AIDS epicenters show annual seroconversion incidence rates between 1.0 and 2.6\% (Dean \& Meyer, 1995; Osmond et al., 1996; Van Griensven et al., 1997). These epidemiological data have initiated research that investigated the extent of risk-taking behavior as well as behavioral determinants. There is still considerable debate whether or not young gay men engage in more risk-taking behavior than their older counterparts, but studies have consistently shown that substantial numbers of young gay men engage in unprotected sex (De Wit, 1996; De Wit \& Van Griensven, 1994; Gold \& Skinner, 1992; Hays et al., 1990; Van de Ven, Noble et al., 1997). The few studies that have investigated determinants, consistently show that type of sexual partmer determines risk-taking level to a large extent: young gay men - like older gay men - have more unprotected sex with primary partmers than with casual partners (Crawford, Kippax, Rodden, Donohue \& Van de Ven, 1998; De Vroome et al., 1995; De Wit, Hospers \& Janssen, 1996; Hays et al., 1997; Kegeles et al., 1996; Meyer \& Dean, 1995; Van de Ven, Noble et al., 1997; Vincke, Bolton \& Miller, 1997). Furthermore, a number of cognitive factors have shown to be related to safe and risk-taking behavior among young gay men, especially attitudes towards anal sex (De Vroome et al., 1995; Hays et al., 1997; Van de Ven, Campbell et al., 1997), attitudes towards condoms (De Vroome et al., 1995; Van de Ven, Campbell et al., 1997), and self-efficacy beliefs regarding avoiding unprotected sex (Rotheram-Borus et al., 1995) and sexual communication skills (Hays et al., 1997).

The results of risk-behavior and behavioral determinant studies play an important role in the development of HIV prevention activities, since they may, for example, guide decisions on target group selection or segmentation, or generate ideas for the content and format of prevention activities. Prevention activities range from large media campaigns (e.g. TV advertisements) to small-scale programs aimed at specific target groups.

Behavior change interventions usually benefit from the incorporation of motivational and skills training components (Bandura, 1997; Fisher \& Fisher, 1993; Kalichman \& Hospers, 1997; Kelly, 1995). The present study specifically focuses on relevant domains of self-efficacy that may be targeted through skills training in small-scale interventions for young gay men. As Bandura (1997) has noted, personal efficacy in sexual situations entails more than just knowing how to properly use condoms. Personal efficacy regarding interpersonal factors, such as communication about safe sex or resisting pressure for unsafe sex from sex partners, as well as personal efficacy regarding intrapersonal factors, such as affecive mood states (e.g. being in love, being attracted, being sexually aroused) may also contribute 
to the level of risk-taking. Distinguishing between these different factors is important, because some factors may be more important than others, which could guide decisions for prevention. This study assessed the relationship between self-efficacy on the one hand, and safe sex intentions and behavior on the other hand, and thereafter identified factors within the self-efficacy domain that pertain to safe sex intentions among young gay men.

\section{METHOD}

\section{Subjects}

Subjects were 88 young gay men who were part of a larger study among 154 young gay men on sexual history, sexual behavior, sexual relationships, and HIV/AIDS-related issues. These subjects received a questionnaire through one of 42 representatives of young gay men's support groups, the Dutch Gay \& Lesbian Association, three independent organizations for young gay men in the Netherlands, or through snowballing.

The selection for the present srudy comprised subjects who were not involved in a monogamous relationship at time of assessment.

\section{Measurements}

The questionnaire assessed demographic information, such as age, educational level, and occupation. Subjects were also asked to describe their sexual activity in the preceding three months with casual partners, including information on the frequency of engaging in insertive and receptive anal sex. For both anal sex practices subjects were asked to estimate the frequency of condom use. Subjects were classified as high-risk if they had engaged in one or more instances of unprotected insertive or receptive intercourse in the preceding three months.

The behavioral intention question asked subjects whether they would use condoms the next time they had sex with a new parıner (range l 'cenainly will not' to 7 'certainly will').

Beliefs on condom use was measured with four items (e.g. "using a condom creates distrust between partners"). These beliefs were scored on a 5-point scale ( 1 'completely disagree' to 5 'completely agree'). Cronbach's $\alpha$ was 0.68. Three normative belief questions assessed the perceived attitude of relevant others on condom use (e.g. "what is the opinion of your gay friends about using condoms?"). These beliefs were scored on a 5-point scale (1 'very 
negative' to 5 'very positive'). Cronbach's $\alpha$ was 0.58 .

Self-efficacy was measured by asking the subject to imagine that they met someone and had sex with them for the first time. Then, 15 situations were depicted, covering 4 skill domains that may be relevant in sexual situations: 1 . The actual use of condoms and the availability of condoms, 2 .

Communicating the desire to use condoms to a sex partmer, 3. Rejecting pressure from a sex partner to have unsafe sex, and 4. Coping with affective mood states. For each situation, subjects were asked to rate the strength of their belief in their ability to use condoms in that situation on 5-point scales ( 1 'certainly cannot' to 5 'certainly can'). Cronbach's $\alpha$ for the selfefficacy measure was 0.91 .

\section{RESULTS}

\section{Subject characteristics}

Subjects' mean age was 22.6 (range 17-31). Almost half of the subjects $(48.8 \%$ ) had a high educational level (university/college), $41.9 \%$ a medium educational level (higher secondary high school/vocational training), and $9.3 \%$ a low educational level (elementary school/lower secondary school). Slightly more than half of the subjects $(51.8 \%)$ were employed, $40 \%$ were in high school, college or university, and $8.2 \%$ were unemployed.

\section{Behavior, behavioral intention and self-efficacy}

Only two men reported unprotected anal sex with casual partners in the three months preceding assessment. As this low level of risk-behavior did not permit any analyses on risk-behavior, behavioral intention - being a good proxy for actual behavior - was used as dependent variable in the analyses. None of the demographic variables (age, educational level, occupaLion) were related to either behavioral intention or its determinants. The mean behavioral intention to use condoms with new sex partners was 6.8 on a 7-point scale, and thus highly skewed to the right end of the distribution. Therefore, subjects were divided into two groups: a group comprising men who had an absolute positive intention to use condoms ( $86 \%)$, and a group comprising men who had a lower intention (14\%). A logistic regression analysis on behavioral intention with the attitudinal belief scale, normative belief scale, and self-efficacy scale as predictors, yielded a significant regression model $\left(\chi^{2}(3)=32.5, p<.001\right)$, with self-efficacy as the only sig- 
Table 5.I Mean scores for young gay men with lower $(\mathrm{N}=12)$ and high $(\mathrm{N}=76)$ intention to use condoms with a new sex partner on I 5 self-efficacy beliefs regarding condom use with anal sex with a new sex partner (all beliefs range I (low perceived self-efficacy) to 5 (high perceived selfefficacy), and the pooled within-group correlation between each self-efficacy item and the standardized canonical discriminant function.

\begin{tabular}{|c|c|c|c|c|c|}
\hline & \multicolumn{2}{|c|}{ Condom use intention } & \multirow[b]{2}{*}{$F$} & \multirow{2}{*}{\multicolumn{2}{|c|}{$\begin{array}{c}r \text { with } \\
\text { discriminant } \\
\text { function }\end{array}$}} \\
\hline & Lower & High & & & \\
\hline \multicolumn{6}{|l|}{ Use and ovailability skills } \\
\hline You want to put a condom on & 3.9 & 4.5 & 4.4 & .05 & .21 \\
\hline You want to put a condom on him & 3.8 & 4.1 & 2.0 & ns & .14 \\
\hline Having condoms available & 3.9 & 4.6 & 13.0 & .001 & .36 \\
\hline \multicolumn{6}{|l|}{ Sexual communication skills } \\
\hline You want to tell him before sex that you want to use a condom & 3.9 & 4.5 & 4.3 & .05 & .21 \\
\hline You want to tell him during sex that you want to use a condom & 3.9 & 4.6 & 12.2 & .001 & .35 \\
\hline \multicolumn{6}{|l|}{ Skills to resist pressure from partner } \\
\hline He wants you to penetrate him without a condom & 3.8 & 4.8 & 32.7 & .001 & .57 \\
\hline He exerts pressure to penetrate him without a condom & 3.4 & 4.7 & 35.7 & .001 & .60 \\
\hline He wants to penetrate you without a condom & 4.1 & 4.9 & 48.9 & .001 & .70 \\
\hline He exerts pressure to penetrate you without a condom & 3.7 & 4.8 & 54.1 & .001 & .74 \\
\hline \multicolumn{6}{|l|}{ Affective mood states } \\
\hline You had a lot of alcohol & 3.3 & 4.3 & 15.5 & .001 & .40 \\
\hline You haven't had anal sex for a long time & 4.1 & 4.7 & 17.2 & .001 & .42 \\
\hline You like him very much & 3.8 & 4.7 & 33.0 & .001 & .58 \\
\hline You find him very beautiful & 3.9 & 4.7 & 18.7 & .001 & .44 \\
\hline You're in love with him & 3.5 & 4.6 & 35.4 & .001 & .60 \\
\hline You're sexually aroused & 3.4 & 4.5 & 32.1 & .001 & .57 \\
\hline
\end{tabular}


nificant predictor (Wald=11.3, $\mathrm{p}<.001, \mathrm{R}=.36$ ), showing that higher intentions were primarily associated with higher degrees of belief in one's ability to use condoms in a variety of situations.

Comparing the mean scores on the 15 self-efficacy beliefs for the high vs. lower intention groups yielded a significant multivariate effect (Wilks' $\lambda$. $F(15,71)=6.6, p<.001)$. Table 5.1 shows the means for each self-efficacy belief broken down by intention (lower/high) with univariate test results. For all items but one, the mean self-efficacy rating was significantly higher for men with high intentions to use condoms. Entering the scores on all self-efficacy measures in a discriminant analysis yielded a significant discriminant function $\left(\chi^{2}(15)=60.1, p<.001\right)$. Based on the discriminant function, $96.6 \%$ of subjects were correctly classified in either the high or lower intention group.

Moderate to high correlations between self-efficacy beliefs and the discriminant function (see Table 5.1) were found for perceived self-efficacy to resisting pressure from sexual partners (r's: .57-.74) and affective mood states (r's: .40-.60), while the correlation with self-efficacy regarding the use and availability of condoms as well as sexual communication skills were lower (r's: .14-.36).

\section{DISCUSSION}

This study found that perceived self-efficacy beliefs regarding condom use with new sexual partners were related to the analogous behavioral intention. Moreover, especially self-efficacy regarding resisting pressure from sexual partners and self-efficacy to cope with affective mood states differentiated young men with high condom use intentions from men with lower condom use intentions, while self-efficacy beliefs regarding the use and availability of condoms as well as sexual communication skills showed lower correlations with the discriminant function. Future HF prevention interventions for young gay men that include a skills-training component might benefit from addressing skills related to resisting pressure and coping with affective mood states.

To resist pressure from sexual parmers requires a certain level of sexual assertiveness. Assertiveness skills can be learned through instruction and modeling, which is put into guided practice through role playing, with ample reinforcement and feedback from experienced trainers (Kelly, 1995). For example, young gay men might be taught to define their personal safe sex rules, how to communicate them to sex partners (preferably before sex), and how to communicate a decision to postpone sex or leave a situ- 
ation where sexual partners are coercive to having unsafe sex. Until now very few studies have been reported in which interventions for young gay men containing skills training elements were implemented. Recently, Kegeles et al. (1996) developed a community-level HIV prevention program for young gay men that was effective in decreasing unprotected anal sex with both primary and casual partmers. The program consisted of - among other components - peer-led small groups that specifically addressed sexual communication skills.

With respect to the relationship between self-efficacy and mood states, research has shown that self-efficacy may influence mood states, that there is a reciprocal relationship, or that mood states influences self-efficacy perceptions (Bandura, 1997). The finding in this study appears to be an example of the latter, i.e. that for some subjects feelings of love, affection and sexual arousal may lead to lower self-efficacy estimates regarding condom use skills. This finding is consistent with results of studies among older gay men that investigated justifications for and circumstances of engaging in unsafe sex. For example, several focus group interview studies among gay men have shown that feelings of love and affection, being under the influence of alcohol or drugs, and sexual arousal are prominent explanations or justifications that these men give for their unsafe sexual behavior (Boulton et al., 1995; Hospers, Molenaar \& Kok, 1994; Offir et al., 1993). Similarly, Kelly, Kalichman et al. (1991) asked men to rate the importance of 21 situational factors associated with their most recent unsafe sex encounter. Positive emotional feelings for the sexual partner, wishing to please the partner, and becoming "caught up in the passion of the moment" were the three situational descriptors that received the highest importance ratings. Interestingly, the research on the influence of mood states on self-efficacy in general has shown that negative mood states lead to lower self-efficacy while positive mood states lead to higher self-efficacy beliefs (Bandura, 1997). One study specifically studied the consequences of falling in love on self-efficacy ratings (Aron, Paris \& Aron, 1995). This prospective study found that subjects who had fallen in love showed a significance increase in general self-efficacy scores. Thus, it appears that positive mood states - like love and affection - induce heightened self-efficacy in a more general sense, but the results of the present study show that this may simultaneously result in lower self-efficacy ratings regarding safe sex behavior with the source of the positive mood state.

To our knowledge, there is little experience with addressing the role of positive mood states in HIV prevention interventions that target young gay men. Techniques derived from relapse prevention theory (Marlatt \& Gordon, 1985) - which addresses positive mood states as a determinant of relapse - may prove to be fruitful. Also, recent studies by Richard and colleagues $(1996 ; 1998)$ have shown positive results of inducing anticipated regret through imagery exercises. In one of these studies (Richard, Van der 
Pligt \& De Vries, 1996), young heterosexual students were asked to imagine how they expected to feel emotionally afterward, if they had or had not used a condom with a new sexual partner. The results show that - compared to a control group - inducing anticipated affective reactions resulted in more favorable behavioral expectations of condom use and in higher reported condom use rates with new sex partners.

A possible limitation of the present study should be noted. Although a strong relationship between self-efficacy beliefs and behavioral intention was found, behavioral intention to use condoms was very high, and actual risk-behavior was rare. This was a very 'safe' sample indeed. However, data from other studies have shown that young gay men are engaging in risky sexual practices as they become more sexually active and are vulnerable to HIV infection (e.g. De Wit, 1996). We therefore believe that young gay men are an important target group for HIV prevention.

In conclusion, the results suggest that future research on understanding and changing sexual risk-taking behavior (and possibly other behaviors relevant for prevention) could benefit from distinguishing between different domains within the self-efficacy concept. More specifically, a focus on skills related to resisting pressure from sexual parmers and skills to cope with affective mood states in interventions, may help young gay men to put their positive intentions into practice. 


\section{CHAPTER 6}

\section{An overview of HIV prevention activities for gay men in the Netherlands between 1983-1993}

\section{Published as:}

Hospers, H.J., \& Blom, C. (1998). HIV prevention activities for gay men in the Netherlands 1983- I993. In Th.G.M. Sandfort (Ed.). The Dutch response to HIV (pp. 40-60). London: UCL Press. 


\section{INTRODUCTION}

This chapter offers an overview of HIV prevention activities for gay men that were developed and implemented in the Netherlands between 1983 and 1993. The structure of the chapter is as follows. First, a concise history of the development of HIV prevention interventions is provided. Second, the cure of this chapter summarizes the wide range of interventions that have been developed and implemented, including each intervention's characteristics and goals and, if available, evaluation results. Third, a description of future directions of HIV prevention for gay men is given. The chapter concludes with a brief discussion of the issues raised earlier.

We have limited ourselves to the period up to 1993 because the majority of HIV prevention funds - and thus activities - were decentralized in that year. Small group projects as well as outreach activities for gay men are now carried out at a local level where once they were developed at a national level. The interventions that were developed at the national level during the first ten years of the epidemic are still influential in HIV prevention today: many current activities are derivatives of the national projects described in this chapter.

\section{THE FIRST CAMPAIGN}

In 1983, the Dutch Blood Bank intended to exclude gay men from donating blood in order to safeguard the Dutch blood supply. This led to upheaval anong gay advocacy organizations. Concurrent deliberations between the Blood Bank and representatives from gay organizations led to the agreement that the Blood Bank would start a campaign, together with the Health Education Division of the Amsterdam Public Health Service, the SAD (initially an Amsterdam based STD clinic for gay men run by gay physicians), and the Dutch Gay and Lesbian Association (NVTH COC). The goal was to inform blood donors and gay men about ADS. The campaign was funded by the Minisury of Health, the City of Amsterdam, and the Central Commitlee for Medical Blood Transfusion. The campaign for gay men consisted of several elements: a brochure, information meetings at ten local chapters of the Dutch Gay and Lesbian Association, activities in two gay bars and a gay sauna, and articles in the gay press (Van der Linden, 1984). The brochure for gay men (circulation 400,000 copies) was published in June 1983 concurrent with the brochure for blood donors. The latter brochure asked members of so-called risk groups (i.e. gay men) to voluntarily withdraw themselves from blood donation programs. The brochure for gay 
men reminded readers that there was considerable uncertainty about the aetiology of the disease at that time. It stated that the exact cause of the disease was as yet unknown, and that the latest theories suggested a viral origin. It further asserted that anal sex could be involved in transmission and "that there are strong indications that the disease is passed on via blood". Clear behavioral advice was not given. The brochure told gay men that receptive anal sex was probably associated with an elevated risk, if it occured with multiple partners. It also stated that "No one will be advised to have less sex. Maybe one could consider to have sex with less men, especially if one does not know them".

The first information campaign was considered successful (Van der Linden, 1984). The information brochure was widely disseminated, the information meetings proved popular among gay men, and almost without exception, owners of gay bars agreed to co-operate. This first campaign was followed up by many small-scale initiatives conducted at a local level for which representatives from the gay community were primarily responsible. For example, a local Amsterdam radio station aired a special program on HIV and AIDS once a year between 1984 and 1987, a number of gay health care workers published a magazine that contained narratives on sexual encounters with a safer sex twist, and the Amsterdam Jacks started to organize safer sex parties in 1986 (Algra, 1988).

\section{THE ORGANIZATIONS INVOLVED}

The co-operation between the three organizations that organized the first campaign was inscitutionalized in a task force (Van Wijngaarden, 1984). As a consequence, gay men contributed at an early stage in the ADS epidemic to the development and execution of prevention activities. The task force focused initially on HIV prevention for gay men. The task force later developed into an official advisory organ to the Dutch government, the National Committee on AIDS Control (NCAB), which became responsible for the formulation of the general HIV/ADS policy in the Netherlands.

From 1984 until 1993 were a large number of mass media campaigns, small group interventions, and outreach activities involving gay men. These activities were organized by a small number of providers. The SAD became responsible for all small group and outreach activities that were organized nationally in the first decade, while the Health Education Division of the Amsterdam Public Health Service became responsible for the development and publication of HrV prevention brochures and posters. The Dutch Gay and Lesbian Association has always played an important role in the distribu- 
tion of written materials and at a later stage in the distribution of condoms. Since 1992 they have operated an organization called Safe Service which distributes condoms to their local chapters, to gay bars and discos and, in the larger cities, to drugstores.

Almost without exception, funding for HIV prevention activities has come directly or indirectly from government agencies. Of the total national budget for HIV prevention campaigns and activities, approximately $20 \%$ has been earmarked specifically for work with gay men.

\section{PREVENTION MESSAGES}

The content of prevention messages for gay men is an aspect of Dutch HN prevention that is worth mentioning, since it has long been markedly different from prevention messages in other European countries. Until 1992, the Netherlands adopted a so-called 'double message'. The primary focus in the message was on abstinence from anal sex while condom use with anal sex was seen being seen as an inferior behavioral option. Thus, the initial message said: "Avoid anal sex. If you can't avoid anal sex, use special condoms". In most other European countries, the focus of HIV prevention for gay men was almost exclusively on condom use.

Although the motives behind the decision to adopt a 'double message' are not well documented, it seems that the following factors contributed to a greater or lesser extent. Key persons at that time were convinced that extreme efforts had to be made to prevent an epidemic similar to that then unfolding in the United States. Decisions had to be made quickly since evidence on the sexual behavior of Dutch gay men, let alone information on their attitudes towards anal sex, was scarce. In addition, at that time there was considerable doubt about the reliability of condoms. These doubts were based on a report that showed high failure rates for six condom brands that were developed for anal sex (Oud, 1986). From the moment the 'double message' was adopted, there were reservations, especially among HIV educators, about the feasibility of advocating abstinence. In the years that followed, research showed that a considerable number of gay men continued to have anal sex, and studies demonstrated the important role that anal sex played in the lives of many gay men (De Wit, 1994). Based partly on these results, prevention workers began to develop activities around condom promotion for men who could not or would not refrain from anal sex. In 1992 the NCAB advised that both abstinence and condom use were to be considered equivalent risk-reducing behavioral options, and that both behavioral options should be addressed in HrV prevention (De Zwart \& Sandfort, 
1993). From that moment condom promotion became a standard conpu nent of HIV prevention for gay men in the Netherlands. The change instigated the development of new brochures and small group activities that focused on promoting condom use with anal sex.

\section{PREVENTION OF DISCRIMINATION}

Besides information materials and activities that specifically targeted gay men, the Dutch policy also explicitly attempted to prevent discrimination and stigmatization of people with HIV and ADS (and hence gay men, since they were and are the largest subgroup within the population with HIV or AIDS). In order to achieve this goal, mass media campaigns were launched, in which risk behaviors were emphasized as opposed to risk groups, an attempt to weaken the almost unavoidable association people made berween homosexuality and Hrv. Also, mass media campaigns for the general public especially the more recent ones - have focused within the same campaign on both heterosexual and homosexual contact, using the same format and the same message. The goal was to disseminate the notion that preventing ADS is relevant to everyone regardless of sexual orientation. Finally, concurrent to primary prevention campaigns for the general public there have been mass media campaigns - with the slogan "No one has acquired AIDS by showing compassion" - that seek to promote greater understanding for people living with HTV or ADS.

In sum, characteristic of HIV prevention activities among gay men in the Netherlands in the first decade of the AIDS epidemic has been the notable influence and substantial participation of gay men in shaping and executing the Dutch policy. During that decade a substantial number of prevention activities were developed and implemented, while the prevention message for gay men changed from an emphasis on refraining from anal intercourse to addressing condom use. Finally, activities for gay men were reinforced by campaigns for the general public that promoted safer sex and attempted to prevent stigmatization and discrimination towards people with HIV and AIDS. 


\section{OVERVIEW OF HIV PREVENTION INTERVENTIONS}

Activilies with respect to HIV prevention among gay men in the Netherlands can be placed in the following categories: written HIV prevention materials, posters, other AIDS information materials, small group HIV prevention activities, and outreach activities.

\section{Written materials}

Between 1983 and 1993, 11 brochures with background information for gay men on HIV and AIDS were published in the Netherlands. Almost from the beginning the development of brochures included a extensive pretesting phase using a standard protocol (Van Kalmthout, 1993). Communication experts, medical specialists and gay men themselves evaluated the first drafts of brochures. Consequently, these drafts were adjusted according to their comments. Table 6.1 shows the year of publication for each brochure as well as a summary of the information and safe sex guidelines provided in these brochures. Several of the brochures in Table 6.1 were also available in foreign languages (English, German, French, Italian, Spanish, Arabic, Turkish, and Papiemento), and targeted both migrants and tourists. These brochures usually targeted all gay men, and provided safe sex guide lines as well as background information on HIV and ADS. In the early years of the epidemic, new brochures were published every year, containing the latest medical and epidemiological facts. As more became known, the text in the brochures got lengthier. While the first brochure contained four pages, the 1990 brochure contained 32 pages of information.

The earlier brochures clearly discouraged men from taking HIV tests, while the later brochures gave extensive information on the advantages and disadvantages of testing. and urged men to consider these carefully before getling tested. As of 1988, brochures provided information about the treatment of AIDS. Furthermore, the brochures became more realistic in their statements about the likely course of HIV infection. Between 1983 and 1987 , it was believed that only a minority of infected men would eventually develop AIDS. Between 1988 and 1992 this prognosis was adjusted to approximately $60 \%$.

Each brochure provided safe sex guidelines. As discussed above, until 1990 the primary message emphasized avoiding anal sex. Men who wanted to have anal sex were urged to use special condoms with the explicit warning that condoms were not $100 \%$ safe. In the autumn of 1990 , this focus on abstinence from anal sex was abandoned. Instead, brochures classified unprotected anal sex and oral sex with ejaculation as unsafe techniques and started to give information on condoms and condom use, leaving to the reader the choice between refraining from anal sex or having protected anal 
Table 6.1 HIV prevention brochures for gay men.

\begin{tabular}{|c|c|c|c|}
\hline Brochure title & Year & Background information & Safe sex guidelines \\
\hline $\begin{array}{l}\text { A.I.D.S. Important announcement } \\
\text { for blood donors }\end{array}$ & 1983 & $\begin{array}{l}\text { - AIDS infection probably via blood } \\
\text { - three risk groups: gay men, IVDU's and haemophiliacs } \\
\text { - symptoms of AIDS }\end{array}$ & $\begin{array}{l}\text { - see a physician if you belong to a risk group } \\
\text { - stop donating blood if you belong to a risk group }\end{array}$ \\
\hline $\begin{array}{l}\text { A.I.D.S.Acquired Immune } \\
\text { Deficiency Syndrome }\end{array}$ & 1983 & $\begin{array}{l}\text { - probably a virus } \\
\text { - anal sex probably involved } \\
\text { - symptoms of AIDS } \\
\text { - no test }\end{array}$ & $\begin{array}{l}\text { - anal sex, especially receptive is risky } \\
\text { - multiple anonymous partners risky }\end{array}$ \\
\hline $\begin{array}{l}\text { A.I.D.S. The situation } \\
\text { at this moment }\end{array}$ & 1984 & $\begin{array}{l}\text { - cause unknown } \\
\text { - no cure } \\
\text { - no test } \\
\text { - infection via blood and sex, mechanism unknown } \\
\text { - anal sex, oral sex, and probably rimming risky } \\
\text { - number of AIDS cases }\end{array}$ & $\begin{array}{l}\text { - limit the number of sex partners } \\
\text { - avoid anal sex } \\
\text { - using condoms for anal sex strongly reduces the risk }\end{array}$ \\
\hline AIDS Information 1985 & 1985 & $\begin{array}{l}\text { - AIDS caused by virus (LAV/HTLV-III) } \\
\text { - infection does not have to result in AIDS } \\
\text { - no cure } \\
\text { - mechanism unknown } \\
\text { - blood tests soon available } \\
\text { - number of AIDS cases }\end{array}$ & $\begin{array}{l}\text { - do not donate blood } \\
\text { - limit the number of sex partners } \\
\text { - avoid anal and oral sex } \\
\text { - avoid rimming } \\
\text { - If you want to have anal sex use a condom } \\
\text { - testing discouraged, instead behavior change encouraged }\end{array}$ \\
\hline
\end{tabular}


Table 6.1 Continued.

\begin{tabular}{|c|c|c|c|}
\hline Brochure title & Year & Background information & Safe sex guidelines \\
\hline STOP AIDS. Have Safe Sex. & 1986 & $\begin{array}{l}\text { - AIDS caused by virus (LAV/HTLV-III) } \\
\text { - mechanism: blood-blood and blood-semen contact }\end{array}$ & $\begin{array}{l}\text { - avoid anal sex, especially receptive } \\
\text { - condom use limits but not eliminates risk } \\
\text { - rimming possibly risky } \\
\text { - avoid 'dirty sex' } \\
\text { - oral sex with ejaculation is risky } \\
\text { - stop use of amylnitrites } \\
\text { - kissing and masturbation no risk }\end{array}$ \\
\hline AIDS Information 1987 & 1987 & $\begin{array}{l}\text { - caused by HIV } \\
\text { - difference between HIV infection and AIDS } \\
\text { - some people who are infected do not get sick, others do } \\
\text { - chances of developing AIDS probably higher than } 30 \% \\
\text { - no cure } \\
\text { - symptoms of AIDS } \\
\text { - number of AIDS cases }\end{array}$ & $\begin{array}{l}\text { - do not donate blood } \\
\text { - avoid anal sex } \\
\text { - avoid oral sex with ejaculation } \\
\text { - no need to limit the number of sex partners } \\
\text { - use a special condom for anal sex condom if you want } \\
\text { to have anal sex } \\
\text { - condoms are not } 100 \% \text { safe } \\
\text { - do not get tested but have safe sex }\end{array}$ \\
\hline Information 1988 & 1988 & $\begin{array}{l}\text { - infection mechanism of HIV (blood-blood/blood-semen) } \\
\text { - difference between HIV infection and AIDS } \\
\text { - symptoms of infection } \\
\text { - syndromes: AIDS, ARC,ADC } \\
\text { - } 30 \% \text { will develop AIDS } \\
\text { - } 30 \% \text { will develop other syndromes } \\
\text { - AZT } \\
\text { - number of AIDS cases }\end{array}$ & $\begin{array}{l}\text { - avoid anal sex } \\
\text { - use a special condom for anal sex if you want to have } \\
\text { anal sex } \\
\text { - condoms are not } 100 \% \text { safe } \\
\text { - avoid oral sex with ejaculation } \\
\text { - carefully consider the advantages and disadvantages } \\
\text { of testing } \\
\text { - get anonymous testing } \\
\text { - report discrimination }\end{array}$ \\
\hline
\end{tabular}


Table 6.I Continued.

\begin{tabular}{|c|c|c|c|}
\hline Brochure title & Year & Background information & Safe sex guidelines \\
\hline The State of Affairs & spring 1990 & $\begin{array}{l}\text { - Infection mechanism of HIV (blood-blood/blood-semen) } \\
\text { - difference between HIV infection and AIDS } \\
\text { - symptoms of infection } \\
\text { - symptoms of AIDS (opportunistic infections, Kaposi's } \\
\text { sarcoma) } \\
\text { - AZT, DDI } \\
\text { - early treatment } \\
\text { - advantages and disadvantages of testing } \\
\text { - number of AIDS cases }\end{array}$ & $\begin{array}{l}\text { - avoid anal sex } \\
\text { - use a special condom for anal sex if you want to have } \\
\text { anal sex } \\
\text { - condoms are not } 100 \% \text { safe } \\
\text { - avoid oral sex with ejaculation } \\
\text { - discuss safe sex with steady partner } \\
\text { - carefully consider the advantages and disadvantages of } \\
\text { testing } \\
\text { - get anonymous testing } \\
\text { - report discrimination }\end{array}$ \\
\hline The State of Affairs & autumn 1990 & $\begin{array}{l}\text { - infection mechanism of HIV (blood-blood/blood-semen) } \\
\text { - difference between HIV infection and AIDS } \\
\text { - symptoms of Infection } \\
\text { - symptoms of AIDS (opportunistic infections, Kaposi's } \\
\text { sarcoma) } \\
\text { - AZT, DDI, Kemron } \\
\text { - early treatment } \\
\text { - referral to AIDS Info for latest news } \\
\text { - advantages and disadvantages of testing } \\
\text { - number of AIDS cases }\end{array}$ & $\begin{array}{l}\text { - refraining from anal sex is the safest option } \\
\text { - use a special condom for anal sex if you want to have } \\
\text { anal sex } \\
\text { - avoid oral sex with elaculation } \\
\text { - discuss safe sex with steady partner } \\
\text { - carefully consider the advantages and disadvantages } \\
\text { of testing } \\
\text { - get anonymous testing } \\
\text { - report discrimination } \\
\text { - extensive and explicit instruction how to use condoms } \\
\text { properly }\end{array}$ \\
\hline $\begin{array}{l}\text { Info for Men who Have } \\
\text { Sex with Men }\end{array}$ & 1991 & $\begin{array}{l}\text { - history, epidemiology, HIV, AIDS, infections mechanism, } \\
\text { unsafe and safe techniques, other STDs, condom use, } \\
\text { coping with being HIV+, solidarity, testing, AIDS medication. }\end{array}$ & $\begin{array}{l}\text { - no behavioral advice } \\
\text { - unprotected anal sex unsafe } \\
\text { - oral sex with ejaculation unsafe } \\
\text { - list of safe techniques (e.g. kissing, masturbation) }\end{array}$ \\
\hline Do it with & 1991 & - no background information & $\begin{array}{l}\text { - there is nothing wrong with wanting to have anal sex } \\
\text { - use special condoms made for anal sex } \\
\text { - extensive and explicit instruction how to use condoms } \\
\text { properly }\end{array}$ \\
\hline
\end{tabular}


sex. In 1991 a brochure was published that was devoted exclusively to condoms and condom use.

Concurrent with these information brochures, small booklets were published in 1986, 1987, 1990, and 1992 that contained only the safe sex guidelines. Between 1988 and 1993, eight folders were printed for gay tourists

$90 \ldots$ about gay life in the Netherlands. Safer sex guidelines were also included in these folders. The Dutch Gay and Lesbian Association published a number of folders (in 1987, 1988 and 1992) that specifically targeted gay youth. Although these folders primarily addressed coming-out issues, each also included information about HIV and ADS, as well as safer sex guidelines. Brochures and folders were distributed through various channels. The majority of gay bars and discos in the Netherlands were supplied with a special rack to hold written HIV prevention materials, both the nationally published brochures as well as local folders and flyers. A widespread distribution network of volunteers, co-ordinated primarily by local chapters of the Dutch Gay and Lesbian Association or local Public Health Services, looks after the supply of informational materials to these venues. A second major channel has been the distribution of safe sex promotion kits by Safe Sex Promotion Teams (to be discussed later). Also, brochures and folders have been distributed to participants of several small-group activities. The exact circulation figures are not known for the brochiores. On average betwicen 50,000 and 100,000 copies of each brochure were printed and distributed. The autumn 1990 brochure and the concise 1990 version - containing only safe sex guidelines - were evaluated after they were published (De Kooning, 1992). In the first phase of this evaluation, prevention workers who contributed to the development of the brochures were interviewed and asked post hoc to reconstruct the intended goals and effects of the brochures.

Subsequently, 31 gay men were sent the brochures and thereafter interviewed. These men were asked to evaluate the graphic design and the content of the brochures (e.g. the feasibility of certain behavioral recommendations) and, more specifically, to comment on whether the intended goals and effects - as stipulated by prevention workers - were covered by the design and content of the brochures. Both brochures received satisfactory ratings. In addition, respondents supplied several useful suggestions for improvement. The evaluation further highlighted the fact that it is hard to please every reader, which should not come as a surprise given the differences in background of a large target population. The length of the text and the tone of the language used were liked by some and disliked by others.

It is difficult to judge whether and to what extent brochures have influenced behavioral determinants and have changed the sexual behavior of gay men, since research in this area has been scarce. A national cohort study involving 364 Dutch gay men who completed questionnaires once a year between 1986 and 1989 (De Vroome, 1994), showed that each year around $95 \%$ of the cohort members reported having been in contact with 
AIDS education brochures. In general, the brochures received a high rating for usefulness. With respect to behavior, the study showed that the frequency of contact with AIDS education brochures was significantly higher among men who consistently used condoms for anal sex, compared to men who never used condoms.

\section{Posters}

Posters have also been used as a means of drawing attention to safer sex messages. In the first poster campaign - in 1986 - two Robert Mapplethorpe phorographs were used as background for safe sex messages. In 1988, a series of 8 posters were published with one theme: 'Safe Sex. Keep it up'. This series used the work of famous Dutch photographers. By selecting diverse photographs, the developers of the campaign wished to acknowledge social variations in gay subculture. This approach was repeated in 1991, when 4 different posters were published with the theme: 'Live Wild. Have Safe Sex'. Besides safer sex messages, posters have been used to announce small-group activities (to be described below), or to recruit volunteers for interventions. There are no data available about the circulation of posters, nor about their effectiveness.

\section{Other AIDS Information}

At the beginning of the epidemic, articles on HIV and ADs concerning gay men were regularly published in both De Gay Krant (a national bi-weekly gay newspaper), and SEK (the monthly magazine for members of the Dutch Gay and Lesbian Association). In 1984, both periodicals started to collaborate and published a new monthly periodical called AIDS Info, initially with a circulation of 40,000 copies (later 60,000). AIDS Info was targeted at gay men - including men living with HIV or ADS - and it contained articles with recent news about a broad array of subjects, such as medical aspects of HIV and AIDS, HIV prevention, and policy aspects. Through its independent status it could be (and was) critical towards developments in HIV/AIDS prevention, treatment, and policy. The Ministry of Health subsidized the distribution. AIDS Info was enclosed in De GAY Kront and SER. It was also distributed to gay bars and discos. The last issue of AIDS Info appeared in 1993. In 1994 it was re-launched as a bimonthly magazine named LUST for LIFE published under the responsibility of the SAD-Schorer Foundation.

A national cohort study (De Vroome, 1994), showed that AIDS Info reached many gay men in the cohort (from $79 \%$ in 1986 to $97 \%$ in 1989), and that it received the highest ratings (in terms of the usefulness of the information supplied) compared to a wide range of other HIV/ADS information 
sources. With respect to behavior, this study showed that the frequency of contact with AIDS Info was a significant correlate of safer sex.

\section{Small group activities}

The first group activity that briefly addressed ADS took place in 1984. It was a five-evening course for gay men on health issues in the broadest sense, including psychosocial aspects. Subjects addressed included STDs, alcohol and drugs, compulsive sex, and promiscuity. Besides trainers from the $S A D$, representatives from government health institutions - including psychologists from mental health centers - contributed to the course. After being piloted, it was agreed that the course would travel through the Netherlands. Support from regular health institutions in other regions, however, was limited. It was therefore transformed into a weekend course that was offered by the SAD and organized nationally. Over time, the focus of the weekend workshops has narrowed from health issues in the broadest sense, to AIDS and (un)safe sex. The initial workshop has been evaluated. With respect to behavior change, this evaluation showed that $72 \%$ of respondents did not have anal sex in the six month follow-up period compared to $55 \%$ in the six months preceding the workshop (Wennink, 1988). The course ran until 1988.

In 1987 and 1988 the SAD set up a workshop that was an adaptation of the Eroticizing Safe Sex Workshop designed by Gay Men's Health Crisis in New York. The goals of the workshop were to strengthen positive attitudes towards safer sex as well as to improve negotiation skills with respect to safer sex. The SAD supplied trainers as well as materials (posters and brochures) for the recruitment of participants. A total of 65 workshops with 758 participants were organized nationwide. No process or outcome evaluation results are available. This workshop was succeeded by the Safe Sex Video Show 1. The Safe Sex Video Show 1 was an intervention developed for small groups, guided by a video that contained information on HIV/AIDS and safer sex. The video also depicted several role plays in real life settings that addressed relevant issues like countering justifications for having unsafe sex, and reactions to meeting an HTV-positive sex partner. In this video, education on safer sex included the message to refrain from anal intercourse. However, the video did offer a brief demonstration of condom use. The Safe Sex Video Show was moderated by two experienced trainers who discussed specific themes with participants (knowledge of risks, the consequences of risk information for individual behavioral decisions, and coping with barriers for safer sex). The aim was to create interaction between participants and to have them discuss safer sex, thereby inducing or strengthening group norms that favored safer sex. From 1988 until 1990, 156 groups with slightly more than 3000 participants were reached nationwide. 
No process or effect evaluation results are available. However, the large number of performances of the show suggests that the show was popular, and that it undoubtedly addressed the need for information about HIV/AlDS among gay men. In 1990, the Safe Sex Video Show 1 was succeeded by the Rubber Road Show.

The policy change with respect to the prevention message for gay men led in 1990 to the development of an activity that explicitly addressed condom use with anal sex. In its test phase, it was named The Condom Workshop. The primary goals were to promote the use of condoms when having anal sex, and to provide skill training in the proper use of condoms. Secondary goals were to provide adequate information about risks of anal sex, to discuss barriers to condom use, and to increase knowledge about condoms and condom use. The workshop was led by two trainers, and lasted approximately three hours. At the start of the workshop, participants were explicilly told that refraining from anal sex was the best way of avoiding HIV infection and that the workshop intended to promote (proper) condom use among men who would not or could not refrain from anal sex.

The format of the intervention was similar to the Safe Sex Video Show 1: it consisted of parts of its videotape, together with a talk show and a condom use skills training. The Condom Workshop was evaluated through process evaluation as well as an outcome evaluation using a pre-test-post-test design (eight workshops with a total of 69 participants; Hoekzema \& Dingelstad, 1991). The outcome study looked at changes in knowledge, skills, attitudes and social norms with respect to condom use and sexual behaviors. There were significant changes between pre- and post-test on several items to do with knowledge, skills, attitudes and social norms. The report also described changes toward safer sexual behavior at the second post-test (two months after the workshop), although no significance levels were provided.

Participants were very satisfied with both the content of the training and the expertise of the trainers.

On the basis of this evaluation, The Condom Workshop was modified into The Rubber Road Show which was implemented nationwide. In 1990 and 1991, 35 shows were organized which attracted 446 participants. Participants were recruited through advertisements in a national newspaper and the gay press, and through flyers that were distributed among local chapters of the Durch Gay and Lesbian Association. The Rubber Road Show was eventually incorporated in the Safe Sex Videoshow 2.

The Safe Sex Videoshow 2 was launched in 1991 under the name 'In The Heat of the Moment'. The small-group format of the Safe Sex Video Show 1 was maintained. A new videotape was developed which was pre-tested by communication experts and health educators. The major differences from the previous video show were the content of the videotape and the way it was used in the program. In the new videotape, additional topics were addressed such as coping with difficult sexual situations and preventing 
relapse. The video depicted a number of scenes that each led up to a moment when a decision had to be made to have safer sex or not. At that moment the video was stopped and the trainers discussed with the group what they would do in such a situation. After this discussion, the video showed one viable solution for handling the situation appropriately. In 1991 and 1992 there were 99 shows with 1680 participants. From 1993 until the present the program has continued to be executed, albeit rather irregularly. The Safe Sex Video Show 2 has been sold to other countries, for example to France and England.

'In the Heat of the Moment' was accompanied by a process and effect evaluation that included 33 shows (De Kooning \& Sandfort, 1993). The study evaluated effect variables before and immediately after the show $(\mathrm{N}=352)$. A second post-test was conducted three months after the show $(\mathrm{N}=166)$. Effect variables included knowledge, attitudes, self-efficacy, behavioral intentions, and behavior. There were significant short- and long-term changes in some of the knowledge items, specifically those related to risks of several sexual behaviors. Most items on attitudes and self-efficacy did not show short- and long-term changes in the desired direction. Finally, there were hardly any changes in sexual behaviors between pre-test and post-test. The process evaluation showed that participants, on average, were very positive about the content of the show and the quality of the trainers. The majority of men reported that the show made them more aware of their attitudes towards safer sex, one third of the men said that they could better distinguish safer from unsafe practices, and $20 \%$ of respondents reported that participating in the show resulted in less anxiety about HIV infection risks.

\section{Outreach activities}

In 1988, the first prevention project at cruising areas for gay and bisexual men was launched in Utrecht. In 1989 the project was extended to the other major cities in the Netherlands (Amsterdam, Rotterdam, and The Hague). The core activity of the project was to send trained volunteers to cruising areas where they spoke with men at these areas about the importance of safer sex. The major goals of the activity were to disseminate information on safer sex, to reinforce a social norm of safer sex in cruising areas, to provide visitors at cruising areas with solutions to overcome personal barriers to having safer sex at these areas, and finally, to refer visitors to organizations that offer information on HIV and ADS (e.g. the ADS Hot Line) or relevant services (e.g. condom sale). Based on a survey conducted among these volunteers which assessed their evaluation of the training they had received (Waldhober, 1990a), the intervention was further developed and implemented nationwide. In 1993, the Public Health Services in 15 cities and regions supported a Cruising Area Project. 
The projects were supported on a national level by the SAD-Schorer Foundation, which provided materials to recruit volunteers (posters and flyers), extensive training for new volunteers, and, as of 1993, registration forms to be used by the volunteers for each conversation at cruising areas to keep track of the activity. Together with the registration form, a computer program for data entry and data analysis was supplied to project co-ordinators in each Public Health Service.

All Cruising Area Projects participated in a nationwide process evaluation in 1993 (De Jong, 1994). One part of the evaluation was based on the registration forms, and consisted of an overview of the number of conversations, the topics that were addressed in these conversations, characteristics of cruising area visitors, and self-reported sexual practices at cruising areas. The results show that in 1993 the 78 volunteers approached a total of 2684 men. Slightly more than $10 \%$ of these men refused to talk with a volunteer. The topics most frequently addressed in conversations were: HIV/AIDS knowledge including misconceptions about sexual risks, intentions and barriers to having safer sex, and the availability of condoms. With respect to self-reported behavior, the results show that $68 \%$ of visitors had oral sex at cruising areas ( $77 \%$ consistently safe), and that $30 \%$ of visitors engaged in insertive and/or receptive anal sex (68\% consistently safe).

Since 1983 there have been several initiatives to reach gay men in bars and discos. From 1990 onwards, this outreach activity has become more structured through the creation of Safe Sex Promotion Teams (Waldhober, 1990b). A Safe Sex Promotion Team comprised three to six gay men who gave shows at gay bars and discos as well as on special occasions with gay audiences. The act most usually consisted of songs, dance, and cabaret with safer sex themes. All members of promotion teams were trained in performing the acts. In addition, they received extensive training in talking with gay men about safer sex after their show. They also distributed safer sex kits containing HV prevention brochures and condoms. The primary goal of this activity was to support gay men who visited bars and discos with behavioral change towards safer sex, and with the maintenance of safer sex behavior. Semi-professional artists were used first of all to ensure a high artistic quality of the acts, but also because it was believed that professional acts would increase the likelihood that bar owners would co-operate. Also, the use of performance acts was believed to be a better method to deal with emotional aspects of safer and unsafe sex. Finally, it was hoped that the active distribution of safer sex materials would reach men who had not been reached by previous safer sex brochures.

Between 1990 and 1994 the Safe Sex Promotion Teams made 229 appearances, reached an estimated 54,000 gay men, distributed over 23,000 safe sex kits, and had over 5,000 conversations with gay men about safe sex (Van Stoppelenburg, 1995). The work of the Safe Sex Promotion Teams has not been evaluated in terms of its effects. 
The end of 1992 is an important landmark in relation to $\mathrm{HW}$ prevention among gay men in the Netherlands. It coincided with a period in which preparations were made to decentralize primary prevention budgets, inclu-

96 ding those related to HIV prevention. Henceforth, budgets for HIV prevention would largely be transferred from national organizations to the local level, and hereafter local Public Health Services in the Netherlands became responsible for HIV prevention, including the development and implementation of prevention activities for gay men in their region. All HIV prevention professionals who worked at the national level in several organizations were placed within one organization, namely the SAD-Schorer Foundation. The Prevention Team of the SAD-Schorer Foundation is currently responsible for the development and publication of HIV education brochures. With respect to group activities, their task changed from program development and program execution to the provision of support for prevention workers in Public Health Services who are organizing HIV prevention for gay men at the local level. This reorganization took considerable time since all parties involved had to get accustomed to their new tasks. Organizing adequate HIV prevention at the local level has become the major challenge for the coming years. With respect to the content of HIV prevention, the focus is shifting towards gay population subgroups, like young gay men, male sex workers, and HIVpositive men. There is also an increased focus on sexual behavior within beginning relationships - especially among young gay men - since recent research has shown heightened levels of unprotected sex with steady partners within relatively short-lasting relationships.

\section{DISCUSSION}

Between 1983 and 1993, HIV prevention for gay men in the Netherlands developed into a highly professional field. The fact that there was a strong involvement of gay men in HIV/AIDS policy organizations from the beginning of the epidemic has had several consequences. First of all, this situation permitted representatives of the gay subculture to directly influence prevention policy for gay men, and to contribute directly to intervention development. It further allowed swift responses to be given to changes and new developments in the gay subculture. On the other hand, most gay men involved in HIV prevention were not trained in health education or related disciplines. Therefore, it has taken time and training to develop interventions systematically, based on germane theories and using appropriate methods. 
With respect to written materials, there has been a constant effort to inform and update the gay community about HIV/AIDS issues. The concurrent publication of background information on the one hand and materials that summarize the safer sex guidelines on the other hand, has aimed to meet differences in information needs. There now exists a relatively well-functioning system to distribute these written materials.

The first group activity that was developed, focused on ADS willin a broader context of (sexual) health. Successive group activities have focused almost primarily on HIV and AIDS. The Safe Sex Video Show 1 successfully introduced the use of video fragments as a catalytic agent for introspection and discussion in groups. A video format was preserved in both follow-up activities. Over 5,000 gay men have participated in these small-group activities over the years.

Outreach work at cruising areas has evolved into an intervention that is planned and implemented by health educators and volunteers at the local level, supported by professionals at the national level who assist with recruitment, training, and evaluation. Safe Sex Promotion Teams have reached substantial numbers of gay men and have proven to be a very satisfactory method of disseminating HIV/AIDS information. Recently, two regions in the Netherlands have launched a program that used the same format. Continuation of these types of outreach activities at the local level ensures that members of the gay community will continue to be informed about HV prevention.

The wide range of ADS prevention activities that were described in this chapter - ranging from information brochures to small-group interventions were in most cases carefully planned. In most instances the intervention goals were made explicit, and development included expert consultation as well as careful pre-testing among target group members. Health education theorists have repeatedly stressed the need for careful and systematic planning if interventions are to be effective (Kok, 1991; Mullen, Green \& Persinger, 1985). In general, one has to make sure that relevant determinants of behavior are addressed by specific intervention methods. The identification of relevant determinants and effective methods emphasizes the indispensable role of theory in intervention development (Fisher \& Fisher, 1992; Kelly \& Murphy, 1992; Mullen et al., 1995).

However, anorher vital component of the planning process consists of process and effect evaluations. Process evaluations provide information about the extent to which interventions were carried out as planned and may highlight unforeseen problems with the execution of interventions. Effect. evaluations have to examine whether interventions led to changes in behavioral determinants and subsequently to changes of behavior. Effect evaluations especially have unfortunately received considerably less attention within ADS prevention intervention research in the Netherlands. Therefore, relatively litcle is known about the effectiveness of much of the work under- 
taken. New activities have usually been based on the experiences of those who carried out previous interventions, while evaluation has often been limited to process evaluation. The most likely explanations for the absence of effect evaluation research are time and financial constraints. Fortunately, the recent policy document of the Program Co-ordination Committee for AIDS Research (PccAo) explicitly acknowledges this problem. Projects that include effect evaluations, as well as initiatives that focus on the effectiveness of new intervention methods, are now among the priorities on the research agenda for the next few years (PccAo, 1995).

The challenge for the coming years will be to maintain the high quality of HIV prevention for gay men that has been achieved by the continuous efforts of numerous professionals and volunteers in the Netherlands over the past decade. 


\section{CHAPTER 7}

\section{Evaluation of an HIV prevention intervention for men who have sex with men at cruising areas in the Netherlands}

Published as:

Hospers. H.J., Debets, W., Ross, M.W., \& Kok, G.J. (1999).

Evaluation of an HIV prevention intervention for men who have sex with men at cruising areas in the Netherlands. AIDS and Behavior, 3, 359-366. 
Preventing HIV infection through education is generally accepted as one of the most potent means of halting the spread of AIDS (Hospers \& Kok, 1995). With male-male unprotected sexual intercourse being the most important vector of HIV infection in many Western countries, vast amounts of time, energy, and funds have been spent on HIV prevention interventions for men who have sex with men. Several methods are used to educate men who have sex with men about HIV and AIDS, such as written materials, small group activities, or outreach activities (Hospers \& Blom, 1998). The present study focuses on an outreach activity, namely HIV/AIDS education for men who have sex with men at cruising areas.

Cruising areas (CAs) are outside venues, such as parks, woods, or rest areas along highways. Together with other venues, like darkrooms, saunas and bathhouses, cruising areas are places where men meet other men, usually with the intention to have sex. The legal circumstances concerning same sex behavior at CAS vary between countries. It depends on whether same sex behavior is legal, on age restrictions for same sex behavior, and on the extent to which (same) sex behavior in public places (such as CAs) is prosecuted or condoned. The Netherlands has a relatively liberal policy. Same sex behavior is legal above the age of 16 , and - although public sex is legally prohibited - sex at CAs is usually not traced or prosecuted.

Compared to the expansive amount of literature on sexual risk behavior and behavioral determinants, based on data from convenience samples of gay and bisexual men, relatively little has been published about sex at CAs. One reason for this is the fact that the anonymous nature of CAS poses restrictions on research at such venues. Many men who visit CAs look for sex and wish to remain anonymous, not only for their sex partners but also for researchers.

Data from the Amsterdam Cohort Study show that $50 \%$ of cohort members report one or more visits to CAs in the six months preceding assessment, and of these respondents, $6.3 \%$ report unprotected insertive and/or receptive anal intercourse at CAs (De Wit, De Vroome, Sandfort \& Van Griensven, 1997). A Dutch study among 1249 CA visitors showed similar levels of risktaking behavior: $30 \%$ of visitors reported engaging in insertive and/or receptive anal sex at CAs in 1993, of which $32 \%$ were not consistently safe (De Jong, 1994). This means that almost $10 \%$ of the total sample reported risk-taking behavior. A smaller study among $82 \mathrm{CA}$ visitors showed that $14 \%$ of their sample reported risk-taking anal sex (De Groot, 1995). Another interesting feature of CAs is the presence of relatively large numbers of bisexual men on those venues. For example, in a pilot study that was conducted to pretest the questionnaires used in the present study, it was found that about one quarter of CA visitors were behaviorally bisexual. Some bisexual men depend on public sex environments to have sex with 
men, especially those who conceal their homosexual behavior. Research shows that bisexual men engage in risk-taking sex with male partners (see Doll \& Beeker (1996) for a review). For example, Weatherbum and Reid (1996) found that among a sample of 745 of behaviorally bisexual men, $14.0 \%$ had engaged in unprotected vaginal sex and unprotected anal sex with men in the 12 months preceding assessments, while $9.8 \%$ had engaged in unprotected anal sex with both men and women. Stokes, McKirnan and Burzette (1993) report a six month rate of unprotected anal sex of $16 \%$ in a sample of 105 bisexual men. They note in this respect, that reported risk rates for unprotected anal sex among gay men are usually substantially higher. Nevertheless, the risk rates among bisexual men are not negligible and are cause for concern, especially when one takes into consideration that research shows that the majority of bisexual men do not disclose to their female partners that they have sex with men (Doll \& Beeker, 1996; Stokes et al., 1993; Weatherburn \& Reed, 1996).

Bisexual men who hide their homosexual behavior may have less access to informational sources regarding HIV-preventive homosexual behaviors, and may not benefit as much as openly gay men can from positive social norms towards safe sex. With respect to the latter, several studies have demonstrated that positive social norms towards safe sex are indeed related to safer sexual behavior (Kelly, St.Lawrence, Brasfield, Lemke et al., 1990; Kelly, St.Lawrence, Brasfield, Stevenson et al., 1990; Ross \& McLaws, 1992). Furthermore, bisexual men may be comparable with gay men who are not involved with the gay community. The absence of gay community involvement has been found to relate to risk-taking sex (Prieur, 1990), and more specifically to unprotected anal intercourse with casual partners (Connell et al., 1990). Seibt et al. (1995) measured both 'sexual identity' and 'acculturation into the gay subculture' in a sample of $282 \mathrm{men}$ in Dallas who ever had anal sex with a man and who where not currently in a mutually exclusive relationship. They found that a non-gay identity as well as low acculturation were strongly associated with lower condom use. Sexual identity and acculturation were also strongly related (i.e. gay-identified men having higher acculturation scores). On the contrary, Stokes et al. (1993) found no relationship between gay community involvement and risky anal sex in a sample of bisexual men in Chicago.

The first prevention project at cruising areas for gay and bisexual men was launched in the Netherlands in 1988. The intervention was further developed and eventually implemented nationwide. In 1995, local Public Health Departments in 14 regions have a Cruising Area Project. The core activity of the project is to send rained volunteers to cruising areas, where they approach visitors to talk about the importance of safer sex. The major goals of the activity are to disseminate information on safer sex, and to reinforce a social norm of safer sex in cruising areas. In practice volunteers visit CAs and actively approach men who are present. Conversations are not forced 
upon $\mathrm{CA}$ visitors and unwillingness to have a conversation is respected. If a $\mathrm{CA}$ visitor has no objection to talk to a volunteer, the volunteer checks whether the CA visitor is aware of the risks of unprotected sex and tries to assess whether he is motivated to have safe sex. If necessary, correct risk information is provided as well as arguments why it is important to (continue to) have safe sex. Finally, the volunteer offers a safe sex information brochure and a condom with lubricant. Volunteers can also refer visitors to organizations that offer information on HIV \& AIDS (e.g. the ADS Hot Line), or relevant services (e.g. condom sale).

The projects are supported on a national level by the SAD-Schorer Foundation, which provides materials to recruit volunteers (posters and flyers), extensive training for new volunteers, and, as of 1993, registration forms to be completed by the volunteers for each conversation at cruising areas. A computer program for data entry and analysis was developed to allow local coordinators to monitor their intervention.

The training for volunteers takes two days, in which they receive an introduction in the objectives of the CA projects, as well as a concise overview of theoretical perspectives on (sexual) behavior and behavior change. A substantial part of the training is dedicated to role playing, in which the volunteers are trained how to approach CA visitors, how to introduce the prevention messages, and how to cope with resistance. They are also taught general conversation skills. The practical exercises also serve as a team building instrument.

All Cruising Area Projects participated in a nationwide process evaluation in 1993 (De Jong, 1994). The results show that the 78 volunteers approached a total of 2121 men in that year. Approximately $85 \%$ of these men actually had a conversation with a volunteer, while $15 \%$ refused to talk to a volunteer. The topics most frequently addressed in these conversations were: knowledge of HIV/ADS, including misconceptions about sexual risks, barriers to having safer sex, and the availability of condoms.

The present study was initiated to collect data on characteristics of CA visitors, including sexual risk-taking behavior. Furthermore, data were collected on gay network affiliation of CA visitors. Finally, it sought to assess whether and to what extent the outreach activities are promoting safe sex behavior at CAs. 
agreed to participate in this study, provided that the study would not interfere with the intervention, and that the anonymous nature of CAs would be respected. Given these restrictions, it was decided to conduct a cross-sectional post-intervention assessment. Participating health departments contributed approximately US\$250 to the study. Major reasons that Health Departments gave for not participating in the study were lack of time or lack of finances.

\section{Questionnaire}

The self-administered questionnaire that was used in this study comprised the following items in the following order: demographics (age, sexual selfidentification (5-point scale, range exclusively heterosexual-exclusively homosexual), homosexual or bisexual behavior (sex with men only or with men and women), frequency of visiting CAs, number of sex partners at CAS in 1995, frequency of sexual behaviors at CAs (4-point scale, range neveroften), frequency of condom use with insertive and receptive oral and anal intercourse (5-point scale, range never-always), risk perceptions for HTV infection regarding unprotected sexual behaviors (6-point scale, range no risk-very high risk), behavioral intention to use condoms with anal intercourse at CAs (5-point scale, range certainly not-certainly), gay network affiliation (going out in gay scene, contact with gay media, contact with HIV prevention for gay men; 3-point scale, range never-often), having gay friends (3-point scale, range none-many), whether or not respondents had been approached by a volunteer in 1995, and if so, whether they had agreed to talk to the volunteer. For respondents who had not been approached by a volunteer, the questionnaire briefly outlined the CA prevention project, and subsequently asked whether or not they would have agreed to talk to the volunteer. It took approximately 10 minutes to complete the questionnaire.

\section{Procedure}

The HIV prevention intervention at CAS was carried out from April until September of 1995. After the intervention ended, volunteers of the local Health Departments returned to the CAs, approached all CA visitors present at the time, and asked them to participate in this study. All volunteers at all cruising areas received a protocol in writing, with the procedure that had to be used for distributing questionnaires. Specifically, volunteers were instructed to present themselves as volunteers for a research project at CAs of their Health Department, without referring to the HTV prevention project that had taken place, and without engaging in conversations about HV prevention. If 
they were asked questions regarding HIV prevention issues, they provided the telephone numbers of the local Health Department and the national AIDS hotline. The volunteers were also instructed to keep track of the number of distributed questionnaires as well as the number of $C A$ visitors that refused to accept a questionnaire. Questionnaires could be completed at the CA or 104 could be taken home, in which case postage free return envelopes were supplied.

Inclusion in the study

One of the research questions of this study was to assess whether or not differences existed between men who had had a conversation at CAs about HIV prevention, and men who had not had such a conversation. Given the cross-sectional nature of the study, special attention went to the composition of the comparison group. The group of men who had not been approached by a volunteer, most likely also comprised men who would have refused to talk to a volunteer about HIV prevention. The questionnaire therefore asked respondents who had not been approached whether they would have refused to have a conversation, which made it possible to remove these respondents from the data set. Likewise, men who had been approached but refused, were excluded as well. Thus, the remaiming group comprised men who had spoken to a volunteer and men who would have spoken will a volunteer, had they been approached.

\section{RESULTS}

\section{Response}

A total of 27 cruising areas in the seven regions were visited on several occasions by volunteers. Five of the seven regions registered the number of men who were approached with a questionnaire, refusal rates and response rates. In these 5 regions, 849 men were asked to complete the questionnaire, of which $300(35.3 \%)$ refused to participate. A total of 322 questionnaires were returned to these 5 local health departments (i.e. $37.9 \%$ of approached men and $58.7 \%$ of distributed questionnaires). Refusal rates per region varied from 32 to $39 \%$ while response rates per region varied from 54 to $64 \%$. In the two regions that failed to register, 66 questionnaires were returned, which brings the total number of returned questionnaires to 388 . 
Of the men who had not been approached by a prevention worker, $1 ;$ would have refused to have a conversation, while of the men who had been approached, 9 had refused. These 26 respondents were excluded from the analyses. Of the remaining 362 respondents, 172 (47.5\%) had spoken with a volunteer about HIV prevention in 1995.

\section{Demographics and CA statistics}

Mean age of respondents was 38.1 years (range 17-78). More than half of respondents $(54.7 \%)$ visited CAs once or more per week. The mean number of sex partners at CAs in 1995 was 19 (range 0-125, median 15). With respect to behavior at CAs in 1995 , it was found that $9.1 \%$ only engaged in kissing or mutual masturbation, $54.4 \%$ had oral sex but never engaged in anal sex, while $36.5 \%$ of respondents reported having engaged in anal sex. The majority of men $(77.8 \%)$ who engaged in anal sex at CAs used extra strong condoms (which in the Netherlands are recommended for anal sex); $46.0 \%$ always used lubricant, $43.7 \%$ sometimes, and $10.3 \%$ never.

\section{Sexual preference and gay network affiliation}

The majority of respondents $(81.9 \%)$ reported that they had only sex with men (MSM), while $18.1 \%$ reported that they had sex with men as well as women (MSMW). Sexual behavior was strongly related to sexual self-identifi. cation: $95.6 \%$ of MSM labeled themselves as primarily or exclusively homu. sexual, while of MSMW $60.0 \%$ labeled themselves as bisexual, $20 \%$ as primarily or exclusively homosexual, and $20 \%$ as primarily or exclusively heterosexual.

Table 7.1 summarizes the data on gay network affiliation. It shows that MSMW less frequently go out in the gay scene, have less contact with gay media and HIV prevention targeted at gay men, and have fewer gay friends. The gay network affiliation variables resulted in a scale with acceptable reliability $(\alpha=.74)$. The mean scale score for MSM was 2.2 (range 1-3), which was significantly higher than the mean of 1.6 for MSMW $(\mathrm{F}(1,356)=82.9, \mathrm{p}<.001)$.

Sexual risk behavior, risk perceptions, and behavioral intention

Unsafe sexual behavior occurs at CAS: $15.5 \%$ of respondents who had oral sex report one or more instances of swallowing semen, $27.6 \%$ of respondents who had anal sex report at least one occasion of insertive anal intercourse without a condom, and $18.6 \%$ report at least one occasion of 
Table 7.I Gay network affiliation.

Never Sometimes Often

Goes our in goy scene

106 MSM'

$\begin{array}{llr}18.8 \% & 49.1 \% & 32.1 \% \\ 50.8 \% & 46.2 \% & 3.1 \%\end{array}$

Contact with gay media

MSM

$13.7 \%$

$51.5 \%$

$34.8 \%$

MSMW

$56.9 \%$

$36.9 \%$

$6.2 \%$

Contact with HN prevention goy men

MSM

$24.7 \%$

$56.5 \%$

$18.8 \%$

MSMW

$47.7 \%$

$49.2 \%$

$3.1 \%$

None Some Many

Number of gay friends

MSM

$4.8 \%$

$46.1 \%$

$49.1 \%$

MSMW

$26.2 \%$

$61.5 \%$

$123 \%$

IMSM: men who have sex with men

${ }^{2}$ MSMW: men who have sex with men and women

All $\chi^{2}: p<.001$.

Table 7.2 Mean risk perception estimates (range I=no risk, 6=very high risk) for five sexual risk behaviors for all respondents, respondents who engaged in the specified behavior without taking risk, and those who took risk.

\begin{tabular}{llll}
\hline & All $(\mathrm{N}=362)$ & No risk (N) & Risk (N) \\
Receptive oral sex with ejaculation & 5.0 & $5.1(234)$ & $4.2(43)$ \\
Insertive anal sex without ejaculation & 4.4 & $4.4(88)$ & $3.6(34)$ \\
Insertive anal sex with ejaculation & 4.8 & $4.8(88)$ & $4.0(34)^{*}$ \\
Receptive anal sex without ejaculation & 4.8 & $4.9(70)$ & $4.1(16)^{*}$ \\
Receptive anal sex with ejaculation & 5.8 & $5.9(70)$ & $5.5(16)^{* *}$ \\
\hline
\end{tabular}

Comparison of 'no risk' with 'risk' group: t-tests * $p<.005 ;{ }^{* *} p<.001$. 
receptive anal intercourse without a condom. Collapsing all risk behaviors, $18.5 \%$ of all respondents report on one or more forms of sexual risk behavior at CAs in 1995.

Table 7.2 shows the risk perception estimates to get infected with HIV for five sexual behaviors. To self get infected through anal sex without ejaculation was considered less risky than through anal sex with ejaculation ( $t_{\text {paired }}$ $(359)=7.6, p<.001$ for insertive anal: $\tau_{\text {paired }}(359)=18.5, p<.001$ for receptive anal). Also, recepcive anal sex was considered riskier than insertive anal sex $\left(t_{\text {paired }}(359)=9.1, p<.001\right.$ for anal sex without ejaculation; $t_{\text {paired }}(359)=$ $15.7, p<.001$ for anal sex with ejaculation). Furthermore, for all sexual behaviors it was found that men who had engaged in the specific risk behavior had significantly lower risk estimates than men who had not. The behavioral intention to use condoms at CAs was high (mean 4.8, range 1-5).

\section{Evaluation of the intervention}

For the evaluation of the intervention, respondents who had a conversation about HIV prevention with a volunteer at CAS in the months preceding the evaluation, were compared with respondents who were never approached by a volunteer. There were no significant differences in mean age, mean number of sex partners at CAs, proportion of men who had sex with men and women, or the proportion of men who had anal sex at CAs (Table 7.3). The proportion of men who frequently visit CAs was significantly bigher in the group that was reached by volunteers $\left(\chi^{2}=5.3, p<.05\right)$. This was to be expected since frequent visits to CAs increase the 'hit rate' (i.e. the probability to be approached by a volunteer).

A 2 (conversation/no conversation) × 2 (MSM/MSMW) ANCOVA with frequency of condom use wirh insertive anal sex as the dependent variable, and frequency of CA visits as covariate, yielded two main effects (see Table 7.4 for means). First, respondents who had a conversation about HrV prevention reported significantly higher condom frequency use with insertive anal sex at CAs $(F(1,121)=5.7, \mathrm{p}<.05)$. Second, MSM had higher mean scores than MSMW $(F(1,121)=5.3, p<.05)$. The regression of insertive condom frequency use on frequency of $C A$ visits was not significant. The same analysis with frequency of condom use with receptive anal sex as dependent variable, resulted in a main effect for having had a conversation. Again, respondents who had a conversation reported a higher frequency of condom use $(F(1,84)=5.4, P<.05)$, and the regression of receptive condom frequency on frequency of $\mathrm{CA}$ visits was not significant. The mean frequency of condom use with receptive anal sex did not significantly differ between MSM and MSMW. Finally, the ANCOVA with frequency of receptive oral sex with ejaculation as dependent variable yielded no significant results. With respect to behavioral intention to use condoms with anal sex at CAS, it 
Table 7.3 Mean scores and proportions for respondents who had a conversation about HIV prevention with a volunteer and who did not have such a conversation at CAs in 1995.

$\begin{array}{cc}\text { Convl } & \text { No conv } \\ (N=172) & (N=190)\end{array}$

Mean age

38.3

37.9

Mean number of sex partners at CAs in 1995

20.1

18.1

\% MSMW ${ }^{3}$

15.1

20.7

\% Engaging in anal sex at CAs

39.0

34.2

\%Visiting CAs once or more per week

61.0

$48.9 *$

'Conv. men who had a conversation with a volunteer

${ }^{2}$ No conv: men who did not have a conversation with a volunteer

3MSMW: men who have sex with men and women

* $\mathrm{p}<.05$

Table 7.4 Mean frequencies of condom use with insertive and receptive anal sex and frequency of receptive oral sex with ejaculation (range I=never, 5=always).

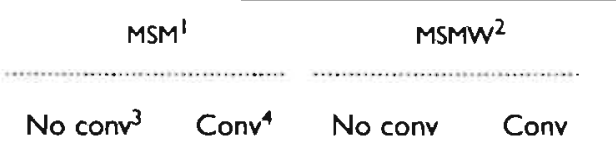

Frequency condom use insertive anal sex

4.5

4.8

3.9

4.6

Frequency condom use receptive anal sex

4.6

4.9

4.8

4.8

Frequency receptive oral sex with ejaculation

1.2

1.2

1.2

I.3

\footnotetext{
IMSM: men who have sex with men

2MSMW: men who have sex with men and women

${ }^{3}$ No conv: men who did not have a conversation with a volunteer

${ }^{4}$ Conv: men who had a conversation with a volunteer
} 
was found that there was no main effect for having had a conversation or not. MSMW had a significantly lower intention than MSM (4.7 vs. 4.9, F(1, $323)=5.1, p<.05)$. This effect remained marginally significant when restricting the analysis to respondents who engaged in anal sex at CAs (4.5 vs. 4.8 , $\mathrm{F}(1,140)=3.3, \mathrm{p}<.07)$.

Finally, among respondents who had anal sex at CAS, a significantly higher proportion of those who had a conversation with a volunteer used recommended condoms compared to men who had no conversation ( $85.9 \%$ vs. $\left.69.4 \%, \chi^{2}(1)=5.0, \mathrm{p}<.05\right)$.

\section{Differences between MSM and MSMW}

Given the difference in anal risk behavior between MSM and MSMW, additional analyses were conducted to further compare these groups. There were no significant differences with respect to the number of sex partners at CAs, nor with the percentage engaging in anal sex at CAs. MSMW were significantly older than MSM (mean 41.3 vs. $37.4, \mathrm{~F}(1,334)=8.1, \mathrm{p}<.01$ ), and were less likely to visit CAs once or more per week (43\% vs. $57 \%$, $\chi^{2}(1)=4.6, p<.01$ ). Of MSM who had a conversation, $85.5 \%$ used recommended condoms for anal sex at CAs, compared to $73.5 \%$ of men who did not have a conversation $\left(\chi^{2}(1)=2.3\right.$, ns). For MSMW, these percentages werc $88.9 \%$ and $50.0 \%$ respectively. Although this difference is large, it failed to reach statistical significance, which could be a result of the small number of MSMW in this analysis $(\mathrm{N}=21)$.

\section{DISCUSSION}

This study examined sexual behavior of cruising area visitors, and more specifically looked at differences between men who bad spoken with a volunteer about HIV prevention and men who had not met a volunteer at CAs. It was found that CAs are visited by men of all ages, and that the majority visit CAs once or more per week. Almost $20 \%$ of respondents report that they have sex with both men and women. As could be expected it was found that MSMW were less affiliated to the gay community. Relatively high levels of risk behavior were found: almost one in five visitors reported one or more instances of sexual practices at CAs that carry a risk of HIV infection. This result is comparable to research carried out previously at cruising areas in the Netherlands, as well as to research carried out abroad. Risk perceptions for anal sex without ejaculation were lower 
than those for anal sex with ejaculation, and insertive anal sex was considered to carry less risk than receptive anal sex. Furthermore, risk perceptions were related to risk behavior, i.e. men who engaged in a certain risk behavior attached less risk of HIV infection to that behavior than men who did not engage in that behavior. As is so often the case with risk perceptions, it 110 is unclear whether these lower risk perceptions are a result of a lack of information about the true risks or are, as others have suggested, a result of cognitive dissonance reducing strategies (Offir et al., 1993). Nevertheless, these findings may be used to design or improve future interventions at CAs. With respect to unprotected insertive anal sex it was found that men who had sex with both men and women used condoms significantly less frequent than men who only had sex with men, and had a significantly lower intention to use condoms when engaging in anal sex at CAs in the future. Furthermore, this study showed that men who had a conversation about HIV prevention at CAs in 1995 used condoms more consistently with both inserLive and receptive anal sex at CAs than men who had not had a conversation with a volunteer. The use of recommended condoms was also more favorable in the group of men that was reached by the intervention. The frequency of CA visits was not related to condom use frequency. No differences were found for the frequency of receptive oral sex with ejacula(ion on any of the comparisons made.

The high levels of risk-taking sex at CAs stress the importance of continuing to target this group of men with prevention interventions. Since it was found that a significant proportion of CA visitors are men who also bave sex with women, it should be investigated whether current interventions at CAs are designed to address specific issues that are relevant to this subgroup (e.g. using condoms with female partners), and whether volunteers are sufficiently trained in understanding and addressing these issues. The finding that behaviorally bisexual men have less ties with the gay community, suggests that these men have less access to HJV prevention information and related services that are tailored to gay men. Intervening at CAs therefore seems to be an adequate strategy to reach men who do not identify themselves as gay.

The fact that co-operation of volunteers for this study could only be obtained when the anonymity of subjects was guaranteed, posed serious limitations on the design of this study. It would have been more ideal if, for example, a pretest could have been included in order to link pretest scores of $C A$ visitors with their posttest scores. As this was not possible, the decision was made to restrict the study to a post-intervention measurement. Although we took measures to increase the comparability of respondents, the results of this study regarding differences between men who were reached by the intervention and men who were not, have to be interprered with caution. The design does not permit a direct attribution of those differences to the intervention. A second limitation is that a number of volunteers 
who distributed questionnaires for this study also served as volunteers in the intervention that preceded data collection, which may have created demand effects in respondents who recognized volunteers. However, we did instruct our volunteers to present themselves as volunteers for a research project and to refrain from engaging in conversations on HIV prevention issues in the data collection period. This study is a first step in determining the effectiveness of this type of intervention and should be corroborated with future research.

Notwithstanding these considerations, the results of this study identified men who visit cruising areas, and more in particular men who have sex with men and women, as an important target group for prevention activities and also demonstrate that outreach activities at cruising areas are a viable way to reach these men. 



\section{CHAPTER 8}

\section{Reducing HIV infection risks for young gay men:The effects of small-group interventions}

Submitted for publication as:

Hospers, H.]., De Wit. J.B.F., Janssen, M., Stroebe,W., \& Kok, G.J. (1999). Reducing HIV infection risks for young gay men:The effects of small-group interventions. 
There is ample epidemiological evidence that young gay men are at substantial risk of getting infected with HIV (De Wit, 1996). Data from young gay men's cohorts show that a considerable number of men in these cohort are HIV-positive (e.g. over 20\% in San Francisco by 1996, Osmond et al., 1994), with annual seroconversion incidence rates between $1 \%$ and $2.6 \%$ (Dean \& Meyer, 1995; Osmond et al., 1994; Van Griensven et al., 1997). Furthermore, behavioral data from these cohorts - as well as from other behavioral studies that studied young gay men - show high levels of riskbehaviors that may lead to HIV infection (i.e. unprotected insertive and receptive anal intercourse), in particular with primary partners (Crawford et al., 1998; De Vroome et al., 1995; De Wit et al., 1996; Hays et al., 1990; Kegeles et al., 1996; Meyer \& Dean, 1995; Van de Ven, Noble et al., 1997; Vincke et al., 1997).

A linited number of studies have investigated the situational and psychosocial factors that may explain unprotected sexual behavior among young gay men. Factors that have been identified include a positive attitude towards anal sex (De Vroome et al., 1995; Hays et al., 1990; Van de Ven, Campbell et al., 1997), gratification from unprotected anal sex (Hays et al., 1997), a negative attitude towards condoms (De Vroome et al., 1995; Van de Ven, Campbell et al., 1997), low self-efficacy regarding avoiding unprotected sex (Rotheram-Borus et al., 1995), and poor sexual communication skills (Gold \& Skinner, 1992; Hays et al., 1997). The factors that have been found to relate to safe and unprotected sex are mostly derived from prevailing theoretical models that explain behavior and behavior change. These models either focus on the role of knowledge (Fisher \& Fisher, 1992), attitudes and social norms (Fishbein \& Ajzen, 1975), self-efficacy beliefs (Bandura, 1997), or a combination of these factors (Ajzen, 1991; Fisher \& Fisher, 1992).

In the Netherlands a large number of HIV prevention activities have been developed and implemented. These include brochures, outreach at gay venues - such as bars, discos and cruising areas - and small-group activities (Hospers \& Blom, 1998). Small-group activities usually targeted the gay population as a whole. The present study reports on the development and evaluation of HIV prevention which we implemented in existing coming-out groups for young gay men in the Netherlands.

Based on the available literature on determinants of safe and risk-taking behavior, three different approaches were chosen to promote safe sex intentions and behavior. The first program focused primarily on knowledge transfer regarding HIV and AIDS, and influencing attitudes cowards preventive behavior. As Fisher and Fisher (1993) have argued, an information intervention can remedy deficits in information about HN transmission issues. They stress that the information given has to be relevant for the 
target group and relate to behavioral issues that concern target group members. With respect to the attitudinal component of this program, theory suggests that negative attitudes can be weakened by providing strong and cogent arguments (Ajzen \& Fishbein, 1980; Petty \& Cacioppo, 1986). This program also reflects to a large extent the content of brochures that are made for young gay men in the Netherlands. The second program was a

skills training program that was intended to promote safe sex communication and negotiation skills. Skills training programs have proven to be effective among older gay men (Kalichman \& Hospers, 1997), and focus on an important determinant of risk-taking behavior of young gay men. The third program was built around the concept of 'anticipated regret' (Richard, Van der Pligt \& De Vries, 1995). Central in this approach is the assumption that inducing anticipated negative affective consequences of unsafe sex leads to more positive safe sex intentions and safer sex behavior. An experimental study among heterosexual adolescents (Richard et al., 1995) has shown that subjects who were asked to imagine which negative emotions they would feel if they had not used a condom showed a significantly higher intention to use condoms directly after the experiment, compared to a control group. Furthermore, a follow-up showed that subjects in the experimental group engaged in significantly less risk behavior than sexually active subjects in the control condition.

The content of the three programs is described in detail in the method section. The main hypothesis in this study was that the three interventions would significantly increase condom use intentions and condom use behavior compared to a waiting-list control group.

\section{METHOD}

\section{Recruitment}

In the Netherlands, young gay men may join coming-out support groups from two national organizations. In addition, in some larger cities there are independent gay youth groups who organize coming-out support groups. In total there are approximately 45 of these support groups in the Netherlands. These groups, comprising 6 to 12 individuals, meet regularly - in most cases once a month - to share and discuss issues that are related to homosexuality, such as coming-out, meeting other homosexual men, relationships, et cetera. Each group is facilitated by a trained gay volunteer. The invitation to participate in the study was sent to all group facilitators. Group facilitators were informed that their group could participate in a 3- 
hour experimental HIV prevention program especially designed for young gay meu al one of their regular meetings. It was further explained that there were three different programs and a waiting-list control group and that groups which agreed to participate would be randomly assigned to one of the programs or the waiting-list control group, and that the participants would be asked to complete anonymous pretest and posttest questionnaires. The waiting-list control groups received one of the three programs after completion of the posttest questionnaires.

\section{Procedure}

After consulting their group members, facilitators contacted the HIV prevention office of the SAD-Schorer Foundation (the Dutch gay and lesbian support organization) for scheduling a program date. The groups were randomly assigned to one of the four study conditions by administrators of the SAD-Schorer Foundation.

\section{Program development}

Based on the theoretical considerations that were outlined in the introduction, three different programs were developed by the research team in cooperation with FIV prevention experts of the SAD-Schorer Foundation. Each prugram was delivered by an experienced trainer.

Prugran 1 focused primarily on knowledge transfer regarding HIV and ADS, and influencing attitudes towards preventive behavior. In the first part of the program, the trainer provided an up-to-date overview of medical and epidemiological aspects of HIV and AIDS, and explained the HIV transmission mechanism and its connection with sexual risk behaviors. Furthermore, he explained preventive options, including the protective effect of condom use. After the overview, participants could ask questions, and were stimulated to express and discuss uncertainties, doubts, and opinions about several preventive strategies. In doing so, participants were stimulated to draw from their personal experiences with safe and risky sexual behavior. The trainer provided arguments for safe sex behavior when participants expressed negative attitudes toward aspects of preventive behavior and reinforced positive arguments that participants gave during the discussion. Finally, participants were invited by the trainer to express and discuss future safe sex intentions. Program 2 started with a brief presentation on HIV and Ams by the trainer, and included an overview of risk behaviors and preventive measures. Subsequently, the trainer explained the role that safe sex communication and negotiation skills play in accomplishing safe sex intentions. Participants were asked to name circumstances under which they had experienced diffi- 
culties with practicing safe sex. Participants without sexual experience were asked to name circumstances that they imagined would be difficult. After this the participants practiced in triplets - through role plays - communication and negotiation skills in a number of difficult situations. More specifically, participants were asked to resist pressure from a sexual partner to engage in unsafe sex, to communicate their safe sex desires to a sexual partner, and to handle a number of situations in which love, attraction or sexual arousal were relevant threats to preventive behavior. Each triplet took turns playing the roles of actor, sexual partner, and observer. Before the role plays started the participants had received instructions how to effectively provide feedback after role plays and had received feedback forms that summarized the feedback categories and that had to be used during observation. After each role play the actor received feedback from the observer and from the trainer if he had been present at that particular role play. The programs ended with the expression and subsequent discussion of future safe sex intentions.

Program 3 also started with a brief presentation on HIV and ADS by the trainer. As in program 2, it included an overview of risk behaviors and preventive measures. Core of program 3 was the introduction of anticipated regret as a motivator for preventive action. First, participants were asked to mentally simulate a situation that would be threatening to their safe sex intentions, and they had to write down specific circumstances of that situation (e.g. Where would it take place? With whom? What would your feelings be towards that partner?). Next, they were asked to express how they would feel after they would have had unsafe sex in the situation that they had described. After each participant had told the group how he would feel after unsafe sex, participants were given the opportunity to ask each other questions, and discuss what had been said. Subsequently, participants were asked to write down and later discuss the steps that they would have to take to maintain sexually safe in high-risk situations. Subsequently, participants were asked to imagine how they would feel afterwards if they would have remained safe during the sexual encounter. The program ended with the expression and subsequent discussion of future safe sex intentions.

A protocol was made for each program. The protocol described each program component, the sequence of components, and the time that could be spent to each component.

\section{Trainers}

Six young gay men were selected as trainers. All were experienced in HIV education, had worked as facilitator or trainer with small groups, and had a basic understanding of behavior change processes. The trainers were instructed during a two-day training program by the HIV training expert of the 
SAD-Schorer Foundation, who acted as their supervisor during the whole intervention period. First, they received detailed background information on each program and its components. Subsequently, each program was then taken through from beginning to end.

During the intervention period, each trainer could contact the supervisor for additional information, instruction or support. In addition, three plenary sessions with all trainers, the supervisor and the researchers were organized, where the progress of the project was evaluated, and where the trainers exchanged experiences, and received feedback or help on specific problems that had arisen during program execution.

\section{Effect evaluation questionnaires}

A pretest questionnaire was handed out at the beginning of the group meetings when the programs were run. A posttest questionnaire was sent to the group facilitator three months after the program. The group facilitator was responsible for handing out and collecting the questionnaires.

To enable matching pretest and posttest questionnaires, respondents were asked to provide the first letter of their first name, the first letter of the city of birth, and the month and year of birth.

In the pretest questionnaire, respondents had to indicate their age, educational level, religious affiliation, and household situation. Next, subjects were asked to respond to questions regarding their sexual history, including age at first sexual encounter, age at first experience with anal sex, number of life-time partmers, and HIV test taking and HIV test results.

In both the pretest and posttest questionnaires, subjects were asked to provide a detailed description of their sexual activity in the preceding three months with primary and casual partners, including information on the frequency of engaging insertive and receptive anal sex, and for both behaviors an estimate of the frequency of condom use. Men who reported primary partners were asked whether or not their partner had had an HIV test, and whether they knew the test result. The questionnaire also asked information on the type of agreement the couple had regarding sex with casual partners (no agreement, monogamous, open without anal sex, open with anal sex). Finally, subjects with a primary partner were asked to rate their intention to use condoms for anal sex with their primary partner on a 7 -point scale ( $1=$ low intention, $7=$ high intention). Respondents without a primary partner at pretest and/or posttest were asked the same intention, but for a future primary partner. All respondents were asked their intentions to use condoms with casual partners. 
At the end of the program, trainers, participants, and group facilitators completed a process evaluation questionnaire. Trainers were asked whether the sequence of the program components was delivered as intended, and whether the time spent at each component was within the advised time frame.

Participants were asked to rate on 3-point scales whether the information the trainers gave was credible, whether the trainers encouraged respondents to ask questions, and whether the intervention had been useful and had met their expectations.

Both participants and group facilitators were asked to evaluate seven trainer characteristics on 5-point scales (not serious-serious, impersonal-personal, indirect-direct, unpleasant-pleasant, not imposing-imposing, uninformedknowledgeable, casual-formal).

Group facilitators were asked to rate their group on a number of communicative variables at the beginning and at the end of the program on 5-point scales (silent-talkative, uninterested-interested, skeptical-accepting, tenserelaxed, indolent-lively, not responsive-responsive). Finally, group facilitators were asked to rate the compatibility between group, program, and trainer on 10 -point scales.

\section{RESULTS}

\section{Respondents}

A total of 33 support groups participated in the study, and 282 young gay men completed the pretest questionnaire. Respondents mean age was 25.2 (sd: 3.5 ). Almost half (47.7\%) of the respondents reported to be religious (45.5\% catholic, $35.7 \%$ protestant, $18.8 \%$ other). The majority $(61.6 \%)$ had a high educational level (university/college), $27.5 \%$ a medium educational level (higher secondary high school/vocational training), and 10.8\% a low educational level (elementary school/lower secondary school). Twenty-seven per cent lived with their parents, $29.0 \%$ lived in student houses, $39.9 \%$ lived on their own, and $7.1 \%$ lived together with their primary partner.

The posttest questionnaire was returned by 223 men (response rate: $79.1 \%$ ). Comparing men who completed both questionnaires with men who did not return the posttest questionnaire yielded no statistically significant differences in age, educational level, or household situation. A higher proportion of nonresponders reported to be religious $\left(65.5 \%\right.$ vs. $\left.43.0 \%, \chi^{2}(1)=9.3, p<.01\right)$. 
Three respondents were excluded from the analyses because of missing values on essential variables. The breakdown of the remaining 220 respondents to programs was as follows: 49 in the Waiting-List Control Group (WLC), 56 in the Information Program (IP), 53 in the Skills Program (SP), and 62 in the Anticipated Regret Program (ARP).

\section{Pretest data}

\section{Sexual history}

One in ten respondents had no experience with sex with men (see Table 8.1). Sexually experienced men reported a mean of 22.1 lifetime sex partners (sd: 54.6, median: 6, range 1-500). Among sexually experienced men, $66.2 \%$ reported any experience with anal sex. A higher proportion of men in relationships had experience with anal sex compared to single men $\left(77.7 \%\right.$ vs. $\left.48.7 \%, \chi^{2}(1)=19.5, \mathrm{p}<.001\right)$. Among men who had experience with anal sex, $35.1 \%$ reported that they had always used condoms with anal sex, $53.4 \%$ inconsistent, and $11.5 \%$ never. Consistency of condom use was unrelated to age, relationship status, and educational level. One in four (23.3\%) respondents had ever conducted an HIV test. All test results were reported to be negative.

\section{Casual partners}

About one third of respondents (35.5\%) reported sex with casual partners in the three months preceding assessment (see Table 8.1).

The mean number of casual sex partners in that period was 2.9 (sd: 3.1 , median: 2, range 1-20). Among men with casual parmers, $23.1 \%$ reported engaging in receptive and/or insertive anal sex with casual partners, and $20.5 \%$ reported being in a primary relationship. From the 18 men who reported anal sex, 6 had not used condoms consistently.

\section{Primary partner}

Almost half (46.8\%) of respondents reported that they were in a primary relationship in the three months preceding assessment (see Table 8.1). However, 30 primary relationships $(29.1 \%$ ) had ended at assessment. The mean relationship duration of continuing relationships was 19 months (sd: 23.4, median: 12, range 1-132). One in three (35.6\%) relationships lasted less than six months. Having a primary partner was unrelated to age and educational level.

Among men with a primary partner in the preceding three months $(\mathrm{N}=103) .55(53.4 \%)$ reported engaging in anal sex in the preceding three montles $(69.1 \%$ insertive and receptive, $12.7 \%$ receptive only, $18.2 \%$ insertive only). Of men who reported anal sex with their primary partmer $(N=55), 34(61.8 \%)$ bad not consistently used condoms. However, six 
Experience with sex with men ( $N=220)$

$\begin{array}{lr}\text { No } & 22(10.0 \%) \\ \text { Yes } & 198(90.0 \%)\end{array}$

Experience with and sex $(\mathrm{N}=198)$

No

Yes

$131(66.2 \%)$

Sex with casual portners preceding three months ( $N=78$ )

No anal sex $\quad 60(76.9 \%)$

Anal sex $\quad 18(23.1 \%)$

- consistent condom use

$12(66.6 \%)$

- inconsistent condom use

$6(33.3 \%)$

Sex with primary partners preceding three months $(N=103)$

No anal sex

$48(46.6 \%)$

Anal sex

$55(53.4 \%)$

- consistent condom use

$21(38.2 \%)$

- inconsistent condom use $34(61.8 \%)$

respondents who reported unprotected anal sex with their primary partner also reported that they and their primary partner had taken an HIV test with reported negative results. For these six men, unprotected anal sex with their primary parmer was coded safe. Thus, among men who engaged in anal sex with their primary partner, the proportion of men who had unsafe sex (i.e. unprotected anal sex without HIV tests) was $50.9 \%$. For the remainder of the results section pertaining to sex with primary parmers we will focus on unsafe sex instead of unprotected sex.

Unsafe sex with primary partners was related to relationship duration $\left(\chi^{2}(1)=7.7, \mathrm{p}<.01\right)$ : among men in shorter relationships ( $1-6$ months), $14.3 \%$ reported unsafe sex, compared to $70.6 \%$ in knger-lasting relationships (>7 months).

Overall risk levels and behavioral intentions

Considering the total study population ( $N=220), 15 \%$ reported unsafe anal sex at pretest (12.3\% with primary partners, $2.3 \%$ with casual partners, and $0.5 \%$ with both primary and casual partners). These different proportions for primary and casual partners are also reflected in the behavioral intention measures. The mean intention to use condoms with primary partners was 
significantly lower than with casual partners (5.7 vs. $6.5 ; \mathrm{t}(217)=7.3$, $\mathrm{p}<.001)$. Men with experience with anal sex had significantly lower intentions than men without experience (5.4 vs. $6.2 ; \mathrm{t}(216)=11.7, \mathrm{p}<.001$ ). The condom use intention regarding casual partmers was unrelated to experience with anal sex.

\section{Program effects: primary partner}

Table 8.2 shows the changes with respect to sex with primary partners. Among men who did not report anal sex at pretest $(N=45)$, posttest data show that 13 had split up, 20 had continued refraining from anal sex, 8 reported safe anal sex, and 4 reported unsafe anal sex. Among men who reported safe anal sex at pretest $(\mathrm{N}=28)$, posttest data show that 6 had split up, 3 reported no anal sex, 18 reported continued safe anal sex, and 1 reported unsafe anal sex. Finally, among men who reported unsafe anal sex at pretest $(\mathrm{N}=30)$, posttest data show that 4 had split up, 2 reported no anal sex, and 24 reported continued unsafe anal sex.

Nineteen men started a primary relationship between pretest and posttest. Of these men, 13 reported no anal sex, 5 reported safe anal sex, and 1 reported unsafe anal sex at postlest.

To assess the effect of the intervention programs on sexual behavior with primary partners, men were selected who reported a primary partner at pretest or posttest. A dichotomous change variable was created that differentiated men who remained or became safe between pretest and posttest from men who remained or became unsafe. Among these 122 men, 28 (23.0\%) remained or became unsafe with their primary partner (see Table 8.3). Restricting the analysis to men who reported anal sex ( $N=76), 36.8 \%$ remained or became unsafe. There were no significant differences in proportions between intervention programs.

All respondents rated their behavioral intention to use condoms with present or future primary partners. There was a mean 0.20 decrease (from 5.7 to 5.5) in this behavioral intention between pretest and posttest. The mean intention change scores did not differentiate between programs.

Additional exploratory analyses were conducted to investigate whether changes in behavior or behavioral intentions could be explained by interactions between intervention program and experience with anal sex or being in a primary relationship or not. None of these analyses resulted in differential effects in behavior or behavioral intentions that could be attributed to intervention programs. 
significantly lower than with casual partners (5.7 vs. $6.5 ; t(217)=7.3$, $\mathrm{p}<.001)$. Men with experience with anal sex had significantly lower intenvous than men without experience ( 5.4 vs. $6.2 ; \mathrm{t}(216)=11.7, \mathrm{p}<.001$ ). The condom use intention regarding casual partners was unrelated to experience with anal sex.

\section{Program effects: primary partner}

Table 8.2 shows the changes with respect to sex with primary partners. Among men who did not report anal sex at pretest $(\mathrm{N}=45)$, posttest data show that 13 had split up, 20 had continued refraining from anal sex, 8 reported safe anal sex, and 4 reported unsafe anal sex. Among men who reported safe anal sex at pretest $(\mathrm{N}=28)$, posttest data show that 6 had split up, 3 reported no anal sex, 18 reported continued safe anal sex, and 1 reported unsafe anal sex. Finally, among men who reported unsafe anal sex at pretest $(\mathrm{N}=30)$, posttest data show that 4 had split up, 2 reported no anal sex, and 24 reported continued unsafe anal sex.

Nineteen men started a primary relationship between pretest and posttest. Of these men, 13 reported no anal sex, 5 reported safe anal sex, and 1 reported unsafe anal sex at posttest.

To assess the effect of the intervention programs on sexual behavior with primary partners, men were selected who reported a primary parmer at pretest or posttest. A dichotomous change variable was created that differentiated men who remained or became safe between pretest and posttest from men who remained or became unsafe. Among these 122 men, $28(23.0 \%)$ remained or became unsafe with their primary partner (see Table 8.3).

Restricting the analysis to men who reported anal sex $(\mathrm{N}=76), 36.8 \%$ remained or became unsafe. There were no significant differences in proportions between intervention programs.

All respondents rated their behavioral intention to use condoms with present or future primary partners. There was a mean 0.20 decrease (from 5.7 to 5.5) in this behavioral intention between pretest and posttest. The mean intention change scores did not differentiate between programs.

Additional exploratory analyses were conducted to investigate whether changes in behavior or behavioral intentions could be explained by interactions between intervention program and experience with anal sex or being in a primary relationship or not. None of these analyses resulted in differential effects in behavior or behavioral intencions that could be attributed to intervention programs. 
Table 8.4 Risk behavior with primary partners at pretest and posttest ( $N=78)$.

Posttest

No primary No anal sex Safe anal sex Unsafe anal sex N partmer

Pretest

No anal sex 16 26 13 60

Safe anal sex

Unsafe anal sex

0

4

2

7

12

2

6

Table 8.5 Proportion of men who remained or became unsafe with casual partners between pretest and posttest broken down by intervention program.

\begin{tabular}{lccccc} 
& WLC & IP & SP & ARP & Total \\
$\begin{array}{l}\text { Men with casual partmers } \\
(\mathrm{N}=111)\end{array}$ & $9.5 \%$ & $9.7 \%$ & $13.6 \%$ & $5.4 \%$ & $9.0 \%$ \\
$\begin{array}{l}\text { Men practicing anal sex } \\
(\mathrm{N}=44)\end{array}$ & $25.0 \%$ & $25.0 \%$ & $23.1 \%$ & $18.2 \%$ & $22.7 \%$ \\
\hline
\end{tabular}

$10(9.0 \%)$ remained or became unsafe with casual partners (see Table 8.5 ). Restricting the analysis to men who reported anal sex $(\mathrm{N}=44), 22.7 \%$ remained or became unsafe. Again, there were no significant differences in proportions between intervention programs.

The analysis on the change in behavioral intention to use condoms with casual partmers did not show a main effect of intervention program. Similar to the analyses with primary parmers, additional exploratory analysis were conducted to investigate whether changes in behavior or behavioral intentions could be explained by interactions between intervention program and experience with anal sex or salience (i.e. reporing casual partners or not). Entering experience with anal sex into the analysis resulted in a significant interaction between intervention program and experience with anal sex $(\mathrm{F}(3,214)=3.7, \mathrm{p}<.05$; see Table 8.6 for means).

Contrast analyses among men without experience with anal sex, with the Waiting-List Control group as the reference category, showed a significant overall main effect for intervention program $(\mathrm{F}(3,214)=3.7, \mathrm{p}<.01)$. Only the Skills Program differed significantly from the Waiting-List Control group $(\mathrm{t}=2.1, \mathrm{p}<.05)$. As can been seen in Table 8.6, especially the Skills Program was responsible for an increase in the intention to use condoms with casual 
Table 8.6 Change in behavioral intention to use condoms with casual partners broken down by intervention program and experience with anal sex.

\begin{tabular}{lrrrrr}
\hline & WLC & IP & SP & ARP & Total \\
\cline { 1 - 4 } & & & & & \\
Experience with anal sex & -.05 & -.36 & +.60 & -.15 & .00 \\
No & -.28 & +.24 & -.06 & +.26 & +.07 \\
Yes & -.18 & .00 & +.19 & +.13 & +.04 \\
Total & & & & & \\
\hline
\end{tabular}

partners. Similar contrast analyses among men who had experience with anal sex resulted in a main effect of intervention program that was marginally significant $(F(3,214)=2.1, \mathrm{p}<.08)$. Among these men, the Information Program and the Anticipated Regret Program differed significantly from the Waiting-List Control group $(t=2.1, p<.05$, and $t=2.3, p<.05$ respectively). Table 8.6 shows that the Information Program and the Anticipated Regret Program resulted in an increase in behavioral intention whereas the Waiting List Control group showed a decrease.

\section{Process evaluation}

At the end of each intervention program delivery, trainers, participants, and group facilitators completed a process evaluation questionnaire. The data from the trainers indicated that the sequence of program components was delivered as intended, while the time spent at each component was in almost all instances within the advised time frame. The only problem frequently reported by trainers was that participants had to leave before the end of the program (average 2 per group meeting).

The participants' data showed high appraisal for the intervention in terms of usefulness (mean 2.4, range 1-3), and the extent to which programs net expectations (mean 2.4, range $1-3$ ).

The rating by participants and facilitators of trainer characteristics (not serious-serious, impersonal-personal, indirect-direct, unpleasant-pleasant, not imposing-imposing, uninformed-knowledgeable, casual-formal). All characteristics were rated with a mean score of 4.0 or higher (range 1-5) in the favorable direction, except the casual-formal measure which was rated 3.3. The information the trainers gave was rated very credible (mean 2.9, range $1-3$ ), and the trainers were evaluated very positive on facilitating respondents to ask questions (mean 2.9, range 1-3).

The rating by group facilitators of communicative variables of their group at the beginning and at the end of the program (silent-talkative, uninterested.- 
interested, skeptical-accepting, tense-relaxed, indolent-lively, not responsiveresponsive), revealed that at the start of the program all measures scored around the midpoint of the scale (3.0), with the exception of the uninterested-interested measure which was rated 3.9. By the end of the program, all measures except the uninterested-interested measure had significantly increased with means around 4.0.

Finally, the rating by group facilitators of the compatibility between group, program, and trainer, showed that the compatibility between group and program was rated 7.2, between group and trainer 7.6, and between trainer and program 7.8 (range 1-10).

For all evaluations in the program evaluation we checked - if applicable whether there were differences between trainers or programs. In no instance these differences were found.

\section{DISCUSSION}

This study implemented three different HIV prevention interventions for young gay men who participated in coming-out groups in the Netherlands, and aimed to increase condom use intentions and to reduce sexual risk behavior. With respect to sex with primary parmers none of the interventions seemed to be effective in bringing about substantial changes in intentions or sexual risk behavior. Only a few men actually changed their behavior with primary partners between pretest and posttest, both in safe and unsafe directions. Furthermore, the interventions did not result in higher intentions to use condoms with primary partners. Yet, the results of this study showed that many young gay men engage in unsafe sex with their primary partners. In addition, this study also showed that there was a bigh turnover in primary relationships. In the six months that we measured, half of the primary relationships had broken up. These results confirm the concerns that other authors have expressed regarding elevated risks of HIV uransnission within primary relationships (Ekstrand, 1992; Gold, 1996). It appears that in order to increase sexual safety within primary relationships, other interventions are needed than the ones that were implemented and evaluated in this study. Since coming-out groups comprised both men with and without primary partners, the decision was made to address safe sex issues in a general sense, without making a difference between sex with primary partners and sex with casual partners. Hindsight suggests that future interventions may want to focus more on sex with primary partners. Interventions could explicitly focus on the ways young gay men change from safe to unsafe sex in primary relationships and raise awareness of the 
potential dangers of this process. Preparing young gay men for this process may be an important component of future interventions. Also, motivating young gay men to extend the period during which condoms are used for anal sex may be an effective strategy to deal with the high rate of unsafe sex in young gay men's primary relationships. The observed resistance to cognitive and behavioral change also suggest that future interventions may need to take more time, and may benefit from targeting both partners instead of only one of the two as was mostly the case in the present study. The finding that the probability of unsafe sexual behavior increases as relationships progress raises the question of the feasibility of a prevention message that centers on condom use as the only strategy for protection. Several authors have suggested that one may accept the apparently natural course of many primary relationships towards unprotected sex and that prevention should focus on increasing safety by guiding this process (Kippax et al., 1997). This so-called 'negotiated safety' strategy advises men in primary relationships who consider unprotected sex to conduct HTV tests, and to negotiate and agree upon arrangements about sex within and outside the relationship. At the end of this process men in HIV-negative seroconcordant relationships may decide to dispose of condoms for anal sex with their primary partmer. At this time, little is known about the advantageous and disadvantageous effects of such a prevention strategy. Future research in countries where this strategy has been implemented may answer the question to what extent it is befitting young gay men's primary relationships.

The comparison of pretest with posttest measures shows that the majority of men who reported casual parmers $(91 \%)$ had safe sex with these partners, primarily through refraining from anal sex. Therefore, we were unable to assess the effects of the interventions at a behavioral level. Since it is unlikely that future studies among young gay men in coming-out groups in the Netherlands will be able to recruit more men than were recruited in this study, both a more simple experimental design (e.g. one intervention and one control group) as well as longer follow-up periods to measure sexual behavior with casual partners may allow evaluations at the behavioral level. With respect to the behavioral intention to use condoms with casual partners the study revealed that men who had no experience with anal sex benefited from the intervention that focused on sexual communication skills, while men with experience with anal sex showed a marginally significant increase in their behavioral intention after exposure to the information intervention and the anticipated regret intervention. One possible explanation for these differential effects may be that men without experience with anal sex can benefit more from communication skills training regarding condom use with anal sex than men who have already been in situations where these skills were needed. Men with experience with anal sex benefited from the information intervention. It may be that this intervention effectively addressed misperceptions about risk behaviors among men who 
had experience with anal sex, while among men without experience with anal sex, accurate knowledge may in fact have guided a decision not to engage in anal sex. The finding that the anticipated regret intervention primarily had an effect among men with experience with anal sex may be understood from the perspective that these men were - through their expe128 rience - more able to envision an unsafe encounter and the negative emotions that result from such an experience. However, these possible explanations are speculative and should be tested in future research. Another finding that is worth mentioning is that $10 \%$ of the respondents had no experience with sex with men. This shows that - at least in the Netherlands - self-identification as homosexual and acting upon that notion by joining a coming-out group, not necessarily implies that one has sexual experience with men. Furthermore, while studies among older gay men usually show that almost all men have experience with anal sex (e.g. De Wit \& Van Griensven, 1994), the present study revealed that one third of respondents had not yet engaged in anal sex. This relative inexperience seems to be another argument to develop interventions specifically for this target group. Those programs may include issues around the initiation of sex with men and initiation of anal sex, especially in the context of primary relationships.

The process evaluation showed satisfying ratings of program content and program delivery. The trainers were seen as credible, and they were able to create an atmosphere which allowed participants to speak freely about sensitive issues.

A number of limitations of the present study are noteworthy. First, since we recruited most of the existing coming-out groups the respondents are most likely representative for young gay men who join these groups. However, they are probably not representative for young gay men in general, which limits generalizing these results to other subpopulations of young gay men. Not only did most participants have a high educational level, they also were motivated to join these coming-out groups to discuss issues and share experiences regarding their homosexual feelings. Second, this study did not distinguish single men from men in primary relationships while hindsight suggests that such a distinction might have been more effective in dealing with particular safe sex issues related to sex with primary partners and to sex with casual partners. Finally, the relatively low level of unsafe sex with casual partners did not permit conclusions about the behavioral effects of the interventions. Notwithstanding these limitations, we believe that the results of this study can stimulate future research and practice that aims at curtailing the spread of HIV among young gay men. 
Adib, S.M., \& Oscrow, D.G. (1991). Trends in HIV/ADS behavioural research among homosexual and bisexual men in the United States: 1981-1991. AIDS Core, 3, 281-287.

Adib, S.M., Joseph, J.G., Ostrow, D.G., \& James, S.A. (1991). Predictors of relapse in sexual practices among homosexual men. AlDS Education and Prevention, 3, 293-304.

Ajzen. I. (1988). Attitudes, personality, and behavior. Milton Keynes, UK: Open University Press.

Ajzen, I. (1991). The theory of planned behavior. Organizational Behavior and Human Decision Processes, 50, 179-211.

Ajzen, I., \& Fishbein, M. (1980). Understanding attitudes and predicting social behavior. Englewood Cliffs, NJ: Prentice Hall.

Algra, Y. (1988). Jack-off parties, een nieuwe methode ter bevordering van de homoemancipatie en ter voorkoming van AIDS. Tijdschrift voor Seksuologie, 12, 123-126.

Aron, A., Paris, M., \& Aron, E.N. (1995). Falling in love: Prospective studies of self-concept change. Joumal of Personality and Social Psychology, 69, $1102-1112$.

Bandura, A. (1986). Social foundations of thought and actions. Englewood Cliffs, NJ: Prentice Hall.

Bandura, A. (1989). Perceived self-efficacy in the exercise of control over AIDS infection. In V.M. Mays, G.W. Albee, \& S.F. Schneider (Eds.), Primary Prevention of AIDS (pp. 128-141). Newbury Park, CA: Sage Publications.

Bandura. A. (1997). Self-efficacy: The exercise of control. New York: Freeman.

Bandura, A. (1998). Healch promotion from the perspective of social cognitive theory. Psychology and Healih, 13, 623-649.

Basch, C.E. (1987). Focus group interview: An underutilized research technique for improving theory and practice in health education. Health Education Quarterly, 14, 411-448.

Bauman, L.J., \& Siegel, K. (1987). Misperceptions among gay men of the risk for ADS associated with their sexual behavior. Joumal of Applied Social Psychology, 17, 329-350.

Becker, M.H., \& Joseph, J.G. (1988). ADS and behavioral change to reduce risk: A review. American Joumal of Public Health, 78, 394-410.

Blake, S.M., Sharp, E.S., Temoshok, L., \& Rundell, J.R. (1992). Methodological considerations in developing measures of HIV risk-relevant behaviors and attitudes: An empirical illustration. Psychology and Health, 6, 265-280.

Bochow, M. (1990). ADS and gay men: Individual strategies and collective coping. Europem Sociological Review, 6, 181-188.

Boulton, M., McLean, J., Fitzpacrick, R., \& Har, G. (1995). Gay men's accounts of unsafe sex. AIDS Care, 7, 619-630.

Buchanan, D.R., Poppen, P.J., \& Reisen, C.A. (1996). The nature of partner relationship and AIDS sexual risk-taking in gay men. Psycholagy and Healtb, 11, 541-555.

Burcau of the Census (1992), 1990 Census of Population and Housing: Summary of Social, Economic, and Housing Characteristics. Washington, DC: Government Printing Office.

Camden and Islington Community Health Services (1995). Goy men, Sex \& Relationships. London: Author.

Catania, J.A., Gibson, D.R., Chirwood, D.D., \& Coates, T.j. (1990). Methodological problems in AIDS behavioral research: Influences on measurement error and participation bias in studies of sexual behavior. Psychological Bulletin, 108, 339-362. 
Catania, J.A., Gibson, D.R., Martin, B., Coates, T.J., \& Greenblatt, R.M. (1990). Response bias in assessing sexual behaviors relevant to HIV cransmission. Evaluation and Program Plenning, 13, 19-29.

Catania, J.A., Kegeles, S.M., \& Coates. T.J. (1990). Towards an understanding of risk behavior: An AIDS risk reduction model (ARRM). Health Education Quanerly, 17, 53-72. 130 Centers for Disease Control (1985). Self-reported behavioral changes among homosexual and bisexual men. Journal of the American Medical Association, 254, 2537-2538.

Centers for Disease Control (1989). Trends in gonorrhea in homosexually accive men King County, Washington. Morbidity and Mortality Weekly Report, 27, 762-764.

Chmiel, J.S., Detels, R., Kaslow, R., VanRaden, M., Kingsley, L.A., Brookmeyer, R., \& the Multicenter AIDS Cohor Study Group (1987). Factors associated with prevalent human immunodeficiency virus (HIV) infection in the multicenter ADS cohort study. American Joumal of Epidemiology, 126, 568-577.

Coates, R.A., Calzavara, L.M., Soskolne, C.L., Read, S.E., Fanning, M.M., Shepherd, F.A. Klein, M.H., \& Johnson, J.K. (1988). Validity of sexual histories in a prospective study of male sexual contacts of men wich AIDS or an ADS-related condition. American Joumal of Epidemiology, 128, 719-728

Connell, R.W., Crawford, J., Dowsett, G.W., Kippax, S., Sinnott, V., Rodden, P., Berg, R., Baxter, D., \& Watson, L. (1990). Danger and context: Unsafe anal sexual practice among homosexual and bisexual men in the AIDS crisis. Australian and New Zealand Joumal of Sociology, 26, $187-208$.

Connell, R.W., \& Kippax, S. (1990). Sexuality in the ADS crisis: Patterns of sexual practice and pleasure in a sample of Australian gay and bisexual men. The Journal of Sex Research, 27. 167-198.

Crawford, J., Kippax, S., Rodden, P., Donohue, S., \& Van de Ven, P. (1998). Male Call 96. National telephone survey of men who hove sex with men. Sydney, Ausuralia: National Centre in HIV Social Research.

Dallas, M. (1990). Onveilige sex bij homomannen. Utrecht, NL: Universiteit Utrecht.

Davies, P.M., Hickson, F.C.I., Weatherburn, P., \& Hunt, A.J. (1993). Sex, Gay Men and AIDS. London: Falmer Press.

Davies, P., \& Weatherbum, P. (1991). Towards a general model of sexual negotiation. In P. Aggleton, G. Hart, \& P. Davies (Eds.), AIDS: Responso; interventions, and care (pp. $111-125$ ). London: Falmer Press.

Davies, P.M., Weacherbum, P., Hunt, A.J., Hickson, F.C.I., McManus, T.J., \& Coxon, A.P.M. (1992). The sexual behaviour of young gay men in England and Wales. AIDS Care, 4, 259-272.

Dean, L. \& Meyer, I. (1995). HIV prevalence and sexual behavior in a cohort of New York City gay men (aged 18-24). joumal of Acquired Immune Deficiency Syndromes and Humon Retrovirolongy, 8, 208-211.

De Groor, F. (1995). Gepicnd gedrug op de baan. Groningen. NL: Universiteit Groningen. DeGuzman, M.A., \& Ross, M.W. (1999). Assessing the application of HIV and AIDS related education and counselling on the Internet. Patient Educotion and Counseling. 36. 209-228.

De Jong, M. (1994). Het baanproject: Landelijke evaluatic 1993. Amsterdam: SAD-Schorerstichting 
De Kooning. D. (1992). Evaluatieunderzoek aidsfolders 'Homoseks \& aids' a 'Stand van when'. Utrecht. NL: Universiteil Utrecht.

De Kooning, D., \& Sandfort, Th.G.M. (1993). Verslag evaluatie-ondernetk Safe Ser Videoshow 2. Utrecht, NL: Universiteit Utrecht.

Detels, R., Fahey, J.F., Schwartz, K., Greene, R.S., Visscher, B.R., \& Gotlieb, M.S. (1983). Relation between sexual practices and T-cell subsets in homosexually active men. lancel, $\mathrm{i}$, 609-611.

De Vroome, E.M.M. (1994). AIDS-voorlichting onder homoseksuele mannen. Diffussie vm veilig vrijen in Nederland (1986-1989). Amsterdam: Thesis Publishers.

De Vroome, E.M.M., Sandfort, T.G.M., Van den Bergh, H.S.P., Keet, I.P.M., \& Van den Hoek, J.A.R. (1995). Jonge homoseksuele mannen: Psychosociale determinanten van onveilig seksueel gedrag. Tijdschrift voor Seksuologie, 19, 4-18.

De Wit, J.B.F. (1994). Prevention of HIV infection among homosexual men. Behovior change and behavinral determinants. Amsterdam: Thesis Publishers.

De Wit, J.B.F. (1996). The epidemic of HIV among young homosexual men. AIDS, 10, S21 S25.

De Wit, J.B.F., De Vroome, E.M.M., Sandfort, T.G.M., \& Van Griensven, G.J.P. (1997). Homosexual encounters in different venues. Intemational Joumal of STD and AIDS, 8, 130-134.

De Wir, J.B.F., De Vroome, E.M.M., Sandfor,, T.G.M., Van Griensven, G.J.P., Metselaar, C., \& Tielman, R.A.P. (1991). De relatie tussen coping-stijl, health locus of control en seksueel gedrag in een cohort homoseksuele mannen. Godrag en Gezondheid, 9, 88-92.

De Wir, J.B.F., Hospers, H.J., \& Janssen, M. (1996). Risk for HIV-infection among young gay men. XI International Conference on ADS. Vancouver, Canada [Absuract WeC3486].

De Wit, J.B.F., Sandfort, T.G.M., De Vroorae, E.M.M., Van Griensven, G.J.P., Kok, G.J., Coutinho, R.A., \& Tielman, R.A.P. (1992). Serieel cross-sectionele en longitudinale veranderingen in seksueel gedrag in een cohort homoseksuele mannen in Amsterdam in de periode 1984-1988. Tijdschrift voor Sociale Gezondheidszorg, 70, 457-462.

De Wit, J.B.F., Sandfort, T.G.M., De Vroome, E.M.M., Van Griensven, G.J.P., \& Tielman, R.A.P. (1991). Determinanten van veilig en onveilig seksueel gedrag bij mannen met homorseksuélè contacten; een cross-sectionele verkenning. In R.W. Meertens, A.P. Buunk. \& R. Van der Vlist (Eds.), Sociale psychotogie \& voorlichting en maatschappelijke problemen (pp. 29. 40). Den Haag: VUGA.

De Wit, J.B.F., Teunis, N., Van Griensven, G.J.P., \& Sandfort, T.G.M. (1994). Behavioral risk-reduction strategies to prevent HIV infection among homosexual men: A grounded theory approach. AIDS Education and Prevention, 6, 493-505.

De Wit, J.B.F., Van den Hoek, J.A.R., Sandfort, T.G.M., \& Van Griensven, G.J.P. (1993). Incrcase in unprotected anogenital intercourse among homosexual men. American Joumal of Public Health, 83, 1451-1453.

De Wit, J.B.F., \& Van Griensven, G.J.P. (1994). Tirne from safer to unsafe sexual behaviour among homosexual men. AIDS, 8, 123-126.

De Zwart, O., \& Sandfort, Th.G.M. (1993). 'Gebrik een condoom of neuk niet'. Een kwolitatid onderzoek naor de wijze waarop de nevenschikkende boodschap kan worden vormgegeven. Utrecht, NL: Universiteit Utrechs. 
Doll, L.S., \& Beeker, C. (1996). Male bisexual behavior and HIV risk in the United States: Synthesis of research with implications for behavioral interventions. AIDS Education and Prevention, 8, 205-225.

Doll, L.S., Petersen, L.R., White, C.R., Johnson, E.S., Ward, J.W., \& The Blood Donor Study Group (1992). Homosexually and nonhomosexually identified men who have sex with men: A behavioral comparison. The Joumal of Sex Reseurch, 29, 1-14.

Doombos, R. (1992). Safe and unsafe sex between men. Utrecht, NL: Universiteit Utrecht.

Ekstrand, M.L. (1992). Safer sex maintenance among gay men: Are we making any progress? AIDS, 6, 875-877.

Ekstrand, M.L., \& Coates, T.J. (1990). Maintenance of safer sexual behaviors and predicrors of risky sex: The San Francisco men's health study. Americen Joumal of Public Heulth, 80 , 973-977.

Emmons, C.A., Joseph, J.G., Kessler, R.C., Wortman, C.B., Montgomery, S.B., \& Ostrow, D.G. (1986). Psychosocial predictors of reported behavior change in homosexual men at risk for AIDS. Health Education Quarterly, 13, $331-345$.

Fishbein, M., \& Ajzen, I. (1975). Belief, attitude, intention, and behavior: An introduction to theory and research. Reading, MA: Addison-Wesley.

Fishbein, M., Chan, D.K-S., O'Reilly, K., Schnell, D., Wood, R., Beeker, C., \& Cohn, D. (1992). Attitudinal and normative factors as determinants of gay men's intentions ro perform AIDS-related sexual behaviors: A multisite analysis. Joumal of Applied Social Psychology, 22, 999-1011.

Fisher, J.D. (1988). Possible effects of reference group-based sucial influence on ADS-risk behavior and AIDS prevention. American Psychologist, 43, 914.920.

Fisher, J.D., \& Fisher, W.A. (1992). Changing ADS-risk behavior. Psychotogical Bulletin, 111. 455-474.

Fisher, W.A., \& Fisher, J.D. (1993). A general social psychological model for changing ADDS risk behavior. In J.B. Pryor \& G.D. Reeder (Eds.), The social psycholing of HIV infection (pp. 127-153). Hillsdale, NJ: Lawrence Erlbaum.

Fisher, W.A., Fisher, J.D., \& Rye, B.J. (1995). Understanding and promoting AIDSpreventive behavior: Insights from the theory of reasoned action. Health Psychology, 14, 255-264.

Fitzpatrick, R., Boulton, M., Hart, G., Dawson, J., \& McLean, J. (1989). High risk sexual behaviour and condom use in a sample of homosexual and bisexual men. Health Trends, 21. $76-79$.

Fitzpatrick, R., Mclean, J., Boulton, M., Hart, G., \& Dawson, J. (1990). Variation in sexual behaviour in gay men. In P. Aggleton, P. Davies, \& G. Hart (Eds.), ADDS: Individual, cultural and policy dimensions (pp.121-132). London: Falmer Press.

Flowers, P., Sheeran, P., Beail, N., \& Smith, J.A. (1997). The role of psychosocial factors in HIV risk-reduction among gay and bisexual men: A quanticative review. Psycholoxy and Health, 12, 197-230.

Gebhardt, M., Rickenbach, M., Egger, M., \& the Swiss HIV Cohort Study (1998). Impact of antirecroviral combination therapies on AIDS surveillance reports in Switzerland. AIDS, 12. $1195-1201$. 
Gezondheidsraad (1999). Heriening van het HIV-testbeleid. Den Haag: Author.

Glasner, P.D., \& Kaslow, R.A. (1990). The epidemiology of human immunodeficiency virus infection. Journal of Consulting and Clinical Psychology, 58, 13-21.

Godin, G., \& Kok, G. (1996). The theory of planned behavior: A review of its applications to health-related behaviors. American Journal of Health Promotion, 11, 87-98.

Gold, R. (1995). Why we need to rethink AIDS education for gay men. AIDS Care, 7. S1 1S19.

Gold, R.S. (1996). Dangerous liaisons: Negotiated safety, the safe sex culture, and AIDS education. Veneorology, 9, 102-103.

Gold. R.S., \& Skinner, M.J. (1992). Siruational factors and thought processes associated with unprotected intercourse in young gay men. AIDS, 6, 1021-1030.

Gold, R.S., Skinner, M.J., Grant, P.J., \& Plummer, D.C. (1991). Situational factors and thought processes associated with unprotected intercourse in gay men. Psychology and Health, 5, 259-278.

Handsfield, H.H. (1985). AIDS and sexual behavior in gay men. American Journal of Public Health, 75, 1449 .

Hays, R.B., Kegeles, S.M., \& Coates, T.J. (1990). High HIV risk-taking among young gay men. AIDS, 4, $901-907$.

Hays, R.B., Kegeles, SM., \& Coates. T.J. (1997). Unprotected sex and HIV risk taking among young gay men within boyfriend relationships. AIDS Educution and Prevention, 9. 314329.

Hoekzema, C., \& Dingelstad, A. (1991). De condoomworkshop. Eveluatie-rappon adar aanleiding van ten preventie-activiteit van de SAD over condoumgebruik bij monnen met homoseksuele contacten. Uurecht, NL: Universiteit Utrecht.

Hospers, H.J., \& Blom, C. (1998). HIV prevention activities for gay men in the Nerherlands 1983-1993. In Th.G.M. Sandfort (Ed.). The Dutch response to HIV (pp. 40-60). Londion: UCL Press.

Hospers, H.J., \& Kok, G.J. (1995). Determinants of safe and risk-taking sexual behavior among gay men: A review. AlDS Education and Prevention, 7, 74-96.

Hospers, H.J., Molenaar, S., \& Kol, G.J. (1994). Focus group interviews with risk-taking gay men: Appraisal of ADS prevention activities, explanations for sexual risk-taking, and needs for support. Patient Education and Counseling, 24, 299-306.

Inspectie voor de Gezondheidszorg (1998). AIDS in Nederland per 30 december 1998. Den Haag: Author.

Janssen, M., De Wit, J., Hospers, H., Srroebe, W., \& Van Griensver, F. (1999).

Socioeconomic status and young gay men's beliefs about condom use. Submitted.

Janz, N.K., \& Becker, M.H. (1984). The Health Belief Model: A decade later. Health Educotim Quarterly, 11, 1-47.

Jones, C.C., Waskin, H., Gerery, B., Skipper, B.J., Hull, H.F., \& Mertz, G.J. (1987). Persistence of high-risk sexual activity among homosexual men in an area of low incidence of the Acquired Immunodeficiency Syndrome. Sexually Transmitted Diseases, 14, 79-82.

Joseph, J.G., Adib, M., Koopman, J.S., \& Ostrow, D.G. (1990). Behavioral change in longitudinal studies: Adoption of condom use by homosexual/bisexual men. American Joumal of Public Health, 80, 1513-1514. 
Joseph. J.G., Montgomery, S.B., Emmons, C-A., Kessler, R.C., Ostrow, D.G., Wortman, C.B., O'Brien, K., Eller, M., \& Eshlernan, S. (1987a). Magnitude and determinants of behavioral risk reduction: Longitudinal analysis of a cohort at risk for AIDS. Psychology and Health, 1, 73-95.

Joseph, J.G., Montgomery, S.B., Emmons, C-A., Kessler, R.C., Ostrow, D.G., Wortman, C.B., O'Brien, K., Eller, M., \& Eshleman, S. (1987b). Perceived risk of AIDS: Assessing the behavioral consequences in a cohor of gay men. Joumal of Applied Social Psychology, 17, 231-250.

Kalichman, S.C. (1998). Post-exposure prophylaxis for HIV infection in gay and bisexual men. Implications for the future of HIV prevention. American Journal of Preventive Medicine, 15, 120-127.

Kalichman, S.C., \& Hospers, H.J. (1997). Efficacy of behavioral-skills enhancement HIV riskreduction interventious in community serings. AIDS, 11, S191-S199.

Kauch, M.R., St.Lawrence, J.S., \& Kelly, J.A. (1991). Reliability of reurospective assessments of sexual HTV risk behavior: A comparison of biweekly, three-month, and twelve-month self-reports. AIDS Education and Prevention, 3, 207-214.

Keet, I.P.M., Albrecht van Lent, N., Sandfort, T.G.M., Coutinho, R.A., \& Van Griensven, G.J.P. (1992). Orogenital st: $x$ and the ransmission of HIV among homosexual men. AIDS, 6, 223-226.

Kegeles, S.M., \& Hart, G.J. (1998). Recent HIV-prevention interventions for gay men: Individual, small-group and community-based studies. AIDS, 12, S209-S215.

Kegeles, S.M., Hays, R.B., \& Coates, T.J. (1996). The Mpowerment Project: A communitylevel HIV prevention intervention for young gay men. Americun Journal of Public Health, 86, 1129-1136.

Kelaher, M., Ross, M.W., Rohrsheim, R., Drury, M., \& Clarkson, A. (1994). Dominant situational determinants of sexual risk behavior in gay men. AIDS, 8, 101-105.

Kelly, J.A. (1995). Changing HIV risk behavior: Practical strategies. New York: Guilford.

Kelly, J.A., Hoffmann, R.G., Rompa, D., \& Gray, M. (1998). Protease inhibitor combination therapies and perceptions of gay men regarding AIDS severity and the need to maintain safer sex. AIDS, 12, F91-F95.

K.elly. J.A., Kalichman, S.C., Kauth, M.R., Kilgore, H.G., Hood, H.V., Campos, P.E., Rao, S.M. Brasfield, T.L., \& St.Lawrence, J.S. (1991). Situational factors associated with ADS risk behavior lapses and coping strategies used by gay men who successfully avoid lapses. American Joumal of Public Health, 81, 1335-1338.

Kelly, J.A., \& Murphy, D.A. (1992). Psychological interventions with AIDS and HIV: Prevention and treatment. Joumal of Consulting and Clinical Psychology, 60, 576-585.

Kelly. J.A., Murphy, D.A., Sikkema, K.J., McAuliffe, T.L., Roffman, R.A., Solomon, L.J., Winetr. R.A., \& Kalichman, S.C. (1997). Randomised, controlled, community-level HIVprevention intervention for sexual-risk behaviour among homosexual men in US cities. Community HIV Prevention Research Collaborative. Lancet, 350, 1500-1505.

Kelly. J.A., \& St.Lawrence, J.S. (1990). The impact of community-based groups to help persons reduce HIV infection risk behaviours. AIDS Care, 2, 25-36.

Kelly. J.A., St.Lawrence, J.S., Betts, R., Brasfield, T.L., \& Hood, H.V. (1990). A skills-training group intervention model to assist persons in reducing risk behaviors for HIV infection. AIDS Education and Prevention, 2, 24-35. 
Kelly, J.A., St.Lawrence, J.S., \& Brasfield, T.L. (1991). Predictors of vulnerability to AIDS risk behavior relapse. Joumal of Consulting and Clinical Psychology, 59, 163-166.

Kelly, J.A., St.Lawrence, J.S., Brasfield, T.L., Lemke, A., Amidei, T., Roffman, R.E., Hood, H.V., Smith, J.E., Kilgore, H., \& McNeill, C. (1990). Psychological factors that predict ADS high-risk versus AIDS precautionary behavior. Joumal of Consulting and Clinical Psychology, 58. $117-120$.

Kelly, J.A., St.Lawrence, J.S., Brasfield, T.L., Stevenson, Y., Diaz, Y.E., \& Hauth, A.C. (1990). ADS risk behavior pattems among gay nien in small souchern cities. American Joumal of Public Heolth, 80, 416-418.

Kelly, J.A., St.Lawrence, J.S., Hood, H.V., \& Brasfield, T.L. (1989). Bchavioral intervention to reduce ADS risk activities. Joumal of Consulting and Clinicol Psychology, 57, 6067.

Kelly, J.A., St.Lawrence, J.S., Stevenson, L.Y., Hauth, A.C., Kalichman, S.C., Diaz, Y.E., Brasfield, T.L., Koob. J.J., \& Morgan, M.G. (1992). Community HIV/AIDS risk reduction: The effects of endorsements by popular people in three cities. American Joumal of Public Health, 82, 1483-1489.

Kingsley, L.A., Detels, R., Kaslow, R., Polk, B.F., Rinaldo, C.R., Chmiel, J., Detre, K., Kelsey, S.F., Odaka, N, Ostrow, D., VanRaden, M., \& Visscher, B. (1987). Risk factors for seroconversion to human immunodeficiency virus among male homosexuals. Lancet, i, 345-349.

Kinsey, A.C., Pomeroy, W.B., \& Martin, C.E. (1948). Sexual behavior in the human male. Philidelphia: Saunders.

Kippax, S., Noble, J., Prestage, G., Crawford, J.M., Campbell, D., Baxter, D., \& Cooper, D. (1997). Sexual negotiation in the AMS era: Negotiated safety revisited. AIDS, 11, 191-197. Kline, A., Kline, A. \& Oken, E. (1992). Minority women and sexual choice in the age of ADS. Sacial Science and Medicine, 34, 447-457.

Kok, G. (1991). Health education theories and research for AIDS prevention. HYCIE, X, 32-39. Kok, G. (1999). Targeted prevention for people with HIV/AIDS: Feasible and desirable? Patient Education and Counseling, 36, 239-246.

Krueger, R.A. (1988). Focus groups. A practical guide for opplied research. Newbury Park, CA: Sage Publications.

Linn, L.S., Spiegel, J.S., Mathews, W.C., Leake, B., Lien, R., \& Brooks, S. (1989). Recent sexual behaviors among homosexual men seeking primary care. Archives of Intemol Medicine, $149,2685-2690$.

Lust for Life (1999). PEP: Vengnet en geen moming-after pil. Amsterdam: SAD-Schorerstichting. Mann, J.M., Tarantola, D.J.M., \& Netter. T.W. (Eds.) (1992). AIDS in the world. Cambridge. MA: Harvard University Press.

Marlatt, G.A., \& Gordon. J.R. (1985). Relapse prevention: Maintenance straiegies in the treatment of addictive behaviors. New York: Guilford.

Martin, J.L. (1986). ADS risk reduction recommendaúons and sexual behavior patrems among gay men: A multifactorial categorical approach to assessing change. Health Education Quarterly, 13, 347-358.

Martin, J.L. (1987). The impact of ADS on gay male sexual behavior patterns in New York City. American Journal of Public Health, 77, 578-581. 
McCusker, J., Stoddard, A.M., Zapka, J.G., Zorn, M., \& Mayer, K.H. (1989). Predictors of AIDS-preventive behavior among homosexually active men: A longitudinal study. AIDS, 3 , 443-448.

McCusker, J., Zapka, J.G., Stoddard, A.M., \& Mayer, K.H. (1989). Responses to the ADS epidemic among homosexually active men: Factors associated with preventive behavior. Patient Education and Counseling, 13, 15-30.

McGuire, W.J. (1985). Attitudes and attitude change. In G. Lindsay \& E. Aronson (Eds.), Handbook of social psychology (pp. 233-346). New York: Random House.

McKusick, L., Coates, T.J., Morin, S.F., Pollack, L., \& Hoff, C. (1990). Longitudinal predictors of reductions in unprotected anal intercourse among gay men in San Francisco: The AIDS Behavioral Research Project. American Jourmol of Public Healtb, 80, 978-983.

McKusick, L., Conant, M., \& Coates, T.J. (1985). The ADS epidemic: A model for developing intervention strategies for reducing high-risk behavior in gay men. Sexually Transmitted Diseases, 12, 229-234.

McWhirter, D.P., \& Mattison, A.M. (1984). The male couple. Englewood Cliffs, NJ: Prentice Hall.

Meyer, I.H., \& Dean, L. (1995). Patterns of sexual risk behavior and risk taking among young New York City gay men. AIDS Education and Prevention, 7 (supplement), 13-23.

Miller, T.E., Booraem, C., Flowers, J.V., \& Iversen, A.E. (1990). Changes in knowledge, actitudes and behavior as a result of a community-based AIDS prevention program. AIDS Educotion and Prevention, 2, 12-23.

Montgomery, S.B., Joseph, J.G., Becker, M.H., Ostrow, D.G., Kessler, R.C., \& Kirscht, J.P. (1989). The Health Belief Model in understanding compliance with preventive recommendations for AIDS: How useful? AIDS Education and Prevention, 1, 303-323.

Morgan, D.L. (1988). Focus groups as qualitative research. Newbury Park, CA: Sage Publications.

Mullen, P.D., Evans, D., Forster, J., Goutieb, N.H., Kreuter, M., Moon, R., O'Rourke, T., \& Strecher, V.J. (1995). Settings as an important dimension in health education/promotion policy, programs, and research. Health Education Quarterly, 22, 329-345.

Mullen, P.D., Green, L.W., \& Persinger, G. (1985). Clinical trials of patienc education for chronic conditions: A comparative meta-analysis of intervention types. Preventive Medicine, 14, 753-781.

Offir, J.T., Fisher, J.D., Williams, S.S., \& Fisher, W.A. (1993). Reasons for inconsistent AIDS-preventive behaviors among gay men. The Joumal of Sex Research, 30, 62-69.

Osmond, D.H. et al. (1996). HIV seroconversion in the San Francisco Young Men's Health Study: 1993-1996. Paper presented at the XI International Conference on AIDS. Vancouver July 1996 [abstract We.C.562].

Osmond, D.H., Page, K., Wiley, J̃., Garret, K., Sheppard, H.W., Ross, A.R., Schrager, L., \& Winkelstein, W. (1994). HIV infection in homosexual and bisexual men 18 to 29 years of age: The San Francisco Young Men's Health Study. American Joumal of Public Health, 84. 1933-1937.

Ostrow, D.G., VanRaden, M.J., Fox, R., Kingsley, L.A., Dudley, J., \& Kaslow, R.A. (1990). Recreational drug use and sexual behavior change in a cohort of homosexual men. AIDS, 4, 759-765. 
Oud, R. (1986). Homocondoom. Een onderzoek naar de rol van het condoom hij het voorkomen van AIDS. Unpublished report.

Pakanichwong, W., Douglas, D., Wright, N.H., Vanichseni, S., et al. (1991). AIDS beliefs and behaviors among intravenous drug users in Bangkok. Intemational Joumal of Addiction, 26, 1333-1347.

PccAo (1995). Programmo aidsondenoek 1995-1997. Amstcrdam: PccAo.

Peterman, T.A., Cates, W., \& Wasserheit, J.N. (1992). Prevention of the sexual transmission of HIV. In V.T. DeVita, S. Hellman, \& S.A. Rosenberg (Eds.), AIDS. Etiolagy, Diagaosis, Treatment, and Prevention (3rd ed., pp. 443-451). Philadelphia: Lippincott.

Peterson, J.L., Coates, T.J., Catania, J., Hauck, W.W., Acree, M., Daigle, D., Hillard, B., Middleton, L., \& Hearst, N. (1996). Evaluation of an HTV risk reduction intervention among African-American homosexual and bisexual men. AIDS, 10, 319-325.

Peterson, P.L., Ostrow, D.G., \& McKirnan, D.J. (1991). Behavioral interventions for the primary prevention of $\mathrm{HIV}$ infection among homosexual and bisexual men. The joumal of Primary Prevention, 12, 19-34.

Petty, R.E., \& Cacioppo, J.T. (1986). The elaboration likelihood model of persuasion. In L. Berkowitz (Ed.), Advances in Experimental Social Psychology (Vol. 19. pp. 123-205). New York: Academic Press.

Prieur, A. (1990). Norwegian gay men: Reasons for continued practice of unsafe sex. AIDS Education and Prevention, 2, 109-115.

Prieur, A. (1991). Mann-mömnliche Liebe in den Zeiten wn AIDS. Berlin: Deutsche AIDS Hilfe.

Reiss, I.L., \& Leik, R.K. (1989). Evaluating strategies to avoid AIDS: Number of partners vs. use of condonis. The Journal of Sex Research, 26, $411-433$.

Remafedi, G. (1994). Predictors of unprotected intercourse among gay and biserual youth: Knowledge, beliefs, and behavior. Pediatrics, 94, 163-168.

Richard, R., De Vries, N.K., \& Van der Pligt, J. (1998). Anticipated regret and precautionary sexual behavior. Joumal of Applied Social Psychology, 28, $1411-1428$.

Richard, R., Van der Pligt, J., \& De Vries, N. (1995). Anticipated affective reactions and prevencion of ADDS. Bricish Journal of Social Psychology, 34, 9-21.

Richard, R., Van der Pligt, J, \& De Vries, N.K. (1996). Anticipated regret and time perspective: Changing sexual risk-taking behavior. Joumal of Bebavioral Decision Making, 9, 185-199.

Robert, B., \& Rosser. S. (1990). Evaluation of the efficacy of AIDS education interventions for homosexually active men. Health Education Research, 5, 299-308.

Rogers, E.M. (1983). Diffusion of innovations. New York: The Free Press.

Rogers, R.W. (1983). Cognitive and physiological processes in fear appeals and attitude change: A revised theory of protection motivation. In J.T. Cacioppo \& R.E. Petty (Eds.). Social Psycbophysiolagy: A sourcebook (pp. 153-176). New York: Guilford.

Ronis, D.L. (1992). Conditional health threats: Health beliefs, decisions, and behaviors among adults. Health Psychology, 11, 127-134.

Ross, M.W. (1987). Problems associated with condom use in homosexual men. American Joumal of Public Health, 77, 877.

Ross, M.W. (1988). Attitudes toward condoms as AIDS prophylaxis in homosexual men: Dimensions and measurement. Fsychology end Health, 2, 291-299. 
Ross, M.W., \& McLaws, M.-L. (1992). Subjective norms about condoms are better predictors of use and intention to use than attitudes. Health Education Recearch, 7. 335-339. Rotheram-Borus, M.J., \& Koopman, C. (1991). Sexual risk behavior, ADS knowledge, and beliefs about AIDS among predominantly minority gay and bisexual male adolescents. AIDS Educotion and Prevention, 3, 305-312.

Rotheram-Borus, M.J., Reid, H., Rosario, M., \& Kasen, S. (1995). Determinants of safer sex patterns among gay/bisexual male adolescents. Joumal of Adolescence, 18, 3-15.

Saltzman, S.P., Stoddard, A.M., McCusker, J., Moon, M.W., \& Mayer, K.H. (1987). Reliability of self-reported sexual behavior risk factors for HTV infection in homosexual men. Public Health Reports, 102, 692-697.

Schechter, M.T., Craib, K.J.P., Willoughby, B., Douglas, B., McLeod, W.A., Maynard, M., Constance, P., \& O'Shaughnessy, M. (1988). Patterns of sexual behavior and condom use in a cohort of homosexual men. American Journal of Public Health, 78, 1535-1538.

Seage, G.R., Mayer, K.H., Horsburgh, C.R., Cai, B., \& Lamb, G.A. (1992). Corroboration of sexual histories among male homosexual couples. Americon Journal of Epidemiology, 135, 79-84.

Seagc, G.R., Mayer, K.H., Horsburgh, C.R., Holmberg, S.D., Moon, M.W., \& Lamb, G.A. (1992). The relation between nitrate inhalants, unprotected receptive anal intercourse, and the risk of Human Immunodeficiency Virus infection. American Joumal of Epidemiology. 135, 1-11.

Seibt, A.C., Ross, M.W., Freeman, A., Krepcho, M., Hedrich, A., McAlister, A., \& Fina'ndez-Esquer, M.E. (1995). Relationship hetween safe sex and acculturation into the gay subculture. AIDS Care, 7, S85-588.

Shernoff, M., \& Bloom, D.J. (1991). Designing effective AIDS prevention workshops for gay and bisexual men. AIDS Education and Prevention, 3, 31-46.

Siegel, K., Bauman, L.J., Christ, G.H., \& Krown, S. (1988). Patterns of change in sexual behavior among gay men in New York City. Archives of Sexual Behovior. 17, 481-497.

Siegel, K., Mesagno, F.P., Chen, J-Y., \& Christ, G. (1989). Factors distinguishing homosexual males practicing risky and safer sex. Social Science and Medicine, 28, 561-569.

Solomon, M.Z., \& Dejong. W. (1986). Recent sexually transmitted disease prevention efforts and their implications for AIDS health education. Health Education Quarterly, 13, 301-316.

Siall, R.D., Coates, T.J., \& Hoff, C. (1988). Behavioral risk reduction for HTV infection among gay and bisexual men. American Psychologist, 43, 878-885.

Stall, R.D., Ekstrand, M., Pollack, L., McKusick, L., \& Coates, T.J. (1990). Relapse from safer sex: The next challenge for AIDS prevention efforts. Joumal of Acquired Immune Deficiency Syndromes, 3, 1181-1187.

Stall, R.D., McKusick, L., Wiley, J., Coates, T.J., \& Ostrow, D.G. (1986). Alcohol and drug use during sexual activity and compliance with safe sex guidelines for AIDS: The AIDS behavioral research project. Health Education Quarterly, 13, 359-371.

St.Lawrence, J.S., Hood, H.V., Brasfield, T., \& Kelly, J.A. (1989). Differences in gay men's AIDS risk knowledge and behavior patterns in high and low AIDS prevalence cities. Public Health Reports, 104, 391-395.

Stokes, J.P., McKirnan, D.J., \& Burzette, R.G. (1993). Sexual behavior, condom use, disclosure of sexuality, and stability of sexual orientation in bisexual men. The Joumal of Sex Research, 30, 203-213. 
Valdiserri, R.O., Lyter, D., Leviton, L.C., Callahan, C.M., Kingsley, L A., \& Rinaldo, C.R.

(1988). Variables influencing condom use in a cohor of gay and bisexual men. American Joumal of Public Health, 78, 801-805.

Van den Hoek, J.A.R., Haastrecht, H.J.A., Henquet, C.J.M., \& Coutinho, R.A. (1993).

Toename van gonorroe bij jongere homoseksuele mannen in Amsterdam. Nederiands

Tijdschrift voor Geneskunde, 137, 14-145.

Van der Linden, J. (1984). AIDS: An information, education, and prevention project til the

Necherlands. Paper presented at the European ADS Conference, Amsterdam, January 20 -

22, 1984.

Van de Ven, P., Campbell, D., Kippax, S., Prestage, G., Crawford, J., Baxter, D.. \& Cooper,

D. (1997). Factors associated with unprotected intercourse in gay men's casual

parnerships in Sydney, Australia. AIDS Care, 9, 637-650.

Van de Ven, P., Kippax, S., Crawford, J., French, J., Prestage, G., Grulich, A., Kinder, P., \&

Kaldor, J. (1997). No relationship between age and HIV risk behaviour among Sydney

gay men. AlDS, 11, 691-693.

Van de Ven, P., Noble, J., Kippax, S., Prestage, G., Crawford, J., Baxter, D., \& Cooper, D.

(1997). Gay youth and their precautionary sexual behaviors: The Sydney Men and Sexual

Health Study. AIDS Education and Prevention, 9, 395-410.

Van Griensven, G.J.P., \& De Vroome, E.M.M. (1987). Failure-rare van kondoonıs gedurende anoginitaal seksueel kontakt bij homoseksuele mannen. Tijaschrift voor Sociale Gezondheidszorg, 65, 703-705.

Van Griensven, G.J.P., De Vroome, E.M.M., Tielman, R.A.P., Goudsmit. I., Van der Noordaa, J., De Wolf, F., \& Coutinho, R.A. (1987). Seksuele gedragsverandering in een groep op HIV-antistoffen geteste homoseksuele mannen. Tijuschriit voor Sociale Gewndheidszory, 65, 345 . 350 .

Van Griensven, G.J.P., Van den Bergh, H.S.P., Jansen, M., De Wit, J.B.F., \& Keet, I.P.M.

(1997). HIV-infectie en riskant seksueel gedrag in een nieuwe cohort jonge homoseksuele mannen te Amsterdam, 1995-1996. Nederlands Tijdschrift voor Geneeskunde, 141, 2293-2296.

Van Kalmthout, M. (1993). De produktie van voorlichtingsmateriaal over AIDS voor hümomannen.

Amsterdam: Buro GVO.

Van Stoppelenburg. E. (1995). Eind-evaluatie Safe Sex Promotieteams. Amsterdam: SAD-

Schorerstichning.

Van Wijngaarden, J. (1984). Evaluatie beleidscördinatie AJDS. Unpublished report.

Vincke, J., Bolton, R., \& Miller, M. (1997). Younger versus older gay men: Risks, pleasures and dangers of anal sex. AIDS Care, 9, 217-225.

Waldhober, Q. (1990a). Op de baan. Rapportage van etn onderzoek onder medewerkers an een outreaching voorlichtingsproject over AIDS en veilig vrijen onder mannen met homoseksuele contacten. Amsterdam:

Bureau Onderzoek, Tekst \& Uitleg.

Waldhober, Q. (1990b). Safe Sex Promotie Teams. Rapportage ven een onderack naar ten iutreaching voorlichtingsproject in homo-uitgoansgelegenheden over AIDS en veilig vrijen onder mannen met homoseksuele contacten. Amsterdam: Bureau Onderzoek, Tekst \& Uitleg.

Wanigarame, S., Billington, A., \& Williams, M. (1997). Initiating and maintaining safer sex: Evaluation of group work with gay men. In J. Catalán, L. Sherr, \& B. Hedge (Eds.), The impact of AIDS: Psychological and social aspects of HIV infection (pp. 27-41). Amsterdam: Harwood Academic Publishers. 
Weatherburn, P. (1992). Using the diary method to enable causal inferences about the relationship between alcohol use and unsafe behaviour. Paper presented at the Second European Conference on Homosexuality and HIV, Amsterdam, The Necherlands.

Weatherburn, P., Davies, P.M., Hickson, F.C.I., Hunt, A.J., McManus, T.J., \& Coxon. A.P.M. (1993). No connection between alcohol use and unsafe sex among gay and bisexual men. AIDS, 7, $115-119$.

Weatherburn, P., Hunt, A.J., Davies, P.M., Coxon, A.P.M., \& McManus, T.J. (1991) Condom use in a large cohor of homosexually active men in England and Wales. AIDS Care, 3, 31-41.

Weatherburn, P., \& Reid, D.S. (1996). Behaviourally bisexual man in the UX. London: Health Education Authority.

Weinstein, N.D. (1987). Unrealistic optirnism about illness susceptibility: Conclusions from a community-wide sample. Joumal of Bebovioral Medicine, 10, 481-500.

Weinstein, N.D. (1989). Perceptions of personal susceptibilicy to harm. In V.M. Mays, G.W. Albee, \& S.F. Schneider (Eds.), Primary Prevention of AIDS (pp. 142-167). Newbury Park, CA: Sage Publications.

Wennink, J. (1988). Resultaten enquête deelnemers aan de SAD GVO-cursus "AIDS, gezondheid en sexualiteit. Unpublished report.

WHO (1998). AIDS epidemic update: December 1998. Source: www.unaids.org

Williams, S.S., Kimble, D.L., Covell, N.H., Weiss, L.H., et al. (1992). College students use of implicit personality theory instead of safer sex. Joumal of Applied Social Psychology, 22, 921 . 933.

Winkelstein, W., Samuel, M., Padian, N., Wiley, J.A., Lang, W., Anderson, R.E., \& Levy, J. (1987). Reduction in human immunodeficiency virus transmission among homosexual/bisexual men: 1982-1986. American Joumal of Public Heolth, 76, 685-689.

Wulfert, E., Wan, C.K., \& Backus, C.A. (1996). Gay men's safer sex behavior: An integration of three models. Journal of Behavioral Medicine, 19, 345-366. 
Almost 5000 people have been diagnosed with AmS in the Netherlands since 1982. The majority of these people became infected with the Human Immunodeficiency Virus (HIV) through homosexual behavior. Despite considerable progress, no vaccine has yet been found, nor are there pharmaceuticals available that can cure HIV infection. Therefore, prevention of HIV infection is still of great importance. Homosexual men in the Netherlands have been intensively educated on HIV and ADS and have been motivated to maintain safe sexual behavior. The design of prevention activities combines insights from research on determinants of sexual risk behavior and the effectiveness of prevention interventions. Understanding and changing sexual risk behavior of men who have sex with men is the subject of this thesis.

Chapter 1 gives an overview of the research in this area. After a concise description of epidemiological developments, a summary is provided of the research into the determinants of safe and risk-taking sexual behavior of homosexual men. This relates to the results that are described in Chapters 2 through 5. Next, a description of the research described in Chapters 6 through 8 is given, all of which are related to prevention interventions. Chapter 1 concludes with a description of the areas of interest for the future regarding the study of behavioral determinants and the study of interventions that aim at changing risk behavior.

Chapter 2 is an inventory of the research into determinants of sexual risk behavior among homosexual men. This inventory showed that demographic variables have little predictive value concerning risk behavior. HIV/ADS knowledge and risk perception also contribute little to the prediction of risk behavior. The study did find that men have more unsafe sex with primary partners than with casual partners. In addition, a number of cognitive variables were identified that were related to unsafe sexual behavior, namely a negative atcitude and social norm regarding condom use and low self-efficacy regarding condom use.

Chapter 3 reports on focus group interviews that were held with men who had engaged in risky sexual behavior. The interviews confirm the findings from Chapter 2 to a large extent. In addition, it was found that a number of men stated that sex was a means of alleviating negative mood states and that the importance of keeping sex safe was secondary to that. Also, a number of men stated that they found it increasingly difficult to maintain safe sex behavior in all instances with all sex parmers.

Over the past years the question has been raised whether or not behavioral determinants of young gay men differed substantially from those of their older counterparts. Chapter 4 describes a study into sexual behavior and its determinants among 154 young gay men. It was noteworthy that few respondents engaged in risk-taking behavior with casual partners. However, 
unsafe sex with primary parmers was found to be more frequent. The analyses showed that these young gay men stopped using condoms relatively early in their primary relationships without being aware of the HIV status of their partner. Also, it was found that primary relationships were relatively unstable: in the three months preceding assessment, one in five primary 142... relationships ended.

In Chapter 5 a study is reported that researched 88 young gay men who were not involved in a primary relationship at that time. A distinction was made between men who had a high intention to use condoms with a new sexual partner and men who had a lower intention to do so. It was found that perceived self-efficacy, in particular, differentiated between these two groups. Further analyses looked in detail at different self-efficacy domains. It was found that especially men with a lower intention to use condoms reported poorer skills for resisting pressure from a sexual partner to engage in unprotected anal sex. They also found it more difficult to have safe sex when they were under the influence of alcohol or drugs and when they were physically or emotionally attracted to a new sex partner. Self-efficacy ratings regarding condom use skills and sexual communication skills regarding condom use contributed to a lesser extent to the explanation of intentional differences.

Chapter 6 is a detailed overview of HIV prevention accivities developed between 1983 and 1993 for homosexual men in the Netherlands. The chapter describes the HIV policy development and gives a description of written materials, small-group interventions and outreach activities. The lack of effect evaluations made it difficult to assess the effectiveness of the prevention activities.

Chapter 7 describes the evaluation of prevention activities at cruising areas for men who have sex with men. The data from 362 respondents showed relatively high levels of risk-taking behavior: almost $20 \%$ of respondents reported one or more instances of unsafe sex at cruising areas in the year that was studied. Secondly, men who had had a conversation with an HIV prevention volunteer were less likely to have engaged in unprotected sex than men who had never been in touch with a volunteer. Thirdly, men who reported that they also had sex with women were more likely to engage in risk-taking behavior at cruising areas than men who only had sex with men. Finally, this study showed that behaviorally bisexual men reported few ties with the gay community and also indicated that they hardly ever had been exposed to prevention materials that were developed for homosexual men.

The final chapter reports on an intervention study that was developed for coming-out groups for young gay men. Three different types of interventions were tested. The first intervention focused on providing and discussing information on HIV risks and on positively influencing attitudes regarding condom use. The second intervention comprised a skills training 
that used roll plays to practice a number of high-risk situations. Especially communication with sex partners about safe sex as well as skills to resist pressures from sex parmers to engage in unsafe sex were practiced in the skills training intervention. The third intervention used mental simulation techniques and asked participants to imagine the emotions that they would experience if they would have had unsafe sex. Other research had found that this procedure induced so-called anticipated regret which in turn had positive effects on safe sex behavior. Next, participants were asked to for mulate strategies to maintain safe sex intentions in high-risk situations. The comparison of the pretest with the posttest showed that, in relation to a waiting list control group, no changes could be observed in the reported sexual behavior with primary partners, despite high levels of unsafe sexual behavior with primary partners. Also, no changes were observed in behavioral determinants that were related to sexual behavior with primary partners. Unsafe sex with casual partners was rare. The interventions did have a positive effect on the intention to use condoms with future casual partners. Men who had experience with anal sex in the Information intervention and the Anticipated Regret intervention had significantly higher intentions compared to the waiting list control group. The same was found for men without experience with anal sex who participated in the Skills Training intervention. This study also found that primary relationships of young gay men were relatively unstable. Half of the primary relationships that existed at pretest had ended 6 months later. This finding, in combination with the observation that condoms are disposed of relatively early in many primary relationships, leads to the conclusion that interventions are needed which focus more on primary relationships. 


\section{SAMENVATTING}

Sinds 1982 is bij bijna 5000 mensen in Nederland de diagnose AIDS gesteld. Het merendeel van deze mensen was geïnfecteerd geraakt met het Humaan Immunodeficiëntie Virus (HIV) via homoseksueel gedrag. Alhoewel er grote 144 vorderingen zijn gemaakt, is er op dit moment nog geen vaccin tegen HTVinfectie noch zijn er farmaceutica die HIV-infectie geheel genezen. Daardoor is het van groot belang te voorkomen dat mensen met HIV geïnfecteerd raken. In Nederland zijn en worden homoseksuele mannen intensief voorgelicht over HIV en AIDS en worden zij gemotiveerd om veilig te vrijen. Bij het vormgeven van deze preventie-activiteiten wordt gebruik gemaakt van inzichten uit onderzoek naar determinanten van seksueel risicogedrag en naar resultaten van onderzoek naar de effectiviteit van preventieve interventies. Het begrijpen en veranderen van seksueel risicogedrag van mannen die seks hebben met mannen vormt het onderwerp van dit proefschrift.

Hoofdstuk 1 geeft een overzicht van het onderzoek op dit terrein. Naast een beknopt overzicht van epidemiologische ontwikkelingen aangaande HIV/ADS wordt een samenvatting gegeven van het onderzoek naar determinanten van veilig en risicovol seksueel gedrag van homoseksuele mannen. De resultaten uit de Hoofdstukken 2 tot en met 5 komen hier aan de orde, aangevuld met recente inzichten uit het onderzoek van collega-onderzoekers. Vervolgens wordt het onderzoek naar HIV-preventie interventies beschreven. De resultaten uit de Hoofdstukken 6 tot en met 8 vormen de basis van deze beschrijving, wederom aangevuld met recente onderzoeksresultaten van collega's. Het hoofdstuk besluit met een beschrijving van de gebieden waarop het onderzoek naar gedragsdeterminanten en gedragsbeinvloeding zich - ons inziens - in de toekomst zou moeten concentreren.

Hoofdstuk 2 is een inventarisatie naar determinanten van seksueel risicogedrag bij homoseksuele mannen. Uit deze inventarisatie blijkt ten eerste dat demografische variabelen weinig voorspellende waarde hebben als het gaat om risicogedrag. Ook kennis over HIV en AIDS en risicoperceptie hebben weinig voorspellende waarde. Wel blijkt dat mannen meer onveilige seks hebben met hun vaste partner. Tevens blijkt dat een aantal cognitieve variabelen, te weten een negatieve atutude en sociale norm ten aanzien van condoomgebruik en een lage eigen-effectiviteit ten aanzien van condoomgebruik gerelateerd zijn aan onveilig seksueel gedrag.

In Hoofdstuk 3 wordt verslag gedaan van focusgroep-interviews die zijn gehouden met mannen die zich seksueel risicovol hadden gedragen. Deze interviews bevestigen grotendeels de resultaten van de literatuurstudie in Hoofdstuk 2. Daarnaast viel op dat een aantal mannen aangaf dat seks een middel was om iets te doen aan negatieve gemoedstoestanden en dat het belang van veilige seks daaraan secundair was. Tevens gaf een aantal mannen aan het in toenemende mate moeilijk te vinden om altijd en met iedereen veilig te vrijen. 
In de afgelopen jaren is meermalen de vraag gesteld of bij jonge homoseksuele mannen andere gedragsdeterminanten van belang waren dan bij oudere homoseksuele mannen. Hoofdstuk 4 beschrijft een onderzoek naar het seksuele gedrag en determinanten van dat gedrag onder 154 homojongeren. Opvallend was dat er weinig risicogedrag plaatsvond met incidentele sekspartners. Daarentegen kwam onveilige seks met vaste partners veel voor. Uit nadere analyses bleek dat deze jonge homoseksuele mannen relatief snel stopten met condoomgebruik (of er niet eens aan beginnen) zonder dat zij op de hoogte zijn van de HIV-status van hun vaste partner. Tevens viel op dat de vaste relaties relatief instabiel waren: in de drie maanden die onderzocht werden, eindigde een op de vijf vaste relaties.

In Hoofdstuk 5 wordt verslag gedaan van een onderzoek onder 88 jonge homomannen die ten tijde van het onderzoek geen vaste relatie hadden. Daarbij werd een onderscheid gemaakt tussen mannen die een hoge intentie hadden om condooms te gebruiken met een nieuwe sekspartner en mannen die een lagere intentie hadden. Het bleek dat met name eigen-effectiviteit tussen deze twee groepen differentieerde. Vervolgens werd gedetailleerd gekeken naar eigen-effectiviteit-domeinen. Mannen met een lagere intentie hadden met name een lagere inschating van hun vaardigheden om weerstand te bieden tegen druk van een sekspartner om onbeschermde anale seks te hebben. Ook dachten zij het moeilijker te vinden om veilig te vrijen als zij alcohol of drugs hadden gebruikt, of als zij zich fysiek of emotioneel aangetrokken voelden tot een nieuwe seksparmer. De inschattingen van vaardigheden met betrekking tot het gebruiken van condooms alsmede communicatieve vaardigheden betreffende condoomgebruik hadden een kleiner onderscheidend vermogen.

Hoofdstuk 6 is een gedetailleerde beschrijving van de Hrv-preventie activiteiten die tussen 1983 en 1993 in Nederland zijn ontwikkeld voor de doelgroep homoseksuele mannen. Er wordt een beschrijving gegeven van de ontwikkelingen in het preventiebeleid, van het schriftelijk voorlichtingsmateriaal, van de voorlichtingsactiviteiten voor groepen en van de outreachactiviteiten. Omdat er in het verleden weinig onderzoek naar is gedaan, konden nauwelijks conclusies worden getrokken over de effectiviteit van de preventie-activiteiten.

In Hoofdstuk 7 wordt de evaluatie beschreven van de voorlichting op ontmoetingsplaatsen (zogenaamde banen) van mannen die seks hebben met mannen. Uit de gegevens van 362 respondenten bleek ten eerste dat er relatief veel risicogedrag op banen plaatsvindt: bijna $20 \%$ van de respondenten rapporteert een of meerdere keren onveilig te hebben gevreeën op banen in het jaar van onderzoek. Ten tweede bleek dat mannen die met een HIV-preventie vrijwilliger hadden gesproken, minder risicogedrag vertoond hadden dan mannen die nooit in aanraking waren geweest met een vrijwilliger. Ten derde bleken mannen die ook seks met vrouwen badden, meer risico's te nemen op de baan dan mannen die alleen met mannen seks hadden. Tot 
slot bleek uit dit onderzoek dat de mannen die zowel met mannen als vrouwen seks hadden, weinig banden te hebben met de homogemeenschap en ook aangaven dat zij weinig in aanraking waren geweest met voorlichtingsmateriaal dat voor homoseksuele mannen is ontwikkeld.

In het laatste hoofdstuk wordt verslag gedaan van een interventie-onderzoek bij homojongerengroepen. Er werden bij deze doelgroep drie typen interventies uitgevoerd. De eerste interventie richtte zich op het geven en bespreken van juiste informatie over HIV-risico's en op het positief beïnvloeden van de attitude ten aanzien van condoomgebruik. De tweede interventie was een vaardigheidstraining waarin - via rollenspelen - werd geoefend hoe men in een aantal moeilijke situaties veilig kon blijven vrijen. Met name communicatie met een sekspartmer over veilig vrijen en vaardigheden om druk van een seksparmer te weerstaan om onveilige seks te hebben, vormden de belangrijkste ingrediënten van deze interventie. In de derde interventie werd via mentale simulatietechnieken aan de deelnemers gevraagd zich een voorstelling te maken van de emoties die ze zouden ervaren als ze een keer onveilige seks zouden hebben gehad in voor hun hoogrisico situaties. Uit eerder onderzoek was gebleken dat deze inductie van zogenaamde geanticipeerde spijt, positieve effecten had op veilig-vrijgedrag. Vervolgens werd de deelnemers gevraagd naar strategieën om veilig te blijven vrijen in hoog-risico situaties. De vergelijking van de voormeting met de nameting liet zien dat er - ten opzichte van de wachtlijstcontrolegroep geen veranderingen waren in het gerapporteerd seksuele gedrag met vaste partners. Dit terwijl onveilig gedrag met vaste partners veel voorkwam. Ook waren er geen veranderingen in de aan het seksuele gedrag met vaste partners gerelateerde gedragsdeterminanten. Onveilig seksueel gedrag met incidentele sekspartners kwam in deze groep nauwelijks voor. Er waren wel effecten van de interventies op de intentie om in de toekomst condooms te gebruiken met losse sekspartners. Deze intentie was voor mannen die ervaring hadden met anale seks uit de Informatie-interventie en de Geanticipeerde Spijt-interventie, significant hoger ten opzichte van de wachlijst-controlegroep. Hetzelfde gold voor mannen zonder ervaring met anale seks die aan de Vaardigheden-interventie hadden deelgenomen. Ook in dit onderzoek werd gevonden dat vaste relaties onder jonge homoseksuele mannen relatief instabiel zijn. De helft van de op de voormeting bestaande vaste relaties waren 6 maanden later beëindigd. Deze bevinding, gekoppeld aan de wetenschap dat er relatief snel in vaste relaties onbeschermd gevreeën wordt, vraagt om interventies die zich meer richten op vaste relaties. 


\section{ACKNOWLEDGEMENTS}

The following people and organizations have played an indispensable role in allowing me to conduct my research and write this thesis. Many thanks!

AIDS Fonds

Cor Blom

Hans Brug

Matt Commers

Anouk Cuijpers

Willem Debets

Maria Jansen

Marc Janssen

Gerjo Kok

Sjaak Molenaar

Nora Oosting

Guy and Sherry Parcel

Michael Ross

SAD-Schorerstichting

Herman Schaalma

Wolfgang Stroebe

John de Wit 
C. $\frac{10}{10}$

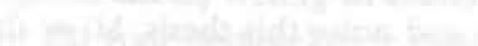




\section{CURRICULUM VITAE}

Harm Hospers werd op 31 mei 1957 geboren in Maastricht. In 1977 behaalde hij het vwo diploma aan de Nijmeegse Scholengemeenschap. In 1978 startte hij zijn studie psychologie aan de Rijksuniversiteit Groningen. In $1985 \mathrm{kwam}$ hij naar de vakgroep Gezondheidsvoorlichting van de Rijksuniversiteit Limburg om de medewerkers van de vakgroep te ondersteunen bij hun onderzoek. In 1988 studeerde hij aan de Rijksuniversiteit Groningen af in de richting persoonlijkheidspsychologie. In 1989 was hij werkzaam bij de vakgroep Health Behavior and Health Education aan de universiteit van North Carolina in Chapel Hill, waar hij verantwoordelijk was voor de uirvoering van een project op het gebied van "tailoring" (voorlichting op maat) met betrekking tot borstkanker- en baarmoederhalsscreening. Van 1990 tot 1999 was hij werkzaam als universitair docent bij de vakgroep Gezondheidsvoorlichting. In 1992 startten de onderzoeken op het gebied van HIV-preventie die in dit proefschrift worden beschreven. Vanaf augustus 1999 is hij werkzaam als universitair docent bij de capaciteitsgroep Experimentele Psychologie, Faculteit der Psychologie van de Universiteit Maastricht. 
